\title{
Critical Perspectives on Gender Norms and Relationships in Aotearoa New Zealand
}

Bonnie-Estelle Kathleen Trotter-Simons

A thesis submitted to Victoria University of Wellington in fulfilment of the requirements for the degree of Master of Arts in Sociology

School of Social and Cultural Studies

Victoria University of Wellington 2018 


\begin{abstract}
Binary and hierarchical enforcements of gender norms may contribute to unhealthy relationships, sexual violence and continued oppression of marginalised groups. Drawing on a critical feminist research approach, I consider how young people perceive these norms in order to theorise on how we can move beyond them to create a more inclusive and empathetic society. I interviewed six professionals who work with young people and spoke with three focus groups of young people aged 16-19 about their views and experiences of gender norms and relationships in the context of New Zealand's gendered culture. This thesis is theoretically driven, with analysis of literature on gender, postfeminism, individualism, community, and dominant constructions of victims for commenting on the research findings. Using thematic analysis, I organised my data into three predominant themes; The Gender Binary and Bro Culture, Pressures and Responsibilities, and Healthy Relationships. Numerous insights were generated from this analysis. In conceptualising New Zealand's gendered culture, some participants identified an imperative to perform gender as staunch individuals. This imperative characterises pressure to live up to idealised expressions of staunchness, and relegates constructions of victimhood as associated with social deviance. Complicating this, young people's solidarity and investments of collective energy to seek social change are equally significant findings for the emancipatory outlook of the project. This thesis provides a glimpse of the contemporary nature of gendered discourses in New Zealand, and indicates some ways in which these are shifting. There is greater complexity yet to be found in future research for theorising on these concepts, as I discuss toward the end of the thesis. All my participants' voices are appreciatively valued for their insights on this topic. They have aided me in thinking about how we can collectively continue these conversations through action.
\end{abstract}




\section{Acknowledgements}

Thank you to all my participants, for sharing your time, ideas and experiences with me. Your insights carry meaning and significance for re-thinking dominant discourses in ways which go beyond this thesis.

I am very grateful to my supervisor, Associate Professor Rhonda Shaw, for always making time to catch up, and for your ongoing kind support and encouragement. Thank you for your thoughtful reading of draft chapters, and helpful feedback. This has aided my confidence in carrying out this project and strengthened my writing and research skills, which will benefit future research I undertake. Your guidance through the research process has been invaluable.

I would also like to acknowledge School of Social and Cultural Studies staff for their support and interest in my research.

Thank you to all my friends and family who have proofread chapters, given advice and share an interest in envisioning alternatives to the gendered status quo! Sharing my experience of the research journey and thoughts about this topic with compassionate and like-minded people has been incredible, and has given me the energy to keep asking complicated questions, exploring different avenues and discovering what it means to do critical feminist research.

Thank you to Jared for always being there for hugs, cups of tea and for encouraging me to keep being creative and mindful in all aspects of life. I love you.

I dedicate this thesis to my late grandmother, Dorothy Simmons. You inspire me to give as generously and unconditionally as you always did. You will always be lovingly remembered for your kindness, care and warmth to others - and for your fondness for Grandad, bromeliads, cups of tea, chocolate and Christmas fruit mince pies 


\section{Contents}

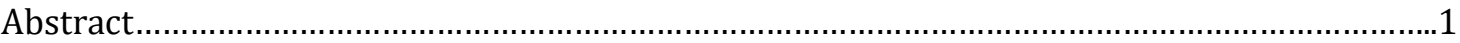

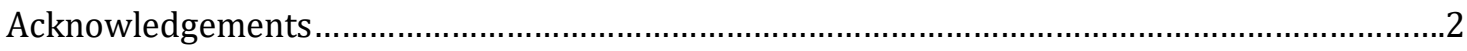

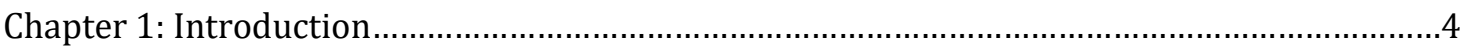

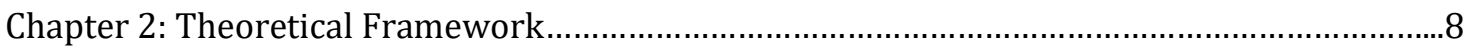

2.1. Background Context: Origins of New Zealand's Gendered Culture..........................8

2.2. Moral Conservatism and Education......................................................................10

2.3. Information as Empowerment...........................................................................12

2.4. Neoliberalism, Self-Management and Personal Responsibility ...............................13

2.5. Postfeminist Gender Discourse .................................................................................16

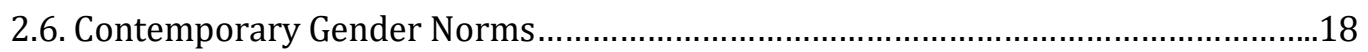

2.7. Gendered Implications of the Coital Imperative......................................................20

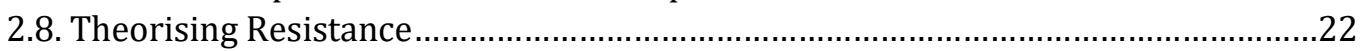

2.9. Heterosexual Matrix, Empowerment and Sexual Violence .....................................23

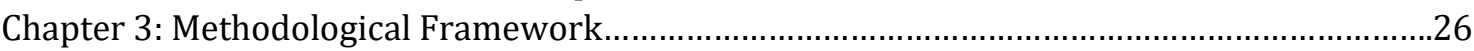

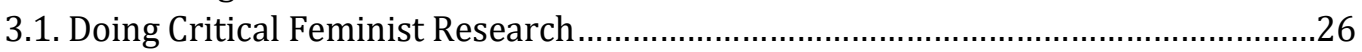

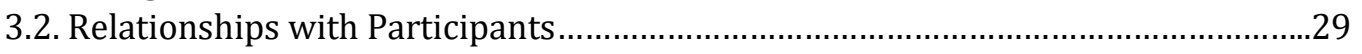

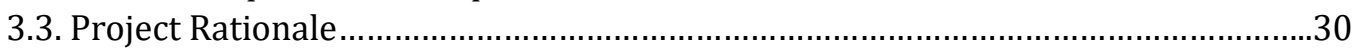

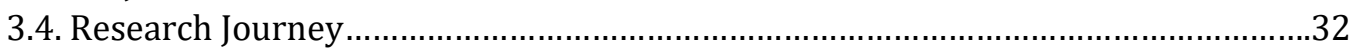

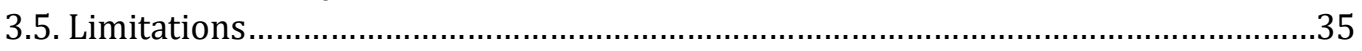

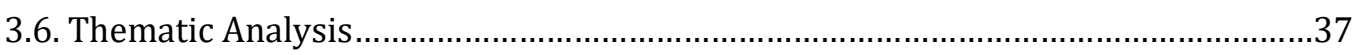

3.7. Presentation of Findings and Three Prominent Themes........................................39

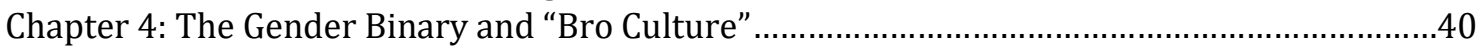

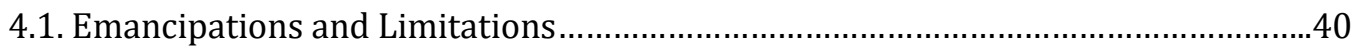

4.2. Policing the Gender Binary through "Bro Culture" ...............................................4

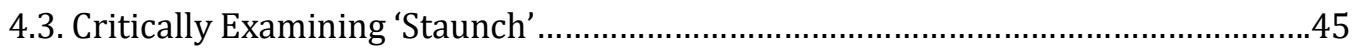

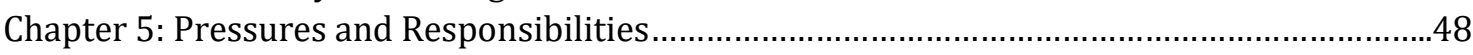

5.1. Feminised Experiences of Pressure and Responsibility ...........................................48

5.2. The "Emotionally Taxing" Pressures of Educating Others.........................................53

5.3. Stereotypes, Uncertainty and Further Implications in Pressure to be 'Staunch' ....57

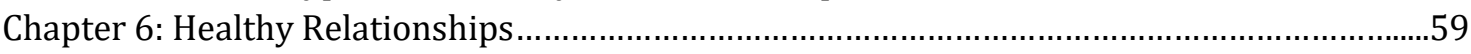

6.1. Perspectives on Healthy Relationship Education..............................................59

6.2. Rethinking the Concept of Healthy Relationships.................................................63

6.3. Gender Norms, Relationships and Communities.....................................................66

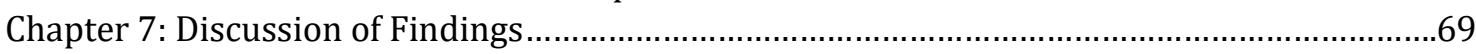

7.1. Critical Perspectives on Idealising Staunch Performances of Gender ......................69

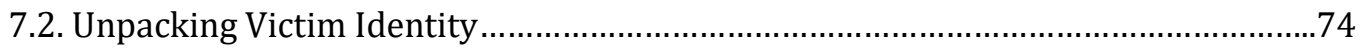

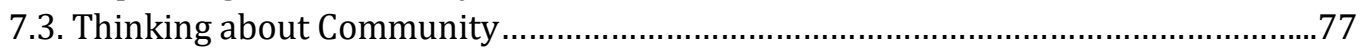

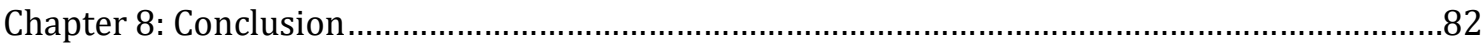

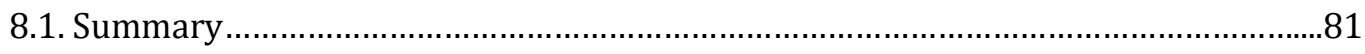

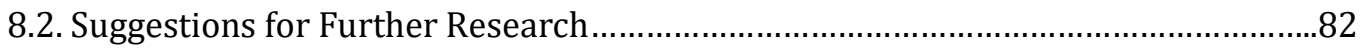

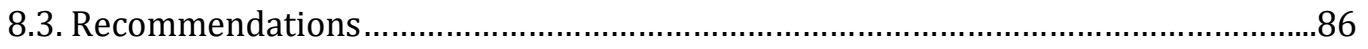

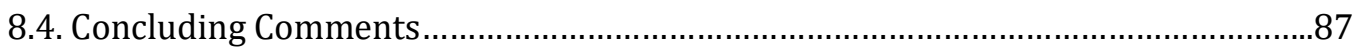

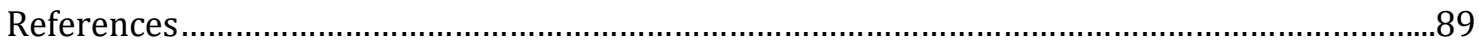

Appendix 1: Interview Participant Information Sheet...........................................................96

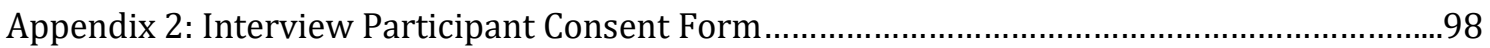

Appendix 3: Focus Group Participant Information Sheet..........................................................99

Appendix 4: Focus Group Participant Consent Form.................................................................101

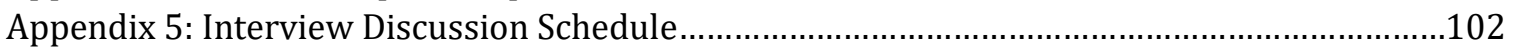

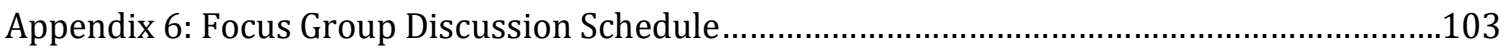

Appendix 7: Ethics Approval Memorandum.....................................................................104 


\section{Chapter 1: Introduction}

Gender can be regarded as a distinct organising principle for social life in Aotearoa New Zealand $^{1}$ (James \& Saville-Smith, 1994). It has ongoing significance for the ways in which people relate to each other and perceive society's social and cultural imperatives. Gender norms are especially visible in the ways in which young people learn about and engage with intimate relationships. From a critical feminist perspective, I will demonstrate some of the ways in which gender is normalised as binary and is implicated within heteronormative and masculine hegemonies. Many critical scholars and analysts contend that this sort of gendered culture substantially contributes to some of the social ills known to this country; namely our high occurrence of sexual harassment and violence, unhealthy relationship patterns, and youth mental illness (see James \& Saville-Smith, 1994, pp. 14-15; Smith, 2012, pp. 171-172; Beres, 2017b, pp. 14-16; Beres \& Farvid, 2010, pp. 389-390; Gavey, 2012, p. 720; Ministry of Education, 2015b, p. 16). This demonstrates the urgent need for researchers to closely understand the ways in which gender norms are currently articulated and how these impact young people's understandings of relationships.

As a critical feminist researcher, I undertook research in this area not only to be able contribute to knowledge on how gender norms are contemporarily articulated, negotiated and resisted by young people in Aotearoa New Zealand; I am also concerned to better understand the nature of dominant values, vulnerability and resistance as navigated by young people in their daily lives, so that directions of emancipatory social change might become visible. This research is motivated by the view that binary gender norms substantively fuel the discrimination and oppression of marginalised groups, and are visible in sexual violence and the variety of behaviours associated with this including stalking, threats, harassment, gender-based bullying and victim-blaming. While my focus does not exhaustively cover the nature of these forms of violence, I explore the wider implications of how contemporary gender norms are perceived by young people in this research.

In this thesis, I identify manifestations of New Zealand's gendered culture within the literature as well as in data I have collected in order to comment on the critical perspectives of young people, and those who support, educate and guide them, on gender norms in their daily lives. Gender norms are identified here in the context of some of the hegemonic principles embedded in New Zealand society. This is imperative for theorising an alternative to New Zealand's gendered culture which moves away from harmful, repressive tropes and instead fosters greater inclusivity, ongoing scrutiny of dominant discourses, and values diverse

\footnotetext{
${ }^{1}$ I use the terms 'Aotearoa' and 'New Zealand' interchangeably throughout the thesis.
} 
experiences. With a view to suggest important areas for future study and to strengthen the ongoing resistance of communities to harmful gender norms, I draw on existing political action by young people and on my study participants' focus on communities, rather than individuals, as effective drivers for social change. This social change is considered in terms of its ability to challenge and recommend alternatives to dominant modes of thinking. In the tradition of critical feminist research, I consider both key areas for future research and some general recommendations to better support young people, based on some of the data I present in the findings chapters.

Between $13^{\text {th }}$ June and 26th July 2017, I interviewed six professionals who work with young people to support them in having healthier relationships - including but not limited to romantic relationships. These people were guidance counsellors, youth workers and a "healthy relationship" educator ${ }^{2}$. Two of the counsellors were interviewed together, so there were five interviews in total, one of which was dyadic. Following these interviews, I facilitated three focus groups between $30^{\text {th }}$ August 2017 and $1^{\text {st }}$ September with young people aged 16-19. The discussion schedules for both the interviews and the focus groups were similar, in that the interview discussion schedule directly related and helped to guide the key topics of the focus group discussion schedule (see Appendices 5 and 6). I asked my study participants about their views on gender norms and the ways in which these norms can influence and shape social life, as well as people's experiences of relationships. Some of the core questions that underpinned our conversations and guided my analysis of the data are:

- What are participants' views on the significance of gender norms in New Zealand?

- Are there pressures to live up to certain gender norms and if so, what might these entail?

- What are participants' views on the ways in which gender norms impact young people's understandings of relationships?

I personally transcribed all the interviews and focus group discussions verbatim, completing the last one on $19^{\text {th }}$ October 2017.

In Chapter 2: Theoretical Framework, I briefly discuss the background behind my study, commenting on what is meant by the term "gendered culture" by noting the historical gendered division of labour in New Zealand after 1840 when the Treaty of Waitangi was signed and settlers began establishing a colonial society in Aotearoa. I then describe some relevant

\footnotetext{
${ }^{2}$ The concept of healthy relationships is widely understood by my participants, as documented in the findings chapters, to be underpinned by qualities such as good communication, trust, love and honesty. Sometimes, these qualities were considered to be ambiguously represented in educational settings and some participants contested the dominant perceptions of what a healthy relationship might be, and what it actually can encompass in their lives.
} 
concepts in the literature for analysing contemporary manifestations of gender norms and relationships. In this chapter I elaborate on the climate of gender and sexuality discourses around young New Zealanders in recent years and clarify how I draw on concepts such as neoliberal social hegemony, postfeminism, the heterosexual matrix, and theorising resistance to the status quo. In Chapter 3: Methodological Framework, I discuss what it means to engage with a critical feminist perspective in research, exploring the researcher and participant relationship in feminist methodology and reflecting on my relationships with participants. I detail the rationale and journey of the project before acknowledging limitations of this study and reflecting on my positionality within this paradigm. Finally, I describe my use of Virginia Braun and Victoria Clarke's (2006) guide to thematic analysis for categorising and interpreting the data, and introduce the final themes I focus on in the following three findings chapters.

My findings chapters, Chapters 4, 5 and 6, are structured around the final themes I selected to focus on in this project; The Gender Binary and "Bro Culture", Pressures and Responsibilities, and Healthy Relationships. I present and analyse the data in these three chapters, before moving onto Chapter 7: Discussion of Findings where I synthesise and critically comment on some of the most significant concepts which have arisen in each findings chapter. In Chapter 4: The Gender Binary and "Bro Culture", I consider the ways in which gender norms impact the delivery of sexual abuse prevention education and how young people experience and perceive these norms in their everyday lives. Pressure to appear to others as staunch, particularly for young women, was discussed by several participants. I follow this up further in Chapter 5: Pressures and Responsibilities, where heightened gate-keeping roles are experienced by marginalised young people and greater responsibility is placed on LGBTQIA+ youth to educate others about their experiences in a heteronormative society ${ }^{3}$. In Chapter 6: Healthy Relationships, I examine the concept of 'healthy relationships' and comment on the ways in which participants understand, critique and suggest alternatives to its typical characterisation in education and social life. Here I also examine the emancipatory potential of valuing community-based approaches and activism for enabling stronger relationships and reformulating gender norms.

In Chapter 7: Discussion of Findings, I propose the value of conceptualising the imperative of staunchness in New Zealand through further research, and examine its

\footnotetext{
${ }^{3}$ The acronym 'LGBTQIA+' refers to Lesbian, Gay, Bisexual, Transgender, Questioning/Queer, Intersex and Asexual identities. It does not cover everyone who will identify outside of heteronormative lines. Terminology shifts rapidly so this acronym may become outdated in time. Sometimes, scholars prefer to use the term 'queer' because it is "antiseparatist" in orientation, defying the rigidity which can come with characterisations of identities like "gay" and "lesbian" (Hennessey, 1994, pp. 966-967). I have opted to use the acronym here because the term was used by most of my participants, and some people do not like to be referred to as "queer" because of negative historical connotations the term can carry. For further discussion and a breakdown of the debates around identity politics and terminology, see Hennessey (1994) and Lovaas, Elia \& Yep (2006, pp. 6-8).
} 
implications within New Zealand's gendered culture. Extending on this, I make the case that there ought to be greater theorising around what it means to be victimised in a gendered culture that values staunchness. There appears to be considerable scope for theorising both these concepts alone, but dominant constructions of victims, as a vulnerable group, have emerged from critical perspectives on imperatives to be staunch as a gendered subject. In the context of my research, I see these identities as intertwined and central to understanding New Zealand's gendered culture. Following these points, I articulate the potential usefulness of thinking about community in the context of this research topic, in light of recent political activity taken by some of the research participants and others known to them. Valuing the actions and ideas generated by and for communities is an important avenue for seeking substantive and meaningful social change. Further, maintaining this focus in research is useful for thinking more broadly about ways in which staunchness and responsibility could be reconceptualised as a shared experience. Chapter 8: Conclusion gives a summary of the project, its contributions to knowledge in this area, and some suggestions for further critical feminist research and policy. These suggestions respond to the most prominent concerns of my participants about gender norms in order to raise significant points of focus for future efforts to challenge our gendered culture and envision emancipatory alternatives. 


\section{Chapter 2: Theoretical Framework}

\subsection{Background Context: Origins of New Zealand's Gendered Culture}

According to Bev James and Kay Saville-Smith (1994, p. 14), New Zealand society is distinctly organised by gender. I will describe some of these gendered norms, exploring the extent to which they have shaped New Zealand's post-colonial society. This extends into a discussion of historical discourses about sexuality, establishing the context for the precedence of moral views on young people's relationships in sexuality education.

James and Saville-Smith (1994, p. 11) note that it is not enough to simply see New Zealand as having a gendered culture because masculine values are privileged as default and natural. Critically, New Zealand's society is distinctly organised by a gender binary. "Masculinity and femininity structure, express and make sense of, at a popular level, the conflicts, interests and inequalities which are integral to [New Zealand] society" (James \& Saville-Smith, 1994, p. 11). New Zealand's gender normativity is similar to the ways in which gender is constructed in other parts of the world, but according to James and Saville-Smith (1994, pp. 11-12) there is a relatively unique hegemony of gender in Aotearoa, which is implicated in perceptions of our settler society as egalitarian in terms of class (James \& Saville-Smith, 1994, pp. 20-21; Belich, 2007, p. 329).

Unlike nineteenth-century Britain, which was organised by rigid class order, New Zealand settlers sought to do away with class as a means of social stratification. The extent to which this was realised tends to be exaggerated in non-critical readings of our nation's history. Some New Zealand sociologists and historians (Pearson, 2004, p. 292, Belich, 2007, p. 330; Toynbee, 1978, pp. 78-79) argue that it is false to suggest that New Zealand really was classless, because class stratification arrived in the ranks on ships, and, according to Toynbee (1978, p. 79) it was also visible in the "ethos of personal thrift and capitalistic enterprise" valued by settlers who sought to create their own society in Aotearoa. The virtue of proper British respectability was key in characterising stratification among settlers, visible via differences in housing, occupation and marital status (Toynbee, 1978, p. 79). Further, working classes were later formed by urbanising Māori, who took up blue collar work in settler-owned factories (James \& Saville-Smith, 1994, p. 85). James and Saville-Smith (1994, p. 14) note that the myth of classless egalitarianism was in part propped up by the establishment of a gendered division of labour for enabling New Zealand's prosperity.

Linda Tuhiwai Smith (2012, p. 171), Jessica Hutchings (2005, p. 49), and Naomi Simmonds (2011, p. 15) concur with this interpretation of gendered culture as a feature of the colonial legacy, because of the ways in which it disrupted Māori social organisation. Prior to 
Pākehā settlement, Māori voices were conceptualised through whanaungatanga (translating approximately to an interrelationship of feminine and masculine roles). This informed the delegation of care toward life. While differently articulated for each gender, whanaungatanga accorded substantive value to both women and men's abilities to lead and care for others (Hutchings, 2005, p. 53). According to Te Awekotuku (1991, pp. 52-54), gender was not a fixed organising principle for Māori as it was for British settlers. Rather, each iwi (tribal grouping) adopted differing means of social organisation, and gender roles held different meanings accordingly.

Missionary and capitalist influences shaped New Zealand's gendered culture by encouraging and normalising the division of women's and men's labour into private and public spheres (James \& Saville-Smith, 1994, p. 23; Smith, 1992, pp. 33-34). These measures attempted to redefine Māori cultural roles, and especially those of Māori women who were defined in terms of their difference to men, and to Pākehā (Simmonds, 2011, p. 11). In the words of Linda Tuhiwai Smith (1992, p. 42), "Māori women were perceived either in family terms as wives or children or in sexual terms...women who had 'chiefly' roles were the exception...not the norm...their autonomy was perceived as immorality and a lack of discipline". Femininity was also embodied through the unpaid reproductive labour and housework many women undertook to support their children's wellbeing and to enable men to participate in New Zealand's public institutions (James \& Saville-Smith, 1994, pp. 41-42).

Women's place in New Zealand's social order was generally located in undertaking domestic labour and expressing "nurturant and maternal capacities" (James \& Saville-Smith, 1994, p. 32). James and Saville-Smith (1994, p. 55) argue that feminine culture was not a derivative of masculine culture, nor were women simply dominated by men. Housewives and mothers were expected to conform to a higher moral standard than the men in their families. Their roles included softening the perceived hardened nature of their husbands and sons, by providing them with care and emotional support. Women's influence on men was deemed to be of "natural purity", restraining men's "barbarous" or "animal-like" tendencies (Phillips, 1987, p. 51). Women were also expected to look after their families' wellbeing and contribute a morally responsible voice on social issues. For example, members of the Women's Christian Temperance Union are remembered for their campaigning for alcohol prohibition laws (Bunkle, 1980, p. 57). Phillida Bunkle (1980, p. 56) notes that evangelical church-goers, who were predominantly middle-class Pākehā, believed that women were "God's great interpreters". Despite this, the church restricted female congregation's access to nomination for leadership or decision-making roles in the parish up until the 1980s. This demonstrates the careful monitoring of the gendered division of participation in public and private spheres of New Zealand settler society. 
Settler society gave rise to the formation of masculinities in a New Zealand cultural context. Connell and Messerschmidt (2005, p. 832) define hegemonic masculinity as the "most honoured way of being a man...[requiring] all other men to position themselves in relation to it...and ideologically legitimat[ing] the global subordination of women to men". The adoption of stoic and unemotional attitudes, and the idea that women were 'other' were common among most New Zealand men (Phillips, 1987, p. 38; Fenwick, 1980, p. 91). Egalitarianism in terms of class was represented as experienced by (Pākehā) men, who were supposedly inclined to express mateship across occupational boundaries because they shared an interest in building a prosperous society without the institutionalised presence of poverty and job instability back in Britain (James \& Saville-Smith, 1994, pp. 85-86). As Fenwick (1980, p. 91) argues, it was in capitalist settlers' interest to keep the majority of women working at home for their families, unpaid. This enabled men to work on farms and in the public sector. Women at home could then care for men outside of work hours, enabling greater productivity for the next work day. Each man with a wife could embody an ideal of a pioneering and respectable settler (Phillips, 1987, p. $5)$.

The settler man was widely perceived as hard-working and innovative, and was celebrated as a normative figure of progress for establishing a new society (Brickell, 2012, p. 13). Physical strength, excessive alcohol consumption, rugby and homosocial relations with fellow men are all common themes in literature about markers of manhood in New Zealand (Phillips, 1987, p. 45; Andrewes, 1999, p. 194). In addition, the rise of rugby and rugby culture at the beginning of the twentieth century fostered feelings of "community, kinship and egalitarianism" among men (James \& Saville-Smith, 1994, p. 41). Rugby culture was an important aspect of men's socialisation, as it privileged physical strength, and scorned the “weak, intellectual" man (Markula \& Pringle, 2006, p. 94). Brickell (2012, p. 15) and Markula and Pringle (2006, p. 93) note that masculine culture was founded heavily on mateship with fellow men, and distancing themselves as a group from women and femininity. Campbell (2000, p. 565) noted that the construction of certain public spaces as distinctly masculine territory, such as pubs, fuelled a shared disdain for femininity. For example, the campaigning of the WCTU for prohibition laws around alcohol consumption was largely perceived by male pub customers as interfering, morally righteous women disturbing their circle of mateship (Bunkle, 1980, pp. 56-57; Phillips, 1987, p. 37).

\subsection{Moral Conservatism and Education}

New Zealand's gendered culture was also implicated in institutional regulating of sexuality. According to Fenwick (1980, p. 82) the New Zealand Family Planning Association (NZFPA or FPA) sought to "educate and enlighten the people of New Zealand on the need for 
birth control...and promote the provision of contraceptive facilities". However, the Association faced difficulty making their services widely available. The most notably vocal opposition to the aims of the NZFPA was the Catholic Church, who recommended to the Prime Minister in 1940 that the "importation, sale, manufacture, and/or distribution of contraceptive goods and appliances and their advertisement or display be prohibited" (Fenwick, 1980, p. 85). Their influence on government also weakened political endorsement of these initiatives. Until the late 1970s, many Labour Party politicians would treat FPA initiatives with caution because the party depended on the Roman Catholic vote (Fenwick, 1980, p. 85).

The Catholic Church's perspective on sexuality at this time can be understood as a morally conservative view (but it should be noted that the public perspective of the church was not always the view of individual Catholics). Moral conservatism as a social and political force had notable influence on the sustaining of a gendered culture. It can be understood in this context as the belief that men and women are fundamentally different, and that their labour ought to be divided as such (James \& Saville-Smith, 1994, p. 60). Morally conservative perspectives of "normal" sex follow that it must be "heterosexual, coital and confined to marriage" (Jackson \& Weatherall, 2010b, pp. 167-168). Conservatives were unsympathetic towards initiatives and policies which sought a greater awareness of sexuality (Jackson \& Weatherall, 2010a, p. 48; Smyth, 2000, p. 182). Further, morally conservative lobbies and institutions feared that providing expansive sexuality education to young people would disrupt civil society, increase promiscuity, teenage pregnancy and endorse a supposed lack of moral rigor.

It was not until the late 1960s that the Family Planning Association gained greater public recognition through government funding and a stronger relationship with the medical establishment, and some high school curriculums underwent a shift to include formal education on sex and reproduction (Fenwick, 1980, p. 86). But each school adopted sexuality education to varied extents. The National government's rejections of important recommendations from the Johnson Report ${ }^{4}$ in 1977 resulted in individual schools making "random" decisions on sexuality education (Smyth, 2000, pp. 171-172). These decisions (which included teaching primarily on anatomical aspects of reproduction rather than sexual and social aspects, for example) were subject to the influence of the moral and political opinions of Boards of Governors (Trustees) and principals. Schools could choose whether or not they updated their own internal curriculums and it remained optional for primary schools to teach sexuality education (Allen, 2005a, p. 117; Smyth, 2000, pp. 169-172). Morally conservative anxieties polarised the way

\footnotetext{
${ }^{4}$ See the Department of Education's Report of the Committee on Health and Social Education, Growing, Sharing, Learning (the Johnson Report) of 1977 for these recommendations.
} 
sexuality education made an appearance in schools up until 1984, when Acquired Immune Deficiency Syndrome (AIDS) was first identified in New Zealand. This prompted public discussion about the necessity of education as protection from disease and other risks, such as pregnancy. According to Smyth (2000, p. 183), the need for informative education began to take precedence over morally conservative arguments against sexuality education.

\subsection{Information as Empowerment}

In the mid-eighties, the Family Planning Association (FPA) reached out to Women's Weekly readers for their views on sexuality education. Readers were asked whether they would support increased sexuality education in schools, due to the presence of AIDS in New Zealand (Smyth, 2000, p. 184). Ninety-five percent of respondents said they would support it, marking a noticeable shift in public attitudes towards sexuality since earlier in the twentieth century. Despite this, the FPA still faced what their spokesperson described as "terrific criticism" from a small but noisy "moral minority" of conservative lobbies (Hughes, 1993 as quoted in Smyth, 2000, p. 184). This meant that many politicians still treated the subject of sexuality education with caution, wary of alienating potential voters. Overall though, New Zealand's governments after 1984 took steps to increase society's awareness of sexually transmitted diseases, such as supporting the FPA's educational work and supplying young people with condoms. Clarke (2001, p. 29) notes that by the time the new millennium came around, New Zealand had adopted a robust sexuality education focused on information, prevention and risk. But it was not without some compromise that sexuality education could be taught in this way. The topics which get the most attention in the classroom remain subject to the moral influence of individual schools' Boards of Trustees, and parents are given the option to withdraw their children from sexuality education classes (Clarke, 2001, p. 29).

In my Honours Dissertation (Trotter-Simons, 2016, pp. 8-9), I analysed changing discourses in two government strategies affecting this area. I examined the Ministry of Health's Sexual and Reproductive Health Strategy (2001) which impacted on the delivery of sexuality education, and the Ministry of Education's recently revised Sexuality Education Guidelines (2015). While the Sexual and Reproductive Health Strategy (SRHS) of 2001 emphasises the importance of empowering students to make "responsible choices" about their sexual health, it does not take into account students' cultural, ethnic and class backgrounds - all of which may impact on their ability to make these choices (Jackson and Weatherall, 2010a, p. 49; Ministry of Health, 2001, p. 7). Fundamentally, the rhetoric of personal responsibility in the strategy also does not acknowledge gender normativity and inequities in the school environment. For example, much decision-making around sexual health is implied to lie with female students young men are scarcely mentioned as 'at risk' in the same way, other than the possibility of 
contracting and spreading HIV/AIDS and other sexually-transmitted infections (Ministry of Health, 2001, p. 7). The strategy appears to be primarily occupied with outlining the potential dangers and risks that sexually active youth pose to New Zealand society.

Jackson and Weatherall (2010a, p. 50) argue that concern about sexual risks and dangers outlined in the SRHS (2001) are framed as health-based rather than moral or religious concerns, but the suggestions given for averting these risks could satisfy conservative interest groups too. The researchers for the Ministry of Health who produced this document also conceived of high school students as acutely unaware of the potential consequences of sex and intimate relationships, treating them as subjects who need to be discouraged from sex to reduce both health and social risks they may encounter. The guidelines encourage sexual health educators to teach students to "value themselves" and to prioritise their own "self-worth" in sexual interactions (Ministry of Health, 2001, p. 9). This may have the effect of educators implying to students that having intercourse may tarnish their reputations among their peers, and notions of self-respect could be co-opted by educators to scrutinise and blame young people for negative sexual experiences.

Moreover, it is a tacit directive with the conservative gendered discourse that one's virginity is something that is lost and gone forever. Lindsay (2005, p. 89) argues that conservative narratives construct virginity as an essential aspect of feminine experiences of growing up; girls learn to see their bodies as objects for the pleasure and manipulation of others. Virginity, or the number of sexual partners one has had, is a threshold used by young people for understanding themselves in relation to their peers (Allen, 2005a, pp. 78-79; Lindsay, 2005, p. 89). Complicating this, there can also be social stigma around refraining from sex for too long (Lindsay, 2005, pp. 89-90). However the extent of one's sexual knowledge and experiences still form criteria which young people may use to compare themselves to each other (Bay-Cheng et al., 2011, p. 1169). In focus group research with young women about sexual risk management, some participants expressed that a lack of agency can result in pregnancy or sexual harassment, and it is up to individuals to mitigate these risks (Bay-Cheng et al., 2011, p. 1175). In later work, Bay-Cheng (2015, p. 282) notes that young people commonly regard the term 'slut' not just to refer to someone with many sexual partners, but to refer to a young woman with a lack of control over her sexual experiences.

\subsection{Neoliberalism, Self-Management and Personal Responsibility}

Neoliberalism is a relevant concept for understanding the nature of contemporary gender and sexuality discourses in New Zealand. Jackson and Weatherall (2010a, p. 50) draw on neoliberalism in their critical examination of the SRHS (2001), where young people are assumed 
to be "rational free-willed subjects", equipped with "individual responsibility" to make sensible and healthy choices about sexual partnership. Because I refer to neoliberal principles in terms of social hegemony throughout the thesis, I will unpack the term and clarify how I refer to it in the context of this research.

As an economic theory, neoliberalism has informed much of New Zealand's social and public reforms since the mid-1980s. To fully account for the lived experiences of the people whom this research concerns, neoliberalism is treated as much more than an economic theory and policy approach. Neoliberal economic principles have resulted in "specific organisation of the social, the subject, and the state" (Brown, 2006, p. 693). This is visible through assumptions of citizens' personal responsibility, their exercise of free choice, and their capacity to pursue success; not only in the global market but also through social and institutional imperatives which people may experience in daily life (Venugopal, 2015, p. 168; Humpage, 2017, p. 126). Neoliberal reforms to public and social policy include the sale of state-owned assets and institutions, expanding the private sphere and taking measures to collapse the welfare state (Kelsey, 2014, p. 88). These reforms constitute the character of neoliberalism not just as an ideology, but as a logic or rationale, where citizens are constructed as self-interested actors in multiple ways. Harvey (2005, p. 3) clarifies this; "neoliberalism has become hegemonic as a mode of discourse. It has pervasive effects on the ways of thought to the point where it has become incorporated in the common-sense way many of us interpret, live in, and understand the world."

This view of citizens is naturalised through persistent emphasis on individuals, and the dissolving of community, solidarity and social connection (Bauman, 2007, pp. 27-28). In this regard, Bauman (2007, p. 3) likens neoliberal social organisation to "networks" (instead of societies) of random individuals with little connection to one another. Nikolas Rose (1996, p. 334) extends on this, arguing that citizens no longer experience meaningful connections and solidarity as they might have in the past; rather "the social" is dying and being replaced by heightened individualism, disengagement from shared values, and disorganised chaos through competitive pursuits of success becoming normalised interaction and expression.

Flew (2014, p. 51) breaks down several ways in which the term neoliberalism can be used in social and cultural studies. I derive my interpretation of neoliberalism as a "social hegemony", where Flew (2014, p. 59) links conceptualisations of neoliberalism to Foucauldian observations of state and self-governmentality, and to Marxian dominant ideology theory5.

\footnotetext{
${ }^{5}$ Harvey (2005) is the primary thinker referenced here by Flew (2014, p. 57); see his work for further insights about neoliberalism using dominant ideology theory.
} 
According to Flew's (2014, p. 59) analysis, the principles of neoliberal economic rationale are relevant for conceptualising the way citizens regard themselves in relation to others, in that the state constructs people with capacity to participate in the market as individual entrepreneurs who are concerned with their personal success. The quest for success in one's chosen life path is aided by one's abilities to shoulder responsibility for their own wellbeing, wealth and social interactions. Neoliberalism as a social hegemony therefore encapsulates citizens' individualised modes of governance to promote an ethos of 'success' in multiple areas of their lives.

Jackson and Weatherall (2010a, pp. 48-50) identify neoliberal rhetoric about personal responsibility in the SRHS (2001). One of the main aims of the policy is to instil within young people the capacity to experience personal success through careful decision-making in their transition to adulthood. It is emphasised throughout the SRHS (2001, pp. 3-7) that New Zealand's high rate of teenage pregnancy is an issue which can be curbed by informing more young people about the risks of unprotected sex and the implications these risks can have for their futures. The strategy highly values citizens' ability to contribute to market productivity becoming pregnant at an early age is perceived as a hindrance to this pursuit (Jackson \& Weatherall, 2010a, p. 50). In this document, teenage mothers are generally regarded as an expense to the neoliberal state. According to Rose's (1996, p. 330) perspective of neoliberal governance as institutionally entrenched, young women, above all others, must become "active in their own government" to avoid risks such as unplanned pregnancy in their navigation of relationships.

Allen's (2005b, p. 398; 2007, pp. 580-581) research has indicated that young people report several limitations of the information-as-empowerment approach of their sexuality education. Students suggested that the emphasis on contraception and risk-aversion prevented their classes from having in-depth discussion on topics like gender in relationships, the emotional aspects of sexuality, and the full extent of what the term 'sexuality' could cover. Moreover, constructing sexuality as private, taboo or shameful has held back the informative potential of sexuality education (Allen, 2005b, p. 395). Young people also reported wanting to participate directly in the planning of discussion topics, have more time to ask questions, and have sexuality education classes more frequently. They emphasised the value of hearing real-life experiences, because these can add substance to abstract concepts, such as protection against pregnancy or STIs (Allen, 2005b, p. 396).

The Sexuality Education Guidelines (2015) were found, in my Honours research, to be underpinned by notably different discourses than the SRHS (2001). While there is still neoliberal, individualist discourse present in some aspects of the document, there is also stronger emphasis than previously on centring Kaupapa Māori perspectives on sexuality in the 
curriculum. The guidelines' objectives are informed by a range of both social and health-based research, such as Allen (2005b) and Fine and McClelland (2006)'s work, which acknowledges young people's desires for honest dialogue on relationships and sexuality. They also emphasise the importance of an education on stratification, inequality and gender norms as part of teaching healthy relationships (Ministry of Education, 2015a, p. 16). This recognises students' abilities to think critically about the potential issues of a gendered culture. It also treats them as epistemic agents with a right to unbiased, helpful and positive information about sexuality and relationships. In this sense, these guidelines have come a long way since the SRHS (2001). It remains to be seen how easily the revised guidelines affect real change, given that individual schools implement these sorts of directives to varying extents, beyond mandatory educational programmes for Year 9 and 10 students (Jackson \& Weatherall, 2010b, p. 170). These differences between schools are illustrated in the findings chapters.

\subsection{Postfeminist Gender Discourse}

Postfeminism is a scholarly term used to describe a cultural shift in perspective on the meaning and relevance of feminism in neoliberal societies. Gill (2007, p. 148) conceptualises postfeminism as a sensibility in which popular discourses about the liberation of women are both feminist and anti-feminist, and both progressive and conservative. McRobbie (2004, p. 256) extends on this idea through describing a postfeminist cultural shift as a 'double entanglement' of discourses. The double entanglement symbolises the ways in which feminism's achievements are taken for granted, yet feminism is also repudiated and deemed contemporarily irrelevant. The supposed irrelevance of feminism as an "ideologically overloaded" collective movement follows the popular individualised ethos of 'Girl Power' in the 1990s (Genz \& Brabon, 2009, p. 69; Caputi, 2013, p. 5), where the position that 'girls can do anything' became realised by the neoliberal state.

Through the lens of postfeminist ideals, young women are likely to have a heightened sense of pressure to make responsible choices in order to attain success in multiple areas of life; in their workplace or education, in sexual relationships, and in how others perceive them. Elliot (2014, p. 217) reported that this construction of young women existed in her study of relationship and sexuality educators in classrooms. Several educators in the study constructed young women as "consequence-bearing" sexual agents who never passively allow sex to "just happen" (Elliot, 2014, pp. 217-218). In these lessons, educators assumed that young women always have an active role to play in sexual scenarios and by extension are held accountable for their experiences. This rhetoric makes invisible how power dynamics can have profound impacts on sexual situations and shape people's experiences differently according to gender, sexuality, ethnicity, class, ability and age. Gill (2007, p. 149) argues that regimes of self- 
surveillance characterise what it means to be a young woman in an era of pervasive postfeminist logic. According to Gill (2007, p. 149), self-surveillance is applied to girls' own bodies as signifiers of successful feminine subjects. Desirable (hetero)sexualities are performed by young women in their consolidation of femininity as empowered, well-managed and responsive to men's desires.

As Flew (2014, p. 59) notes, the neoliberal state seeks to establish ideal conditions for increasing citizens' self-management. Both Gill (2007, p. 148) and McRobbie (2015, p. 4) extend this notion of neoliberal social hegemony by contending that women in particular are held up to high standards of success in both their public and personal lives. 'Perfect' girls are normative figures for women who seem to be able to do it all, according to McRobbie (2004, p. 257; 2015, p. 9). Creating an ideal feminine appearance is not the only signifier of postfeminist success. Describing today's 'can-do' girl as one who embraces "perfection" in all aspects of her life from a young age, McRobbie (2015, pp. 4-5) emphasises that young women increasingly scrutinise their own performances at school or in the workplace, anxious to stand out as exceptional at what they do now that they are seemingly afforded equal opportunities to men, and there are more career path options available to them. In this fashion, young women now micro-manage several aspects of their own lives. This can include their intimate relationships.

Viewing relationships or sexual experience as a marker of success, many young heterosexual women appear to be very attentive to the desires of young men while emphasising their own agency and choice in relation to these desires (Bay-Cheng, 2015, p. 281; Harris \& Dobson, 2015, p. 150). This can be seen in young women's talk about how they consolidate their femininity in heterosexual intimate relationships, through dual prioritisation of responding to a man's wishes for sexual intimacy and at the same time carefully determining who they choose as a partner and the sorts of intercourse they engage in, to avoid being labelled as a slut (Allen, 2005a, p. 78; 89). Emphasising their own agency in intimate relationships is important for young women, according to those who have participated in a variety of focus group research about gender and intimate relationships (Allen, 2005a, pp. 79-80; Bay-Cheng at al., 2011, p. 1175, Jackson \& Weatherall, 2010b, p. 169). Their individual self-governance characterise how group members present themselves in relation to others. In Allen's (2005a, p. 89) words, their conversations were "constantly modified" to reflect individuals' own expression of an ideal responsible, self-managing subject. In this way, girls' self-management goes beyond successfully channelling desirable articulations of femininity. Young women often are responsible for "gatekeeping" the social and emotional aspects of sexual relationships (Jackson \& Weatherall, 2010b, p. 169; Bay-Cheng, 2015, pp. 280-281). 
Individualised notions of 'girl power' is a highly valued and popular discourse among young women in a postfeminist context (Gill, 2007, pp. 148-150; Tasker \& Negra, 2007, pp. 1819). One way this is visible is through the 'ladette' phenomenon, theorised by several scholars. The ladette is a normative female figure who can be regarded as one of the lads. Through distancing themselves from traditional notions of femininity as confined to domestic and carework realms, ladettes instead identify as being on a more equal footing with young men through adopting a 'lad'-like persona (Dobson, 2014, p. 258). Among young people, ladettes typically adopt various cultural expressions of a reckless, 'don't-care' attitude about social order. This is visible in girls' increased engagement in binge drinking, smoking, swearing and other traditionally masculine activities (McRobbie, 2009, p. 84; Jackson, 2006, p. 346; Dobson, 2014, p. 256). The ladette is described by a participant in Jackson's (2006, p. 344) study as "one of [the] mates" in a group of rowdy lads. Young men "put their arm around her and rub her on top of the head and that kind of behaviour" ('Mr Garner' as quoted in Jackson, 2006, p. 344). In this way, the ladette is granted access to mateship circles of young men - in contrast to the social norms of historical gendered divisions of labour.

The ladette is up for anything and is never too serious - often engaging in casual sex and lacking commitment to a partner (McRobbie, 2009, p. 83; Jackson, 2006, pp. 346-347). The figure of the ladette is constructed as highly (hetero)sexual, and ought not be confused with tomboys, whose sexuality is implied to be less obviously heterosexual by the participants in Jackson's (2006, p. 346) study. Not so long ago, teenage girls were largely understood by teachers to their male peers as a "more mature and sensible influence", reminiscent of New Zealand sociological literature which argues women were predominantly constructed as a morally responsible voice in a male-dominated settler society (Jackson, 2006, p. 340; Bunkle, 1980, p. 56). In the twenty-first century however, girls who adopt a ladette persona are described by their teachers as "brash", "shameless" and "unruly" (Jackson, 2006, pp. 345-346). Their defiant and disruptive behaviour in the classroom makes a strong break with traditional notions of young women as innocent and pure. The ladette illustrates the aspect of postfeminist double entanglement where women's liberation from traditional roles is now achieved, because she "gives the impression of having won equality with men by becoming like her male counterparts" (McRobbie, 2009, p. 83). I pick up on this phenomenon later when discussing how the research findings resonated with notions of 'ladettes' and 'perfect' girls.

\subsection{Contemporary Gender Norms}

Postfeminism can be drawn on for understanding the way gender norms are articulated in Aotearoa New Zealand today. As Allen (2005a, p. 89) found in her study, teenage girls individually undertook identity work in focus groups to ideally perform their femininity. This 
established the ways in which they identified as empowered and well-informed about navigating intimate relationships. On the other hand, their descriptions of their roles in heterosexual relationships may reproduce an aspect of New Zealand's gendered culture, where women are generally expected to be more morally responsible than men, and become their emotional gatekeepers. For example, emphasis is placed on not "hurting his feelings" among girls when discussing how they might tactfully refuse their male partners' insistence on doing something irresponsible in sexual intercourse, like not wearing a condom (Gavey, 2012, p. 720). This can make negotiating consent a complex and contradictory experience, and indicates the presence of gendered discourses in young people's heterosexual relationships.

Expanding on this, Gavey (2012, p. 719) notes that critical feminist theorists must take care not to conflate ones' reported feelings of empowerment with actually being emancipated from an oppressive gendered culture. She problematizes the notion that young women are automatically empowered when they have an ability to choose. Ringrose (2012, p. 62) echoes this: "Does girls' agency simply mean the capacity to speak and think?" More critically in this context, young women may frame having sex with their partner even when they are not in the mood, as their choice because of an imperative to identify as an empowered individual. While Gavey (2012, p. 720) is not weighing up whether individual women who frame their part in sexual situations as a choice are empowered or not, she questions the weight that empowerment is given in postfeminist discourse when it is conveyed as individually possessed and is not talked about in terms which disrupt the status quo.

Riordan (2001, p. 291 as cited in Budgeon, 2011, p. 287) contributes to this critique of 'empowerment' as a popular postfeminist buzzword, arguing that it signals "a celebration of what girls already do rather than encourage girls to seek power through direct economic and political means". Gill (2012, p. 737) illustrates 'empowerment' as a tool for consolidating agentic femininity, and claims that it can be a characteristic which young women co-opt "to perform confident, knowing hetero-sexiness". McRobbie (2009, p. 18), Projansky $(2007$, p. 53) and Harris and Dobson (2015, pp. 150-151) go further, identifying that the empowerment of young women is constrained by the silence of the ideal postfeminist subject about critical issues. McRobbie (2009, p. 18) notes that that young women's status and power are achieved via their lack of voice on social issues, like sexism among other axes of oppression. The "modern and sophisticated" young women sign a new sexual contract by withholding any critique of the status quo because it is supposedly advantageous to their relationships and career moves as aspects of life where success can be measured (Harris \& Dobson, 2015, p. 150; McRobbie, 2015, p. 8). The use of 'empowerment' as a shallow buzzword to signal an appearance of equality with 
men may ultimately be complicit with hegemonic masculine ideals by making invisible their ongoing dominance.

In the context of postfeminism, heteronormativity continues to be an important organising principle for maintaining a gendered culture (Gill, 2007, p. 149; McRobbie, 2009, pp. 66-67). Part of young men's experiences of this culture might involve pressure to demonstrate their masculinity in strongly heterosexual terms, and to define themselves as opposites to young women. Young men in mixed-gender classrooms respond in various ways to the presence of young women, demarcating and establishing the norms of gendered culture in that particular classroom (Kenway \& Willis, 1997, p. 19; Measor, Tiffin \& Miller, 2000, p. 73). Their responses to sharing the classroom with girls can vary, from making gendered jokes to sexual harassment and bullying. Measor, Tiffin and Miller's (2000, pp. 96-97) work has identified that young men are less receptive to engaging seriously with relationship components of sexuality education, and had therefore demonstrated less knowledge of how gender normativity impacts on intimate relationships.

Lindsay (2005, p. 91) notes that a key marker of adulthood for young men is having sex for the first time with young women. Because of this, there is considerable peer pressure on boys to become sexually active. In a New Zealand context, a lack of sexual experience can signal failure to attain the popular and knowing masculinity of one's sexually active peers (Allen, 2005a, p. 70). Importantly, men's consolidation of masculinity as (hetero)sexually experienced often takes place in homosocial contexts, with other male peers, whereby constructing themselves as gendered subjects is "accomplished in the course of social interactions; reconstructed from moment to moment with specific discursive and rhetorical contexts and distributed across social contexts" (Edley \& Wetherell, 1997, p. 205). Jackson and Weatherall's (2010b, p. 175) focus group research with a group of young men from an all-boys high school demonstrated that what the young men considered "actual sex" as coital intercourse only. These ideas of "actual sex" and what it involves can be considered with regard to Gavey, Braun and McPhillips' (1999, pp. 41-42) concept of the coital imperative, which I elaborate on below.

\subsection{Gendered Implications of the Coital Imperative}

Gavey, Braun and McPhillips (1999, p. 37) facilitated an important study with mostly heterosexual Pākehā graduates in New Zealand to formulate dialogue about the concept of the coital imperative. The coital imperative can be understood in simple terms as the normalising and naturalising of penetrative sex and male orgasm for constituting legitimate sexual intercourse. The participants in Gavey, Braun and McPhillips' (1999, pp. 41-42) study overwhelmingly reported that they perceived penetrative intercourse concluding with male 
orgasm as a "natural progression" of intimacy, and that actual sex always involves coitus because of "biological reasons". A discourse which privileges the 'male sex drive' was apparent throughout participants' rationalisations of why people engage in sexual intercourse, because of the notion that it is natural for men to "plant [their] seed" (Gavey et al., 1999, p. 40). This contributes to the naturalisation of penetrative sex. As mentioned earlier, Jackson and Weatherall's (2010b, p. 175) study with a focus group of young men appeared to indicate that a coital imperative shaped their understanding of what constitutes real, legitimate sex. Students in this study dismissed other forms of sex as "slutty", dirty or simply "foreplay" (Jackson \& Weatherall, 2010b, pp. 173-175). At a similar time to Gavey, Braun and McPhillips' (1999) study, Measor, Tiffin and Miller (2000, p. 115) facilitated interviews with students from mixedgender secondary schools, where young women disclosed feeling considerable pressure to agree to coital intercourse with their boyfriends, and young men experienced pressure from their male peers to successfully engage in coital intercourse.

In McAllum's (2014, p. 81) study with bisexual young women in New Zealand secondary schools, several participants reported that many teachers did not offer adequate support to queer students. Because queer identities like bisexuality were dismissed in health classes by some educators as "just semantics", wider school cultures were not often perceived as safe places where these students could easily ask for information and feel their identity was validated (McAllum, 2014, p. 83). The coital imperative and its consequential othering of nonheterosexual students is evidently an issue in secondary schools. A key aspect of the holistic approach to sexuality that the guidelines discuss is the importance of acknowledging sexuality as a healthy and exciting aspect of a young person's life (Ministry of Education, 2015a, p. 3). The guidelines stipulate that the wider school culture should value this, and all teachers, not just Health teachers, ought to recognise sexuality in this way (Ministry of Education, 2015a, p. 16).

One bisexual participant in McAllum's (2014, p. 82) study reported having the opposite experience. She described working on a project about gay rights in one of her classes and the teacher proceeded to loudly ask the student if she was gay, in such a way that the whole class could hear. The student was very embarrassed because her peers began to laugh at her, so she felt pressured to publicly announce that she was no different to other students. The participant described this event as confusing because she did also like boys, and there was no safe way to articulate her identity in that classroom environment (McAllum, 2014, pp. 82-83). There was no recognition of her possible identity from the teacher, as well as no respect shown for the student's privacy. This event indicates that there can be a lack of empathy from school staff about the marginalisation of some young peoples' identities in wider society. Such attitudes from school staff pose challenges to establishing supportive school environments which 
celebrate diversity. Furthermore, the position of authority which teachers hold over their classes impacts on how students treat their peers. When a student's gender or sexuality is implied to be out of the ordinary by a teacher, it may fuel bullying by other students (Measor et al., 2000, p. 73; Kenway \& Willis, 1997, p. 20).

\subsection{Theorising Resistance}

Renold and Ringrose (2008, p. 315) raise the concern that critical studies of young people's gender discourse rooted in McRobbie's work on postfeminism can paint an "overwhelmingly bleak picture and melancholic tone" about how young people fare in hegemonic masculine cultures, when young people may not always use such a tone when they talk about the gendered issues that they are faced with. This is not to suggest that young people are not critical of their surroundings, rather that much theorising about young people may not adequately capture the ways in which they challenge, resist and subvert heteronormativity, sexism and neoliberal hegemonies. This is where it is important to identify any possible assumptions from the standpoint of the researcher (I describe my own assumptions in Chapter 3: Methodological Framework).

Gavey (2012, pp. 720-721) indicates that actual emancipation from masculine hegemony is complicated to theorise because neoliberal articulations of 'choice' and heightened personal responsibility co-exist alongside subtle and substantive resistance expressed in everyday relations. McAllum's (2014, pp. 78-79) and Allen's (2005b, p. 394) research with young people report on their willingness to identify, critique and suggest alternatives to the neoliberal and morally conservative articulations of sexuality education and gender discourses in their classrooms. Renold and Ringrose (2008, p. 316) draw attention to the "ruptures" young people make to hegemonic masculine norms - these are also referred to as "lines of flight" that individuals actively choose to make from the status quo where they are not just withdrawing from it, but actively subverting it. These ruptures are understood as critically endowed with an anti-systemic undercurrent, as opposed to movements to alter the system from within (Deleuze \& Guattari, 1987, p. 10). They are illustrated as "moments of deterritorialization" which occur on a micro level, but they carry value for theorising young people's means of resistance against the hegemony of a gendered culture (Renold \& Ringrose, 2008, p. 319). In their study, one young girl talked about her response to an older boy who called her derogatory sexist names such as 'slag'. She recalled the experience in a way that subverted his intended power dynamic over her, where she put his abusive language down to him being a victim to peer-pressure to "look big to his friends" ('Erica' as quoted in Renold \& Ringrose, 2008, p. 328). While her views about this young man were complicated by the fact that she also liked him, she contested that he 
really was "big" by noting the hegemonic masculine social imperatives that he was compelled to exercise in front of his peers.

In this field of research, it is essential to note discourses of rupture like this, even when they are only mentioned in passing by participants. Multiple accounts of individual ruptures can "crystallise" to prompt a movement which challenges an oppressive aspect of the status quo for the group in question (Deleuze \& Guattari, 1987, p. 10). The importance is raised for theorising these ruptures and their complex social contexts because they can help formulate an alternative to New Zealand's existing gendered culture.

\subsection{Heterosexual Matrix, Empowerment and Sexual Violence}

Another key concept which is useful for understanding the ways in which gender normativity in New Zealand shapes sexuality discourses among young people is the heterosexual matrix, or "compulsory heterosexuality" (Rich, 1983 as cited in Renold \& Ringrose, 2008, p. 313). Butler (1990, p. 151) offers her definition of the heterosexual matrix as a "gender intelligibility" wherein gender identities are "oppositionally and hierarchically" defined as binary (masculine and feminine) and are seen in the practise and expression of heterosexuality. The heterosexual matrix is a concept for identifying a gendered culture's constructions of 'femininity' and 'female' and 'masculinity' and 'male'. The very words and linguistic tools which describe both sex and gender distinctions "naturalise" heterosexual relations, thereby concealing them from critique (Butler, 1990, p. 150). Renold and Ringrose (2008, p. 314) apply the heterosexual matrix to further understanding "depoliticised" postfeminist neoliberal cultures where both regulations and ruptures are taking place. The concept helps to further contextualise the construction of 'can-do' young women who are conveyed as "unambiguous success stories of late capitalist societies, where discourses of choice, freedom and autonomy coexist in a schizoid fantasy proliferation of highly restrictive and regulatory discourses of hypersexualised femininity" (Renold \& Ringrose, 2008, p. 314). Beres and Farvid (2010, p. 383) found that while some young heterosexual women in New Zealand assertively set boundaries in relationships and intercourse, indicating a shift away from passive femininity, they were also taking on more responsibilities as gate-keepers and "managing men's sexual desires".

Gill (2012, p. 738) argues that a popular discourse of 'empowerment', "emptied of its political significance" has become hegemonic for characterising confident and assertive femininity. This mystifies the nature of negotiating consent in heterosexual in relationships ${ }^{6}$.

\footnotetext{
${ }^{6}$ This project does not span far enough to cover the complexity of the debates around sexual consent and teaching on consent, but it should be acknowledged that the term 'consent' has ambiguous and multiple interpretations. Beres $(2014$, p. 374) points out that scholars often take for granted the meaning of the
} 
Beres (2014, p. 377) notes that "one important question to ask is what exactly educators are trying to accomplish when they teach people about consent". She explains that aiming to reduce sexual violence through a consent-focused prevention model alone does not go far enough to address the social and gendered discourses underpinning ideas about sex, consent and relationships (Beres, 2017a, p. 2). My focus on theorising young people's views and experiences of gender norms acknowledges the need for greater understanding of these discourses because they can be implicated in negative outcomes like sexual violence and harassment. This theorising must take place before it is possible to suggest how critical gender-focused pedagogy in schools can address these inadequacies.

In her report for the New Zealand Family Violence Clearinghouse, Beres (2017b, p. 1) found that verbal and physical violence is an under-researched yet increasing issue for New Zealand young people's relationships. Beres (2017b, pp. 6-7) draws on the recent media coverage of an incident involving two students from a local boys' school who wrote about raping young women on Facebook, to illustrate that it is absolutely crucial to educate our young people about New Zealand's entrenched gendered culture. She uses this example to illustrate how gender norms can contribute to the normalisation of harmful tropes. As documented in the findings chapters, many of my participants made reference to this incident on several occasions, and to a street march against rape culture and misogyny that was organised by young people in response to these online comments.

While I elaborate on the significance of this incident for the topic of the thesis in the findings chapters and Chapter 7: Discussion of Findings, I will offer a definition of rape culture here to draw on later when analysing the findings. A 'rape culture' can be understood as one which "fosters and encourages rape by teaching males and females that it's natural and normal for sexual relations to involve aggressive behaviour on the part of the males" (Herman, 1984, p. 52). In a gendered culture which is underpinned by hierarchical gender norms, femininity as passive and masculinity as dominant becomes normalised. A rape culture is also normalised through various "rape myths", which are explored extensively in the literature (for more on this, see Cuklanz, 2000; Ryan 2011; Oliver 2016). These can be regarded as popular but erroneous notions about what constitutes legitimate rape, and perceptions of how rape typically occurs. For example, rapists tend to be constructed in such a way where they, as individuals, are pathologised as psychologically deranged (Cuklanz, 2000, p. 38). This makes invisible the ways in which sexual violence is routinely excused, and is not helped by the prevalence of individualised articulations of 'empowerment' despite young women potentially 'consenting' to

term, without explicitly defining it. The concept has great legal, moral and social significance, and it is essential to continue working towards producing a sound feminist conception of consent. 
intercourse they do not want (Harris \& Dobson, 2015, p. 150). Drawing on the concept of rape culture, I assume in this work that sexual violence is implicated in structural inequalities and hierarchical, binary gender norms that construct women and men in particular ways.

Referencing international evidence about successful relationship education programmes, Beres (2017b, pp. 14-16) emphasises that a gender-transformative approach is most effective at addressing sexual violence and abuse. Attention to critiquing and analysing New Zealand's gendered culture in education could supply young people with greater critical tools to develop healthy relationships. Through speaking with professionals and young people in interviews and focus groups I aim to theorise this gendered culture informed by the views of my participants, to shed light on the implications of these discourses for understanding where to go from here. I elaborate on this further in the following chapter. 


\section{Chapter 3: Methodological Framework}

Qualitative research often yields unexpected and rich data that can be interpreted in countless ways. In this chapter I explain my research aims using critical feminist theory, and discuss how I engage with feminist methodology and research praxis. I then describe my research journey for this project, commenting on the ethical considerations of speaking with professionals and young people about this topic. I discuss some limitations of my research project before finally describing how I have used thematic analysis to organise meaningful passages from my interview and focus group transcripts, and refined this selection to establish three key themes I focus on in the findings chapters.

\subsection{Doing Critical Feminist Research}

I define critical feminist research as research which documents and theorises the views and experiences of marginalised groups, particularly groups of women, in academic literature (Hesse-Biber, 2007, p. 3; Maynard, 1994, p. 16). The 'critical' aspect of critical feminist research can be understood as the influence of critical social theory on research praxis (see Fraser, 1987; Rexhepi \& Torres, 2011; Baum, 2015, Caputi, 2013). Critical theory is driven by a political perspective which shapes its research frameworks (Fraser, 1987, p. 13). Here, feminist methodology can be seen as the political substance of the critical approach to my research topic. Critical feminist research does not take "normative reinforcements" of discourses at face-value (Baum, 2015, p. 420). Rather, a critical feminist research perspective is characterised by its "partisan though not uncritical identification" of oppression and subordination (Fraser, 1987, p. 31). Fraser (1987, p. 13) notes that critical feminist research, coming from the tradition of critical social theory, ought to "employ categories and explanatory models" which expose and critique gendered social relations and the potential marginalisation which may be experienced by those "subordinate" in these relations. In addition to adopting research praxis that elevates the voices of research participants, the data is considered through "critical questioning" of the hegemonic discourses in participants' lives, and insight to potential subversion of these (Baum, 2015, p. 422; Caputi, 2013, p. 18).

The 'feminist' aspect of 'critical feminist research' differs depending on researchers' views about the source of women's oppression. Stanley and Wise (1993, p. 45) problematise the tendency for researchers to try and "fit women in" to pre-existing paradigms (like traditional Marxism) which are historically articulated in masculinist terms (Stanley \& Wise, 1993, pp. 5455). They emphasise that there are always limitations of self-identifying with a specific feminist perspective (for example 'Marxist-feminism' or 'liberal-feminism'), because of the inevitable engagement with other non-feminist schools of thought that take place in this identification 
(Stanley \& Wise, 1993, p. 58). In light of the limitations of different labels, Letherby (2003, p. 72) proposes a widely applicable definition of feminist research from noting similarities in the research praxis of many different feminists. According to Letherby (2003, p. 73), feminist research can be regarded as research with "gives continuous and reflexive attention to the significance of gender" in social life and in research. It challenges the idea that knowledge "can be collected in a pure, uncontaminated way", values the personal as political and therefore "worthy of study", and seeks to develop meaningful, mutual relationships with research participants in a reflexive manner (Letherby, 2003, p. 73).

With respect to these criteria, feminist research should also recognise how researching gender in people's lives is significant for creating a "feminist understanding of the world" (Letherby, 2003, p. 73). Stanley and Wise (1993, p. 53) argue that while radical feminist researchers may only see women's experiences as valuable, socialist feminists might choose to include men's voices in research, emphasising the fact that gender is relational and that "we can't [dismantle sexism] alone". While feminist researchers often choose to do research with women, because their voices were invisible in earlier research, Letherby $(2011$, p. 67) notes that it is essential to consider "the social construction of both femininity and masculinity" in order to fully theorise about gender relations. This not only debunks the myth that feminist researchers never include men in their research, but also gives the research analysis more potential to break gendered boundaries through acknowledging the ways in which "men can be victims, women can be powerful, [and] men and women often share experiences of powerlessness" (Letherby, 2011, pp. 65-67). Further, I chose to put no limits on who was included in my research, because the risk of only including women was to potentially exclude the voices of non-binary people. It seems best fitting, from a critical feminist perspective, to put no restrictions on participant involvement because people who might be affected negatively by New Zealand's gendered culture are not just women. Gender non-conforming youth are at high risk of gender-based bullying and violence in New Zealand (Ministry of Education, 2015b, p. 16). Young men may be disempowered by non-gendered forms of oppression which have implications for their masculinity - for example men who experience discrimination due to sexual orientation, ethnicity, class or (dis)ability (Allen, 2005a, p. 70; Connell, 2005a, p. 78).

While there is ongoing debate among scholars about what feminist research constitutes, there is a general understanding that feminist methodology refers to the connectedness of theory with analysis of data, and that epistemology plays a central role in researching the views of marginalised groups (Wilkinson, 1999, p. 233; Maynard, 1994, p. 10). Feminist research usually values qualitative research over quantitative, because qualitative methods enable better documentation of the lives and experiences of the research participants (Maynard, 1994, p. 12). 
These experiences of women were not accounted for or were absent in much social research prior to the late 1970s, particularly research which was facilitated using quantitative methods (Oakley, 2016, p. 196). Feminist research shifted this focus in sociology; "sociologies 'of' were reframed as sociologies 'for' women” (Smith, 1988, p. 160). Women's views and experiences became regarded as invaluable by feminist researchers because of their previous absence from sociological literature.

Feminist research is often characterised by the relationship between research participants and the researcher, where information is shared between both parties and participants feel comfortable to ask the researcher questions too. This rejects the masculinist view of participants as "simply a source of data"; instead inviting "naturalistic", non-exploitative dialogue between the participants and researcher (Maynard, 1994, p. 16; Wilkinson, 1999, p. 233). Oakley (1981, p. 40) argued that the interviewer-interviewee relationship has been widely articulated in masculinist terms, due to focus being retained on "extracting information" is valued much more than the process of "yielding it". In other words, the power dynamic between the interviewer and interviewee becomes hidden through the "rationalisation of inequality", where the participant is not at liberty to 'talk back' to the interviewer; in fact their agency and capacity to question the interviewer has been actively denied in patriarchal qualitative research praxis (Oakley, 1981, p. 36). Male scholars, who have historically formed the "dominant group" in universities, may also situate themselves as determiners of the "model for normal human relationships" (Miller, 1976 as cited in Oakley, 1981, p. 39). Within this framework, there is little opportunity to recognise and seek to eradicate inequality in research processes.

In this way, feminist researchers often find that non-directive approaches to interviews and focus groups allow for this dialogue. Instead of asking directed questions with the goal of getting specific answers, the questions are open-ended and can follow what participants want to talk about (Stewart, Shamdasani \& Rook, 2007, p. 91). Non-directive approaches to interviews and focus groups may run the risk of not covering in depth some aspects of the research question, but I utilised a non-directive approach because it is consistent with feminist methodology. Such an approach enables life experiences of participants to not be described in "fractures", but as a partial "social truth" (Letherby, 2003, p. 89). Ongoing conversation, rather than the researcher looking for specific answers will likely yield good quality information and build meaningful connections with the people who are giving the researcher their time and insights. 


\subsection{Relationships with Participants in Feminist Research}

Oakley (2016, p. 197) proposes that feminist interviewing is not limited to "rapport" being built with the participants as a technique for encouraging richer description of experience. Rather, if participants are as enthusiastic about the study as the researcher is, there should be no difficulty or hesitance on their part to "talk extensively" (Finch, 1984, p. 72). Certainly, my experience of interviewing professionals who work with young people was that most of the participants were very interested in the project and asked me questions about it before, during and after the interviews. Oakley (2016, p. 209) notes that it is possible, in feminist methodology, to conceptualise the researcher and participants' ongoing mutual interest in the research conversation as a 'friendship' in which 'rapport' may not necessarily have to be worked at as it would in a more formal, distanced interaction. She emphasises though that there needs to be further analysis into the concept of 'friendship' with participants in feminist research praxis, as it can often overlap with other relationships such as 'kinship' or 'community'.

Duncombe and Jessop (2002, p. 107) argue that even though feminist researchers hold a critical view that 'building rapport' simply for the sake of generating data is impersonal, "phoney" and unethical, there are still many problems to consider about how 'friendship' is framed versus how it is experienced by researchers and participants. An interview with a person whom the researcher has not met previously will be managed by the researcher creating some polite social distance. The interviewer might withhold their own views on the topic of conversation and "avoid inappropriate expressions" that could deter the participant from contributing to the interview in an in-depth manner (Duncombe \& Jessop, 2002, p. 110). The interview situation will require the researcher to manipulate their manner and emotions in a way which encourages the interviewee to respond meaningfully to the interview schedule (Hochschild, 1983 as cited in Duncombe \& Jessop, 2002, p. 110). In this sense, interviews may be quite "detached", calling into question the appropriateness of describing all feminist interviews as an expression of 'friendship' (Duncombe \& Jessop, 2002, p. 111).

In most of our conversations, I was relatively open about my research perspective because participants enthusiastically shared their views and were interested in what I thought. This is likely because the research topic appealed to people with pre-existing beliefs that gender norms and relationships are important, and interesting to discuss. The views I shared with my participants about the value of this research topic was reflected in their work or the interest they had in improving their school culture. However, there was one interview participant who expressed opinions which I disagreed with. In this conversation, I was more aware of the selfmanagement I adopted to respond encouragingly to the participant, despite not agreeing with 
what they were saying. As Duncombe and Jessop (2002, pp. 113-114) note from similar experiences, it felt quite the opposite of naturalistic to nod and smile at comments which I did not want to probe further.

Further to this dilemma, it is the researcher who maintains focus on the research topic in conversation, even when using non-directive approaches, and the researcher alone controls the analysis (Duncombe \& Jessop, 2002, p. 113). Of course, the manner in which they control the analysis should be done with mindfulness and care toward the participants, but it is unavoidable that the researcher independently presents the conversations in the final publication or thesis. Critically, the carrying out of this research was not solely instrumental, nor was it based on uncomplicated, naturalistic expressions of friendship. The experiences of interviewing and doing focus groups carried both an instrumental intention of completing the project in a way which speaks to the theory and research perspective I discussed earlier, and intentions to value and advocate for young people, regarding this project as a vehicle for documenting their perspectives to construct a vision of a more inclusive society.

Instead of 'friendship', I regard my relationships with participants as fellow members of a community. From their respective standpoints, they share similar views about the significance of gender in New Zealand. The term community best fits the way participants relate to each other as well as myself, because of this shared vision for deconstructing the hegemonic gendered culture and emancipating groups who are marginalised by it. Almost everyone indicated on their consent forms that they would like to be sent a summary of my findings upon completion of the thesis. Some participants commented that having a record of our conversations would be useful so they can continue reflecting on the ideas we discussed, and draw on these to inform new approaches to their work. This research is not only serving the purpose of writing my thesis; rather, it is equally intended to be of use and benefit to all participants involved.

\subsection{Project Rationale}

The aims of my project are to value the knowledge of young people about gender discourses and relationships, and to consider their views and experiences for informing the direction of emancipatory social change. Reporting on their views and experiences is essential for strengthening theory in this area, and it enables the research participants to respond to oppressive discourses and discuss strategies for challenging them. Emphasising epistemology in feminist research is consistent with the recent acknowledgement of young people's useful insights into education and discourses in the wider school environment by the Ministry of Education (2015a, p. 24). Privileging their views in the journey for positive change in social 
discourse both extends on this government strategy and honours the feminist research tradition to conduct emancipatory, valuable research not just for other theorists and scholars, but for the participants (Maynard, 1994, p. 16). It is important to do research with young people that enables them to offer their perspectives about gender norms in a safe, informal manner. Facilitating focus group discussions about gender and relationship discourses with students recognises the lack of opportunity there might be for this critical conversation to take place during the school day. In addition, it provides some scope for potentially complicating these claims if young people respond to the discussion topics in ways which are subversive of the status quo.

My own feminist perspective has influenced the literature I have chosen to focus on and the ways in which I facilitated the interviews and focus group discussions. In the previous chapter, I discussed the argument that many societies in the West are living in an era of postfeminism, or at least in an era of watered-down feminism which is complicit with neoliberal ideologies. It could also be argued that we are seeing something of a resurgence of feminism at the moment, with protests against sexist behaviour and rape culture, emerging feminist political groups led by young women, and more profound endorsements of feminism in film and celebrity culture in recent years (Tennent \& Jackson, 2017, p. 2; Gill, 2016, p. 611). It is essential that self-identified feminist researchers identify their position as best they can to clarify their research purpose. Scholars who adopt feminist methodology often explicitly identify their preexisting situation and research background to disclose any assumptions and biases which would shape their interpretation of data (Maynard, 1994, p. 12). This avoids the pitfalls of "seeing everything from nowhere", as Donna Haraway (1991, p. 189) describes, referring to nonsituated research that claims to be objective or all-encompassing. In this manner, I identify as Pākehā, middle class, educated, cis-gendered, heterosexual, female, and a critical feminist. My understanding of feminism is shaped by my tertiary education where I studied feminist theories in my undergraduate and Honours degrees.

There are numerous understandings of feminism in 2017, which seem to be constantly expanding and changing. I identify my position as a critical feminist for a few reasons. "Rugged individualism" and neoliberalism have co-opted popular feminist movements, where individualised expressions of "empowerment" appear to justify claims of feminist goals being achieved (Caputi, 2013, p. 12). Critical feminist theorists, such as Caputi (2013, p. 17), McRobbie (2009, p. 83) and Bay-Cheng (2015, p. 282), do not accept these depoliticised ideas as unproblematically 'feminist'. The voices of those who are marginalised, "suffering", or relatively powerless in capitalist societies' gendered cultures are valued by critical feminist researchers for the multiple and complex ways in which they articulate their experiences of inequality 
(Caputi, 2013, p. 6-7; Fraser, 1987, p. 31). They are regarded as well-equipped to offer ideas on theorising what peaceful, equitable and inclusive societies could look like. Doing research with a group of people on the issues they are affected by gives voice (to an extent) to those who may not have otherwise had one in academic conversations (Oakley, 2016, p. 196; Rexhepi \& Torres, 2011, p. 689).

There can be limitations to "giving voice" to research participants if the researcher does not make it clear that their voices are also situated in time (Silverman, 2011, p. 227). For high school students, their perspectives on many aspects of gender and relationships are likely to shift as they grow older. Davis (2007, pp. 56-57) and Maynard (1994, p. 20) note that people's experiences are always partial truths, and researchers should write about them in such a way. Experiences should be theorised, rather than inserted into pre-existing ideas in literature. Critical feminist researchers should also have their pre-existing perceptions challenged so that new insights can be explored. As my study is qualitative, the data is not generalizable and the people who contributed to this project responded in complex, contradictory and meaningful ways. Their views and experiences were significant for prompting new conversations, many of which I will not have the space to cover here.

\subsection{Research Journey}

In my Honours Dissertation, I undertook an in-depth policy analysis on the delivery of Sexuality Education which was guided by gender-focused literature on youth sexuality and the theoretical frameworks of feminism, postfeminism and neoliberalism. This prepared me to facilitate empirical research into gender discourse in young people's views of relationships. It is imperative to theorise about high school students' perspectives on this topic, as they are primarily impacted by discourse around gender and relationships in their schools. Documenting young people's views is also consistent with the shift in Sociology to include youth perspectives in academia, rather than only focusing on the voices of adults as authoritative (McAllum, 2014, p. 78).

Prior to facilitating these focus group discussions, I interviewed people with professional expertise on youth and gender, sexuality and relationships. Understanding their views on these issues enabled me to consider the framing of the focus group discussion schedule, and to gain deeper insight into the value of the research topic is to counsellors, youth workers and community educators. Speaking with these people helped me to check that my research focus would be relevant for young people. These conversations also allow me to comment on the wider network around young people in high schools, and their roles in reformulating influential discourses about gender, sexuality and relationships. Rather than 
doing a focus group with professionals, I chose an individual interview setting with each participant so they could feel comfortable discussing their views and experiences of work without being subject to the scrutiny of colleagues.

I received ethics approval from the Human Ethics Committee at Victoria University of Wellington for this research (approval number: 0000024493). My project was approved in the first instance, with some minor amendments to re-format the participant information sheets and consent forms to adhere to the Committee's guide. It was fortunate that my application was approved with little amendment, as it can sometimes be difficult to obtain approval for topics of a potentially sensitive nature. I encountered this problem with my Honours dissertation in 2016, where I initially sought to speak with young people about their views on sexuality education and had many difficulties and hold-ups getting approval for my ethics application. I had to change my entire project to a policy analysis, because of the time constraints of completing my dissertation (see Hammersley \& Traianou, 2012 for elaboration on the difficulties researchers can sometimes experience with Human Ethics Committees when their project might be deemed risky to the moral rigor of institutions like universities).

My interview and discussion schedules were purposefully kept general, to avoid any leading questions which could result in participants feeling obliged to share uncomfortable personal stories. In the case of the interviews, questions were focused on the work professionals did rather than their personal lives. In the focus groups, the questions posed were about participants' views about gender norms and relationships. There was no question which specifically asked participants to recall particular social interactions, feelings about others, or any specific event. This was done intentionally so that there was no pressure for participants to bring up anything which made them feel upset or uncomfortable. They were free to consider the questions in general or specific terms.

I conducted interviews with experts in relationship education to understand their perceptions of young people's views and experiences, and how school cultures play a role in shaping gender discourse. I spoke to the founder of InsideOUT, a support group for LGBTQIA+ youth, the general manager at the Sexual Abuse Prevention Network (SAPN), three school counsellors and a youth worker. One counsellor worked at an all-girls state school. Two of the school counsellors worked at a co-educational state school and they wished to be interviewed together, which was of benefit to the project. One of them had just started working at this school, so they were each able to compare their experiences of working in different schools around New Zealand. Not only did this provide me with some useful insights, but it enabled the counsellors to get to know each other. A key benefit of having a dyadic interview in my research project was that the "sharing and comparing" between the two counsellors generated more in- 
depth discussion than would necessarily have occurred in a typical one-to-one interview (Morgan, Ataie, Carder \& Hoffman, 2013, p. 1277). The counsellors often asked each other questions, in addition to considering my questions. This produced more data than could be anticipated through my emphases in the interview schedule. All the people I interviewed identified as cis-gender women.

Finding people to interview was straightforward. I was helped by some of the first research participants referring me to others who work in similar areas, so much of the recruitment happened via snowballing. I sent interview participants information sheets before meeting with them. All interviewees were interviewed at or nearby to their work, for approximately one hour. I bought them a coffee or a voucher for coffee to thank them for their time. The interview schedule generally covered questions about gender, personal responsibility and healthy relationships.

Several interview participants expressed interest in helping me recruit focus groups, and put me in touch with teachers or guidance counsellors in different schools who shared information about my project with their senior students. I emailed six different high schools, five of which were co-educational. Two schools apologised that this time of year was too busy, with senior students preparing for their end of year exams. Three of the other schools never responded to my request. One school did respond, and was happy to speak with their students and provide the space needed for the discussion.

After three weeks, a Year 13 student contacted me. She and four friends were interested in meeting for a discussion. I met them at school and we talked during their lunch hour. A second focus group with four more young people was recruited through a youth organisation. We had our discussion in a meeting room provided by their leader. The third focus group was recruited through another researcher who forwarded some information about my research to a high school student she had worked with previously. This student and four of her friends came up to a seminar room on campus for the discussion. Each focus group was approximately one hour to one hour and fifteen minutes in length. I wrote up the interview and focus group transcripts verbatim, but chose to eliminate unnecessary words in the passages included in the thesis in the interest of space.

The students I spoke with were quite diverse. On a slip of paper, I asked them to record their gender, age, ethnicity and sexual orientation at the beginning of the focus group discussion. Across all the focus groups, four participants identified as female (two out of four wrote 'female - questioning'), three identified as male, one as a transgender male, two identified as non-binary, and one as gender-fluid. The participants' sexual orientations included bisexual, 
asexual, gay, heterosexual, pansexual, unknown, bi-romantic and pan-romantic (some participants identified with more than one of these terms). Eleven participants identified as Pākehā, one as Māori, one as Columbian/Hispanic and one as Chinese. Six participants were aged 16, four were 17, three were 18 and one was 19.

In the focus groups, I talked through what my project was about, and emphasised that everyone's opinions were valued. I reassured the groups of the anonymity of individual group members and made sure they read the focus group ground rules and signed consent forms prior to starting the discussion. We all introduced ourselves before beginning the discussion. These steps attempted to make the discussion environment feel "non-threatening and non-evaluative" (Stewart et al., 2007, p. 89). The process of introductions relaxed the groups before we got into the discussion proper. Stewart, Shamdasani and Rook (2007, p. 100) claim that doing a focus group discussion with people who are friends can have drawbacks, such as the potential inhibition of different opinions being expressed by individual group members, and participants possibly engaging in private conversations off to the side. Nevertheless, I chose to speak with groups of friends for some key reasons. Recent social research (Allen, 2007; McAllum, 2014; Jackson \& Weatherall, 2010b) has indicated young peoples' willingness to openly converse about social and sexual discourses with friends. Recruiting focus groups through friend circles enabled the participants to feel supported when discussing personal experiences and views about gender norms and relationships. As there were some occasions where participants recalled traumatic experiences, having their friends present helped them feel safe. Their friends reassured them and sometimes moved closer towards them as they spoke. Because friends know each other well, they also extended on a participant's story with more details that they believed were important for me to know. This data was enriched because of this supportive network of the focus group.

\subsection{Limitations}

While qualitative research is useful for yielding rich data in many respects, Oakley (1998, pp. 714-715) has commented that there are some limitations of qualitative methods which researchers need to be aware of. These include the reactivity of the researcher in all parts of the research process, from the questions asked in interviews and focus groups to the selection of data during analysis (Oakley, 1998, p. 714). In addition, there can be potential issues in presenting anecdotal findings as all-encompassing, or drawing bold conclusions from the perspectives of a limited sample of people. Care should be taken by researchers to elect methods which will best suit their research question, rather than trying to make the topic fit with a "favourite technique" (Letherby, 2011, p. 66; Stanley \& Wise, 1993, pp. 6-7; Oakley, 1998, p. 709). Feminist researchers often prefer to use qualitative methods, but are not limited to 
using these methods. I elaborate on some limitations I experienced using qualitative research methods.

The project is geographically and culturally limited by only reaching out to participants within one metropolitan region. If I was undertaking a larger project I would have considered travelling around New Zealand to do a comparative regional analysis of gender norms and relationships. Certainly, this is an important focus that a future study in this area could take on. The nature of my research journey was such that local organisations I initially contacted often referred me to other participants who were personally known to the organisations. Through this technique of recruitment, all the contacts suggested to me were based in the same region.

In addition, the time of year may not have been the best for recruiting a great variety of participants for focus groups. I contacted schools in August 2017, which is when most senior students were sitting preparation exams for their nation-wide final exams later in the year. One school declined my request for making contact with their students because both the staff and students were too busy with exams to help me facilitate it at the school. Other schools never responded, which may be indicate that the time of the year was also too busy for them. Future research could minimise this constraint by setting a date to contact schools much earlier in the year, when time is more flexible for staff and students.

Another limitation of the research is that there were difficulties getting access to different high schools. I predominantly chose to contact co-educational schools, to allow more easily for the focus groups to be mixed gender. I contacted three single-sex schools (one girls' school; two boys') in the local area, to request initial interviews with their school guidance counsellors before exploring the possibility of doing focus groups in the school. One counsellor (from the girls' school) took part in the study, one politely declined, and the other never replied. Some interview participants emphasised that all-boys' schools are often more difficult to reach out to, for healthy relationship workshops from external providers like SAPN, which is discussed in the first findings chapter. Of course, it would have been interesting to speak with a counsellor from one of these schools, or a group of students, but it proved to be difficult to reach them from a researcher perspective too.

Private, integrated and religious schools were regarded by some interviewees as even more challenging to approach for education and research in this area. One school counsellor I spoke to who had previously worked at a private single-sex school said that she was the first guidance counsellor the school had ever employed, and the institution of the school held morally conservative views about gender norms which contrasted to the more inclusive values of the co-ed school she is now employed at. I did not attempt to contact private or religious 
schools in this project, as they likely would have been challenging to interact with according to many interview participants. However, in a future project it would be useful to focus primarily on these institutions' discourses about gender norms and relationships, given they are commonly constructed as morally conservative by those who work in state schools.

Finally, my positionality as heterosexual, Pākehā and middle-class may have impacted on my capacity to fully build a trusting, non-hierarchical relationship with some participants. It may also mean that I was unintentionally oblivious to certain power-dynamics in the data and may not have fully accounted for these in my analysis of the data. The different ways in which women and feminine people experience the world inevitably problematizes the category of 'women' in itself, because these experiences are not generalizable (Davis, 2007, p. 53). I have endeavoured to demonstrate the diversity of participants' experiences in my presentation of the data by documenting the complex and contradictory ways in which our gendered culture is perceived. In light of my participants' shared interest in this topic, they were all seemingly happy to talk about their views and experiences in our conversations (Finch, 1984, pp. 70-72). Because participants' voices are invaluable in social research, it is imperative that the researchers carefully interpret and present the data in such a way that it "cannot be used against those who gave it" (Letherby, 2011, p. 66). As researchers, we have an ongoing duty to participants to acknowledge the inevitable objectification of their voices in the research process, and to document the conversations in a manner which fairly represents their views and experiences as partial social truths (Davis, 2007, p. 57).

\subsection{Thematic Analysis}

The thematic analysis I undertake in this work follows the steps given by Braun and Clarke (2006, pp. 84-85) of a theoretically based method where the primary themes are driven by selected topic areas from the literature. Braun and Clarke $(2006$, p. 85) note that themes are always mediated by the researchers' pre-existing interests and values. Themes do not simply "emerge" from data with no pre-determining factors for discovery (Fereday \& Muir-Cochrane, 2006, p. 3). I outlined earlier that my research perspective is influenced by literature where dominant discourses are critiqued and social change sought. The critical feminist point of view I described earlier influenced my focus on key concerns from the literature. This theoretical position favours collective action in forming emancipatory social change and recognises value in the experiences of participants. Given my already existing views on this topic, it seemed bestfitting for me to undertake a theoretical approach. Theoretical approaches entail prior understanding of relevant literature before embarking on data collection and analysis (Braun \& Clarke, 2006, p. 87). Inevitably, my own undertaking of thematic analysis yields an emphasis unique to my pre-existing perspective. 
A potential limitation of theoretical approaches to thematic analysis is that the researcher risks losing sight of other important themes in their data, which may not be related to their theoretical perspective. During transcription and immediately after each interview and focus group, I took note of interesting ideas and patterns I noticed, even if they deviated from the focus of this research. I also read the transcripts closely numerous times and noted down key passages, as a technique to avoid missing useful data. Braun and Clarke (2006, p. 87) and Fereday and Cochrane (2006, p. 4) propose this is a crucial step for producing rich analysis and minimising oversights. To mitigate the limitation of my subjective biases, I broadened my focus and considered numerous themes worthy of critical analysis, which I did not have the scope to cover in this thesis, but which are important for informing further study in this area. Other potential themes could include (but are not limited to) the visibility of asexual young people; the "privilege" of engaging in activism; perspectives on sexting; the relationship between personal and professional experiences in youth work; considering the significance of feminism/s for young New Zealanders; the application of hauora7 in secondary school teaching; and how 'community' is defined and created by young New Zealanders. Some of these ideas will be discussed in relation to my three main themes in the findings chapters. Because there are many overlaps of themes under this topic, there are endless ways to organise data. The scope of analysis is already limited, as I am the only researcher in this study. If others were engaging in the same data analysis processes, a wider variety of themes would be found (Fereday \& MuirCochrane, 2006, p. 9).

I analysed the interview and focus group transcripts using the same process, and took note of the connectedness in how the topics were discussed. The most significant themes were drawn out through the following criteria. They were decided upon by their relevance to my literature review, the amount of attention on a subject or the frequency at which a discussion occurred in both the interviews and focus groups. This meant that the three final themes had relatively equal significance in both sets of data, so the interviews and focus group transcripts were considered in relation to each other rather than separately. I colour coded each transcript, beginning with the interviews. Upon a first reading I looked for themes which they shared, and upon a second reading I looked out for new themes. On a third reading, I highlighted the richest data, and organised the selected passages into separate documents (one for interviews, one for focus groups) for each theme. The final themes which I decided to focus on were re-named to sound more "concise" and "catchy" (Braun \& Clarke, 2006, p. 93). The three themes, as introduced in the next three chapters, are entitled The Gender Binary and "Bro culture"; Pressures and Responsibilities, and Healthy Relationships.

\footnotetext{
${ }^{7}$ Hauora can be understood here as a Māori framework of good health, with a multi-faceted focus on social, emotional, physical and spiritual wellbeing.
} 


\subsection{Presentation of Findings}

As noted previously, my interpretations do not exhaustively cover the entire scope of this topic. Rather, my discussion is shaped by the research and literature focus discussed earlier. In the three following chapters, I present the perspectives and experiences of participants, as well as the ways in which they perceived these experiences in the context of wider gendered discourses. I articulate the ways in which participants' experiences can be thought about using some of the frameworks introduced in Chapter 2: Theoretical Framework, and suggest how the conversations also pushed the boundaries of theory, calling for expansion and complexity in critical feminist thought about gender norms in Aotearoa.

Each theme is significant for both academic knowledge in this area and for informing substantive action to address dominant discourses affecting young people's communities. I will present, analyse and discuss the data, according to each theme. In Chapter 4: The Gender Binary and "Bro Culture", I comment on some connections to and divergences from New Zealand's gendered culture, and consider the implications of hegemonic constructions of gender. Chapter 5: Pressures and Responsibilities provides insight into how gender norms are present through various pressures on young people in relationships, both inside and outside the LGBTQIA+ community. I also consider the unique pressures on LGBTQIA+ young people to self-govern and educate others about issues pertinent to their inclusion in wider society, examining how individual responsibility permeates lived experiences of gender and sexuality. In Chapter 6: Healthy Relationships, I consider several points made by participants (particularly in the focus groups) about the need to unpack what is implied by the term 'healthy relationship' in education and look at community support approaches to this.

I have indicated the focus group or interview using the following formula. IV = interview and FG = focus group. I have numbered these conversations, so IV1, FG2 = interview one, focus group two. In the case of focus groups, where there is more than one respondent, I have identified each participant by letters, for example: FG1:B = focus group one, participant B. In the case of the third interview, which was dyadic, I have identified participants as IV3:A and IV3:B. Where a participant is quoted, I include these details at the end of each sentence in brackets. 


\section{Chapter 4: The Gender Binary and "Bro Culture"}

\subsection{Emancipation and Limitations}

The participants' ideas about the dominance of gender as a binary were quite varied, but most interviewees and focus group members concurred (to different extents) with the claim that identifying outside of this binary is easier because gender identities are increasingly described as more diverse and fluid in both education and popular discourse. "Identifying as non-binary is definitely becoming more accepted" (FG3:A). "People's understandings of gender have expanded" considerably beyond traditional perceptions of femininity and masculinity, according to the founder of InsideOUT (IV1). Gender is not just passively enacted by young people in their interactions with each other; rather gender norms, as implicated in a heterosexual matrix, are increasingly observed, negotiated and critiqued as educators "talk openly about those gender norms and [find that] students have already thought about that stuff a lot" (IV2). But there are still many obstacles to full recognition of gender and sexuality diversity, some of which will be covered in the following discussion.

One of these obstacles, which was discussed in almost every interview and focus group, was that single-sex schools naturalise the gender binary in several respects. The difference in the ways in which girls' schools and boys' schools respond to the educational services of the Sexual Abuse Prevention Network (SAPN) was significant; "So we're currently in most schools in Wellington...the ones we're not in are boys schools" (IV2). Girls' schools almost always respond positively to SAPN, "Yes please, we really need to talk about this stuff" whereas boys' schools often do not respond, and sometimes effective communication was difficult with both teachers and students when they do work in boys' schools (IV2). "Sometimes you're really, really trying to get them to talk in the session...they're [either] undermining the session, acting up, or just not engaged with it" (IV2).

Gender norms can shape the ways in which students at boys' schools respond to female educators, let alone the ways in which they digest the messages of relationship education. The general manager at SAPN recalls an occasion where a female and male facilitator were running a session at an all-boys' school:

The female facilitator was much more experienced than the male facilitator. He was quite new. And the boys were just not listening to the woman at all. They were not engaging when she talked, and they only listened to the man. He had to stop the class and point it out to them, that that's what was going on (IV2).

When I asked what factors contribute to this difficulty connecting with male students, she considered that the conservative notion of gender identities being limited to male and female, and being constructed as fundamentally different from one another fuelled these issues. For 
example, she noted that single-sex schools provide ideal conditions for "highly sexualising" students of the other gender, which I elaborate on in the following chapter (IV2).

It remains a significant problem, in the view of SAPN as an organisation and its general manager, that many boys' schools are not apparently concerned about the socialisation of boys in how they view heterosexual relationships. "Men are taught to hold in their emotions...particularly [about and in comparison] to women" (IV2). The normative figure of the stoic, sporty and hardened New Zealand man is still alive and well in the culture of many boys' high schools: "sports...rugby, and farming, that rural culture [influence] how men appear to hold in their emotions a lot more" (IV2). This might provide some context behind the difficulties in educating young men and reaching out to boys' schools about healthy relationship education, due to the implicit belief among school staff that healthy relationship education would not be necessary for their students. This may be due to young men's apparent lack of voice on the topic; "young men do not as often experience sexual violence....and it is a typical characteristic of male survivors to be less likely to talk about [abuse]" (IV2). I extend on this point below in exploring participants' views about contemporary masculinities, and how young people navigate their gender around hegemonic constructions of 'bro' culture.

It is important for educational programmes about healthy relationships to avoid gender stereotyping within the delivery of education itself, to further show that sexual violence is an issue which everyone needs to be aware of and begin to talk about. There are challenges for education providers like SAPN to use resources which do not further naturalise the gender binary. "It is actually really hard to find [resources] that are not gendered and where the man is the person doing the harm and the women is the person being harmed" (IV2). The lack of availability of relationship education resources that do not represent masculinity as driven by (hetero)sexual conquest, and femininity as irresponsible and naïve pose ongoing challenges for SAPN, who wish to make their sessions as inclusive as possible. The organisation makes their own resources which avoid gender stereotypes and heteronormativity, "we work hard to make sure that the examples we create are really diverse in genders and sexualities" (IV2).

Students attending a co-educational mufti school were critical of the fact that "gender generates uniforms" (FG1:A). They perceived gender norms within their school as less emphasised than in other schools because there was no uniform; "we're lucky here, we can express ourselves" (FG1:E). In other conversations, there was emphasis on the recent addition of gender-neutral options to school uniforms in a couple of single-sex schools. A school counsellor noted "we've launched shorts, which are really good...we've got some pants in the making as well" (IV5). Students attending single-sex schools had mixed views about these uniform changes. A transgender participant reflected "Just being able to wear pants every day 
did so much for my mental health" (FG2:C). But another young person noted, "there is something attached to wearing shorts, like you can't just wear the shorts for the sake of wearing the shorts" (FG3:A). She was concerned that although there was ultimately emancipatory values in expanding the uniform options, there would be a period, while these options were still relatively new, where people who elect these clothing choices would make their non-binary or transgender identity more visible which may make them more vulnerable to bullying.

The power of gender neutral language was also increasingly substantive in one school, where the Head of Department had a meeting with other key staff and students to discuss whether "[the high school name] should have the word 'girls' in it,...because not everyone who attends is necessarily a girl" (FG3:A). A school counsellor noted that there was more receptiveness from her school this year than previously about noting the "preferred name [and] preferred gender" of their students (IV5). One focus group participant believed gender norms in schools were "unnecessary as a concept" (FG2:A). Another school counsellor agreed, "if you're working with young people and you want to support them and remove barriers to their learning, then you get on board with everything that is possibly a barrier and do the best you can to remove it" (IV3:B).

It appeared that while some schools (only state schools) were attempting to shift in this general direction, there was still perceived ignorance among a few staff about diverse gender and sexuality identities. This could lead to some unwillingness to play an active role in removing gendered constructions from the schools' bureaucratic organisation and identification of students. This issue results in students who openly identify outside of the gender binary "pretty much single-handedly teach[ing] my teachers everything", particularly when "it was supposed to be the counsellor's job and she didn't know anything... she felt uncomfortable using gender neutral pronouns in emails" (FG2:C). I examine this point more closely later on in discussion of the second theme, Pressures and Responsibilities. School management can also be slow to change documentation to accommodate fully for students' gender identity preference; and many participants said that private or religious schools are more likely to refuse to accommodate the student's identity at all. One of the school counsellors I spoke with had previously worked in a private single-sex school, and described the barriers put up by this school to changing a student's gender on documentation:

I'd had a conversation with the principal, who was absolutely appalled to think there would be students in the school who were transitioning from female to male... [they] said 'we can't have boys in this school'...I found it difficult to know where to start to have the conversation about that, so I just decided not to have it at all (IV3:B).

The counsellor went onto say that "it wasn't ever going to change there...now they are enrolled at a different school which is much more accepting" (IV3:B). I pick up this point again later, in 
considering the challenges of this research with the moral conservatism of private schools and how critical feminist researchers might grapple with this.

\subsection{Policing the Gender Binary through 'Bro Culture'}

Poignantly, the first focus group conceptualised New Zealand's gendered culture in today's terms as a 'bro culture', using this term as a reference point throughout the discussion. 'Bro culture' referred to a culture which was predominantly represented by "males, [putting] a lot of pressure on their friends" to live up to a normative hyper masculine stereotype of a young New Zealand man (FG1:A). Despite their schools' support for gender diverse students, the first focus group were in unison in making the point that "we have quite a bit of [bro culture] here" (FG1:E). This is visible in the ways which young men's behaviours change when they are in a group:

FG1:A You see that all the time in groups...I know a couple of them wouldn't be acting like thisFG1:E: Oh yeah.

FG:A: But when they're in this group, they act like sexist, racist, homophobic pricks.

FG1:E: They're arseholes, a little bit.

FG1:A: Well that's the thing. A couple of them are really bad. But there are a couple of them who aren't wouldn't be nearly as bad if they weren't with them.

The general manager at SAPN echoed this issue of encouraged harmful behaviour in peer groups in our conversation about gender norms. She noted that young men encouraging each other to behave like this contributes to a culture which enables sexual violence. "Men can be socialised to have a really strong sense of entitlement. They're entitled to have a girlfriend, they're entitled to have sex - and they're entitled to have what they want when they want it" (IV2).

An important and interesting aspect of 'bro culture' was discussed not only in terms of the effects of young men performing a noisy, intimidating and "entitled" masculinity through mateship in school peer groups, but also through a strongly individualised experience of manhood. This was described in the words of Focus Group One members through the analogy of DIY (do-it-yourself):

FG1:E: It's like the bro culture!

FG1:B: It's like DIY culture. It's like, do it yourself, don't get anyone to help you.

FG1:A: Yeah exactly.

FG1:B: Don't even hire a professional, just don't even talk to anyone. Just build that fence.

FG1:D: Yeah, "do it". 
FG1:B: Yeah, and if you have an emotion - figure it out for yourself.

The students described how this individualism characterises the pressure to appear to their 'bro' groups as a self-reliant and stoic young man.

The visibility of physical strength and ability to successfully engage in heteronormative relations with women, while at the same time distancing oneself from femininity, remains significant for the ways in which the gender binary is expressed. Yet many of the young people also positioned themselves as "a generation of change", where gender equality is valued (FG3:A). There was resounding critique of 'bro culture', especially with regard to how 'bro' discourses uphold an ideal of masculinity as opposite to, yet dependent on femininity. This was exemplified in the second focus group's critical discussion of the shallowness of heterosexual relationships where men and women are believed to be fundamentally different to the point where they have very little in common with one another. "The way my friends and my parents talk about relationships - it's almost as if they don't want to be friends with their partners" (FG2:C).

There are some divergences from the archetype of 'bro culture' too however, which convey possible ruptures of the status quo. A youth worker I interviewed perceived that performances of masculinity were visibly different among New Zealand teenagers than the typically hardened 'kiwi bloke' masculinity of older generations. "He's fifteen and the way he talks with his mates...there's a lot of love in there like 'yeah man, love you bro'. I'm not used to that, like males showing that much...outward feeling" (IV4). In addition, a school counsellor noted the surprisingly deep impact of a healthy relationship programme on young male students attending a co-ed school:

One of the trains I catch is full of students from this college. And there were three or four boys sitting behind me after the day [of the healthy relationships workshop] and having this animated conversation....about what makes an abusive relationship and the differences in people's ideas about all of that...that was all the way from the stop here into [the city] (IV3:B).

She went on to note that they were discussing how to look out for the early signs of an unhealthy relationship, to prevent harm before it started. "If that was just one little snapshot of some of the kids who came out of it, there would have been lots of conversations" (IV3:B). This compares interestingly to the experiences of SAPN educators having difficulty delivering healthy relationship workshops effectively to classes of boys. Because this particular school was co-educational, it could be that the familiarity of a mixed gender learning environment meant there was easier communication between educators and students. It also shows variation within 'bro culture', that when given the opportunity, young men may use the time they spend with their friends to critically think about gender stereotypes and the ways in which these might 
enable and justify sexual violence. This is a useful insight in light of Connell's (2005b, p. 1807; Connell \& Messerschmidt, 2005, p. 851) studies about how well-considered educational interventions can spur "positive" hegemonies of masculinity, which resist harmful behaviour.

The founder of InsideOUT spoke to me about how the gender binary permeates nonheteronormative relationships, and the subsequent impacts on the LGBTQIA+ community. Part of InsideOUT's services are to support schools in moving toward greater inclusivity of their LGBTQIA+ students, and to provide educational workshops and seminars for young people. These services are needed as "a lot of bullying is usually based on gender norms, which is a huge problem especially for young people of minority sexualities and genders" (IV1). While "some of the exciting stuff around queer relationships is that...people are already challenging and thinking about gender differently", there is also an ongoing issue of "toxic masculinity within queer communities" (IV1). A heteronormative gender binary is often encountered by those in LGBTQIA+ relationships, as each partner is perceived as adopting binary gender roles, even when they identify as the same gender. "There's always that one person who's like 'who's the guy and who's the girl?'...we're both girls, there's no guy in the relationship!" one frustrated student recalls (FG2:D). The aspect of this presence of the gender binary in queer relationships which illustrate the "toxic masculinity" that the first interviewee mentioned can be seen through tropes such as 'who wears the pants?' which is really implying the question, 'who has more power or control in the relationship?' The fourth interviewee considers this:

I remember hearing a comment about [a woman who was dating another woman]... 'the problem with that relationship is that they're both trying to wear the pants'...is it that they're both trying to wear the pants, or is it that they're not...willing to compromise? (IV4).

This led into a conversation about the unique "staunchness" of New Zealand women, which is visible among today's young people in an individualised manner (IV4). In "big rural communit[ies]", which the participant believed set the tone for wider New Zealand society, "girls can do anything...they're as headstrong as men" (IV4). Young women were described as "staunch"; "strong and independent" and "resilient" by interviewees, and some described themselves in these terms too (IV3:A, IV5, FG1:A, FG3:A). This was seen in the fact that they are now more likely than they were previously to call out their male peers on sexist attitudes or bullying behaviour: "[Girls are] getting the boys to take responsibility for their own actions...saying 'we're very clear about where the blame should be and who's at fault here. And it's not us'...that's pretty cool to see that" (IV3:A).

\subsection{Critically Examining 'Staunch'}

A reoccurring pattern in both interviews and focus groups was the construction of an idealised 'staunch' femininity. It followed that girls could grow up successfully exercising 
personal autonomy and freedom of choice, expressing their views confidently and standing up substantively to gender-based bullying, threats or sexual harassment. From my perspective as a feminist researcher and as a young adult who attended high school in New Zealand, I was pleased to hear about this increased resilience among some female students. However, I began to think more and more about what 'staunch' and words like this actually mean for emancipation. I consider the less obvious discourses that staunchness might also be implicated in, and why it is important to probe into this discourse further.

With respect to the acclamation of being staunch, as a sign of female empowerment, there was also a clear rejection of a notion of femininity which is tied to fragility, restriction and victimisation. Instead girls' abilities to confront and resolve unjust situations were seen as significant and worth celebrating. But some conversations transcended and complicated this discourse too. For example, one interviewee commented that substantive resilience among young people could be most profoundly realised by those who are "forced to think differently because you know who you are...and you know that the dominant discourse isn't going to work for you...[this] can come quite early for queer kids" (IV5). She went onto mention that there needed to be greater discussion in relationship education and by extension the wider communities around young people that "everyone has different ways of being in the world...being vulnerable" (IV5). She made the point that vulnerability through systemic marginalisation can create greater resilience among those who experience the world in this way, because they have more knowledge of society from the view of an outsider. This knowledge is significant for informing social change and for implementing more comprehensive education on social, gender and relationship issues.

Further, one focus group member emphasised that it was simply not enough for me to take away from our conversation that just because she considered herself "strong and independent", not everyone could easily live up to this normative notion of femininity; “Someone who's more timid or shy...it's so much worse for someone like that" (FG1:A). This was exemplified through another member of this focus group describing how she felt uneasy with seeing herself as a 'staunch' young woman because of her past experiences of gender-based bullying and receiving "threats of rape, threats of death, threats to attack my friends" (FG1:B). However, she was hesitant to identify herself as a victim, even though it appeared to be the most appropriate word to describe how she felt at the time. "I wasn't sure where I fit, because I wasn't a victim of things that had happened...I wasn't sure if I was almost allowed that sympathy" (FG1:B). The participant feared the scrutiny from other peers about her receiving these threats as it were, and concluded that identifying as a victim would simply invite even more speculation about whether she was a deserving victim or whether she was over- 
exaggerating her experiences by framing them in this way. Through explaining the response of peers, staff members and parents, who downplayed her experience; "they kind of underestimated it. Dad said 'boys are stupid'..." she noted that to identify as a victim in this situation would be perceived as socially deviant for many reasons (FG1:B). This point strengthened the wider observance of this group that individualised shows of strength are valued as the hegemonic way to perform 'empowered' femininity, and that explicitly identifying as a victim goes against this hegemony and potentially invites more violence from others.

It is essential that we more critically consider the ways in which the identity of victim is constructed and represented, in light of the hegemony of staunchness for both femininity and masculinity in New Zealand. Stringer (2014, p. 7) argues that the term 'victim' has connotations in both popular and academic discourse, as women who are victims of men's harmful behaviour. According to neoliberal victim theory (which I discuss at more length later), there are two dominant constructions of victim identity. Firstly, there is a normative figure of an ideal, deserving victim who is "passive", "compliant" and silent about their experiences (Stringer, 2014, p. 10-11). Secondly, there is strong cultural criticism of the 'power-victim' or 'fraudulent victim', who is, as my participant articulated, seen as lying about or exaggerating their experience if they describe it publicly and in a supposedly angry or unforgiving way. The doubt about the authenticity of their victimhood is particularly strong if they draw on the experience to seek systemic change (Stringer, 2014, p. 10). They might be blamed for what happened to them, or they may not be believed in the first place. In this sense, they are constructed as "playing the victim", rather than truly being a victim (Stringer, 2014, p. 11). It appears then, that the identity of victim is not available for a person to self-identify with; rather the term is endowed upon those who are deemed deserving enough by society.

I extend on this key point in Chapter 7: Discussion of Findings, where I look at the relationship between these constructions of victims and the postfeminist celebration of individual female empowerment, as several scholars (Gavey, 2012, p. 719-720; Harris \& Dobson, 2015, p. 150-151; Gill, 2012, p. 737; McRobbie, 2009, p. 18) have critiqued. I make the case that understanding dominant constructions of victims and the wider context which they are implicated would give researchers insight into the hegemony of staunchness in New Zealand's gendered culture. I come back to this phenomenon throughout the next two chapters in relation to responsibilities of young people, and in relation to re-thinking the concept of healthy relationships. 


\section{Chapter 5: Pressures and Responsibilities}

In this chapter, I examine the presence of gendered discourses implicated in the pressures and responsibilities spoken about by several participants. This is significant for understanding their views on how the normalisation of personal responsibility is experienced along gendered lines. Literature describing the neoliberal logic implicated in postfeminist subjectivity positions the notion of personal responsibility as complicit with reinforcements of the presence of hierarchical gender norms in people's lives (see McRobbie, 2015; Elliot, 2014; Jackson \& Weatherall, 2010a; Bay-Cheng, 2015). I described this literature in Chapter 2: Theoretical Framework and will reflect on some of these arguments through presenting and discussing participants' views on emphasis on individual responsibility. Firstly, I comment on the 'feminising' of personal responsibility, examining the care-work undertaken in these enactments of responsibility. I then present some LGBTQIA+ experiences of responsibility to educate others about issues affecting them, before examining some pressures on LGBTQIA+ relationships in this context.

\subsection{Feminised Experiences of Pressure and Responsibility}

Exercising personal responsibility in self-governance and seeking success was unsurprisingly discussed by many participants as predominantly known to young women and people who identify performatively with femininity. The three school counsellors I spoke with discussed at length their concerns about multiple pressures on young women to embody a "perfect" lifestyle and position in society (McRobbie, 2015, p. 4). They shared the view that these gendered pressures potentially imposed significant harm in young people's lives. One counsellor commented that there is an expectation of students at her school to be involved in as many extra-curricular activities and opportunities as they can.

There's this discourse around being a [name of high school] girl... being involved in committees and [taking on] millions of opportunities...becoming a leader. The way the institution tries to shape the students is obviously to become a successful, high-functioning young individual...but what I am noticing is that there are a lot of students who come in and they are just flat tack...it's kind of like that Super-Mum thing that emerged maybe ten or twenty years ago where you've got to be good at everything... because we've got feminism, we can do everything (IV5).

This resonates interestingly with observations of the multiple pressures on young women to be living the "good life" as over-achievers like McRobbie (2015, p. 9) describes, where exercising self-governance and discipline is imperative in efforts to attain successful lives, as the participant describes. 
More pertinently to the area of gender norms and relationships, the counsellor was deeply concerned about the number of young women she worked with who invested to care for male peers. "Certainly, I've seen a theme around young women taking responsibility for caretaking for their friends who are male who have mental health issues...and finding it really hard to step back" (IV5). She clarified this can happen when the young people were in a relationship, "They might have initially come from an intimate relationship...I don't want to say rescuer...but it is a bit of a rescuer thing" (IV5). The "theme" of this care-taking she describes can be considered in this way:

There's no boundaries there...[young women feel that] men need to be looked after and they need women to look after them ...and if you step back they are definitely going to kill themselves (IV5).

Gender norms here seem to be rooted in historical colonial discourses that construct women as the saviours of men, which may come at the expense of their own wellbeing. There is also urgent cause for further enquiry about the nature of gendered personal responsibility and mental health in a specifically New Zealand context, given that we have some of the highest rates of youth suicide in the OECD, and the majority of these suicides are committed by young men (Tolley, 2016; Ministry of Health, 2017, p. 11). I will extend on this in a discussion later about the impacts of a heteronormative and sexist gendered culture on young Kiwi men and their experiences of masculinity.

Secondly, this characterisation of responsibility can be taken to remind scholars in this area to be careful to not construct personal responsibility, as a term with neoliberal connotations, as merely individually exercised in a self-interested pursuit of success. Critically, there are motives to take on responsibility out of care for others' wellbeing. The young women whom the participant spoke about may be putting the needs of those they care about before their own. Trnka and Trundle (2017, p. 8) note that "not only is there a variety of responsibilities that govern social and political life, but there are also the myriad ways that people respond to calls to be responsible". Documented here is merely one way that young people might respond to the needs of disempowered peers. The word 'care' is important here, because perceiving this as responsibility being taken out of love could be perceived as an inherently positive phenomenon and the participant did not describe it in these terms at all. Referring to this dynamic as love potentially hides the negotiating of power dynamics and discomfort which may be experienced by either party where one's sense of responsibility for the other's wellbeing is carried out (Trnka \& Trundle, 2017, pp. 11-12).

Other school counsellors focused on the dangerous intensity of pressure on young women to be visibly successful in their intimate relationships. One participant noted that this 
unchecked pressure could potentially lead to horrific violence, such as in the media reported brutal murder of Sophie Elliot by her partner Clayton Weatherston in Dunedin in 2008:

They did say "look, why don't you leave?" There was a week basically where she was getting ready to move away from Clayton and come to Wellington, so everyone thought it was going to be ok. And it was in that week that he actually murdered her. But Sophie, because she was a perfectionist...giving up on the relationship would have meant that she had failed (IV3:A).

The counsellor went on to note that the shared pressure among young women to be successful in multiple aspects of their lives can increase the chances of them staying in abusive relationships, coupled with the control tactics of the abusive partner. This demonstrates the importance of focusing on how personal responsibility is expressed and experienced in gendered ways, particularly when this can at times violently reinforce gender relations as unequal and hierarchical.

This all further problematizes the notion that simply adopting 'staunch' femininity gives young women the capacity to avoid harmful interactions with peers, as I analysed in discussion of the first theme. In this sense, one focus group member commented that it was often difficult for young women to express their feelings about male peers who bully, abuse or sexually harass them, because of pressure to be seen as successful in interacting with others in order to fit in with their peers and be liked. "Thinking about gender norms, girls are [encouraged to think that] guys are everything...and like, oh we can't hate on this dude...so they blame the victim" (FG1:A). The idea that "we can't hate on this dude" for seemingly no other reason than he is a young man with high social status is not new in its influence on groups of young people. It was articulated in focus group research about adolescent girls' perception and management of risk, in the sense that girls' ability to exercise self-regulating agency was cited as the correct, 'common-sense' way to avoid experiencing sexual harassment, violence or teenage pregnancy (see Bay-Cheng et al., 2011, p. 1175).

The lack of support for young women or feminine people to report and critique genderbased bullying, sexual harassment or violence seems consistent throughout the school culture and within peer groups. A couple of interview participants concurred with this focus group member's observation that young people face considerable social barriers to engage in open critique of the status quo:

In the girls' school I've worked in, in the heterosexual world- [there is] a slightly skewed view of boys by the girls that are there...I found that quite disturbing because of the recent incident with [local boys' high school]...some of the girls had attended some of the parties where this sort of behaviour was going on...and while they didn't think it was great, they were kind of accepting that this was a range of behaviours and this is what happens (IV3:B). 
Another interviewee, working at a different school, extends on this apparent acceptance of sexually violent behaviour among girls as implicated in a sort of backlash to feminism:

We have this space to talk about gender issues. But there's this other discourse that is like 'feminazi', you know, 'you hate guys'. That is still there. When this stuff came up with [local boys' high school], there was almost victim-blaming... then yet also [our students had] a phenomenal response around initiating the march... I think that was a really positive thing (IV5).

This school counsellor describes dominant perspectives underpinning students' responses to the leaking of misogynistic comments online made by students at a local boys' high school which advocated raping drunk young women to experience masculinity successfully as a student of the boys' school. In this extract, she notes the backlash from some female students to the feminist response of their peers in forming part of the protest against these comments. Constructing feminism as an extreme and dogmatic ideology, implied by the use of the term "feminazi" and the "victim-blaming" elements of this discourse may signal the neo-conservative undercurrent as part of McRobbie's (2004, pp. 256-257) notion of the 'double entanglement' of discourses about female empowerment. Within this logic, young women are assumed to be "empowered" individuals on an equal gendered playing field (Gavey, 2012, p. 719). Feminism is constructed as a militant and outdated perspective which should not be taken seriously for understanding the present. Further, some scholars (see Sommers, 2000; Paglia, 1994) have purported that contemporary feminism, in its concern with rape culture alienates a majority of women in the West. It is assumed that these women already see themselves as liberated and not in need of 'rescuing' by feminists. By extension, critique of masculine hegemony is construed as redundant and politically disruptive. I critically explore this discourse of empowerment further, particularly with regard to its rejection of 'victims' in Chapter 7: Discussion of Findings.

Further, the issues with single-sex schools' cultures reinforcing gender norms as discussed in the previous chapter may contribute to young people's fear or rejection of the idea of publicly questioning the sexist, entitled attitudes that are harboured by some young men about women's bodies. One interview participant noted that these attitudes can be normalised in how single-sex school environments promote a fascination with the other gender: "when the boys would come in [to a girls' school to participate in sexual abuse prevention programmes] everyone's head would turn and there would be this like, 'oh God, all these boys are here'. You'd notice that immediately" (IV2). These schools' decisions to invite the Sexual Abuse Prevention Network to hold mixed gender sessions was acknowledged as well-intentioned, yet not always effective in practise: 
They were saying '[the students] have got to be able to talk to young men about this stuff' and that's absolutely true. But if you're not used to a mixed gender environment, then our material is a very intense topic to be covering suddenly in a mixed gender environment (IV2).

Further, the schools' decisions to include boys' schools in these sessions may also have been motivated by heteronormative assumptions about the types of sexual and intimate relationships school staff believed the majority of their students would experience. This is particularly pronounced by the fact that these schools apparently did not have mixed classes for other educational areas:

If we're socialising our students in these single sex environments...it's really othering [people of different genders] ... I think you do need to bring in people of other genders [to participate in these sessions]...but then talking about sexuality is probably not the first occasion to do that...[schools should] do that for drama or debating first (IV2).

Suggesting mixed gender classes for more subjects may be useful efforts to de-naturalise gender as a binary, in the same strain as changing the 'single-sex' status of schools mentioned by Focus Group Three Participant A in the previous chapter. The socialisation of young people to perceive femininity and masculinity as implicated within a heterosexual matrix and as fundamentally oppositional to each other appears to fuel the feminisation of pressure to withhold critique of hegemonic masculine principles, as described by the Focus Group One participant, in her contention that identifying misogynistic behaviour in a critical feminist way risks being perceived as "hating" young men.

Extending on her description of "toxic masculinity" in queer communities, the founder of InsideOUT told me that femmephobia was a significant, ongoing problem among groups of queer young people (IV1). Femme is an identity which extends to "trans women, non-binary people...and men" (IV1). According to InsideOUT's documents, femmephobia is understood as a "phobia or form of prejudice...directed towards femme-queer people. It is society's resistance to femme's existence [and to the] reclamation of their femininity" (IV1). As per our conversation, femmephobia is visible in the increased responsibilities on femme people, including but not limited to having to prove or justify their existence. The participant describes this as visible in "not being taken seriously...being expected to take care of people's emotional needs and having to do a lot of work [such as organising meetings] that is not acknowledged or recognised" (IV1). The marginalisation of femmes stem from "queer people with masculine identities feeling like they are the most important and the most queer and the most radical" (IV1). In her description of the nature of femmephobia, it appears that not only is femininity implicitly devalued. There are also expectations that femmes take on greater responsibility for the physical and emotional work which helps sustain the community. In this way, my conversation with the InsideOUT founder about toxic masculinity and femmephobia shows that queer communities are not 
immune to discriminatory attitudes or practices based on an unequal division of labour between masculinity and femininity. I consider the potentials of a community wide response to disestablish the gender binaries within the ways in which responsibilities are conceptualised, with particular investment toward reducing femmephobia experienced by feminine LGBTQIA+ people in the final discussion.

According to several participants, work in both self-governance and in rescuing disempowered men is primarily done by feminine people, women and femmes. Their undertaking of responsibility for others is relied upon for sustaining the status quo of a gendered culture, arguably expressed through an imperative to be staunch, empowered and unaffected by oppression. The participants' concerns about pressure and responsibilities here demonstrate that sexual violence or gender-based bullying may be pathologised as individual issues, and the shared experiences of these issues are downplayed through some of the pressures on feminine and femme people to conform to particular gender norms. The reality, at least according to some of my participants in their everyday interactions, appears to be that personal responsibility is not simply undertaken with self-interested motives; rather a lack of acknowledgement of gender norms and the types of pressures these can elicit is potentially implicated in enactments of care for others (Trnka \& Trundle, 2017, p. 11).

Young men and masculine people are largely constructed as forming a dominant group that routinely and violently oppress the 'other' (young women, feminine people, femmes). The fifth interview participant's pointing out of young women's care-taking of young men with mental health issues is equally of interest, considering the shared fear of femininity as described in literature on New Zealand masculinity (Phillips, 1987, p. 38; Brickell, 2012, p. 15) and young men's engagements with bro culture as described in the previous chapter. In this project, I do not have the capacity to closely examine how young men construct their gendered identity in the context of a gendered culture and discourses which individualise experiences of gendered issues. However, I consider some key areas for focus in further research in the conclusion.

\subsection{The "Emotionally Taxing" Pressures of Educating Others}

There is much more to be said about how LGBTQIA+ young people experience and navigate individualised pressures and responsibilities unique to their experiences. The second focus group in particular explored how they respond to various pressures and responsibilities they are expected to deal with in a heteronormative society. As mentioned in earlier discussion of the gender binary and bro culture, the hegemony of staunchness and resilience affects LGBTQIA+ people in a particular way. These young people may indeed have "some power in knowing that [they're] different", because they are already thinking critically about New 
Zealand's gendered culture and heterosexual matrix (IV5). But there are particular pressures upon young people who are open about their non-heteronormative identity which largely go unnoticed and unaccounted for, although they can be considerably stressful for the young person.

A significant pressure on LGBTQIA+ youth is being expected to educate others about their identity, correct terminology, and about rainbow community issues. One student recalls asking their biology teacher why she used an outdated term to describe intersex people, and going onto explain to the teacher, who had not heard of the term 'intersex' before, that using this outdated term is considered offensive and that it was best to use 'intersex' instead.

FG2:A: It was really hard to find a way to explain it that wouldn't just throw a bunch of new terms at her too quickly...you can say the word intersex and they don't know what that means...we were trying to explain it, and then another teacher came in at that point and said 'Do you mean transgender'? And I was like NO!

FG2:C: We just confuse them even more!

This focus group discussion ended in agreement with this participant's point that "it's really difficult when people don't have knowledge of different terms and concepts that exist and you're trying not to confuse them" (FG2:A). There was a shared concern that this lack of knowledge came from staff seeming to think that nothing needed to change. "They think they're already OK...and they don't need to improve" (FG2:A). This lack of attentiveness to diversity within school communities results in heightened pressure on the students to constantly explain themselves and encourage teachers to be more inclusive. The participants described these efforts as sometimes being futile, because of the power dynamic between students and teachers; "when it's one person going up against eight teachers, [asking for change] doesn't really work" (FG2:C). Moreover, "I was the one that confronted [the biology teacher] about [using outdated terminology] - me being a student, her being a teacher...I couldn't really then say 'google what all of these words mean'..." (FG2:A).

One participant believed that school staff would be better able to support LGBTQIA+ people if they took an active role in learning, rather than just expecting these young people to explain new concepts to them. "They should probably try educating themselves. Because it's not our responsibility to educate people" (FG2:D). Not only does the participant identify this source of pressure, they also make it clear that it is not fair that it is expected to be their responsibility to educate others. Other group members agree, commenting that the effects of being used "as [other people's] own search engine" is "hugely emotionally taxing" (FG2:A, FG2:C). One participant explains this further, in relation to his own experiences of coming out as a gay transgender man: 
There's this whole situation of you're asking me these questions, and you think it's the only time you're ever going to ask them. But, it might be the $30^{\text {th }}$ time I've been asked that question that day...I almost want to print out little cards that [have] links to the Wikipedia page and other resources...[because] it's very stressful saying the same thing over and over and over (FG2:C).

Beres (2017b, p. 7) notes that members of marginalised minority groups are likely to experience greater levels of stress "due to [structural] discrimination, marginalisation and stigma", which can increase the likelihood that they will also experience relationship abuse or violence. This stress is likely to be compounded for LGBTQIA+ young people who may engage in spending a lot of time educating others and answering questions, without recognition from others of the emotional toll it can have.

However, because LGBTQIA+ young people have often already reflected on their own experiences of living in a gendered culture, they want to help their communities learn how to best support them through education. One participant felt more comfortable interacting with others in their school after they publicly announced and described the way that they preferred to identify. "I came out to the year group and my teachers...I did a speech on non-binary things, and I think that sharing the knowledge...forced everyone to see that there was something else [outside of the binary]" (FG2:B). Extending on this, the first focus group spoke about educating different peer groups within their own schools as a largely enjoyable experience because it validated who they were as young LGBTQIA+ people, and treated them as epistemic agents rather than always already oppressed.

FG1:E: You have been great, because you went round junior classes and we did talks...

FG1:C: Yeah, yeah!

FG1:A: Yeah, LGBTQ-themed talks, [which I did] with the QSA for a couple of years.

In addition to this, Participant $A$ and some of the other participants previously organised a Day of Silence within their school, which recognises the "silencing effect of homophobic, biphobic and transphobic bullying, name-calling and harassment in schools" (InsideOUT, 2017). Many people in the school take part in this day: "there are so many people in the school who get involved with things like Day of Silence, even if they don't typically get involved with things like that" (FG1:A). Part of the fun of the day is that every communication is written on whiteboards rather than verbally spoken, which becomes an impressionable and creative way to answer questions. "[At first] a lot of people had questions, a lot of people did not always understand what it was about" (FG1:D). The group delivered the initiative for three years, and others appeared to become more engaged every year. "Everybody is quiet...all the teachers are fine with it and understand everything. We write everything down on whiteboards...it's a good time" (FG1:A). 
The particular school which these students attend is known to substantially foster inclusivity and diversity, creating an open community which enables LGBTQIA+ young people to educate others in a supported way. The diversity is valued through opportunities for LGBTQIA+ young people to talk openly about how other students can join them in seeking social change. This contrasts greatly with the cultural values of a private single-sex school attended by another young person: “We couldn't start an LGBTQIA+ club because they were scared that people might go home thinking that they were gay!" (FG2:B).

While schools endorsing the knowledge of LGBTQIA+ young people through allowing them to educate other students in a supported and student-led way appears to have been successful for Focus Group One members, some young people were hesitant about how studentled education through different initiatives would work in other schools. In particular, they expressed concern that the emotional well-being of students who wanted to educate others could be compromised if school staff did not oversee it sensitively:

FG3:A: I think [young people educating others in their school] are in a very vulnerable situation...I mean if they want to, then sure.

FG3:C: It wouldn't be something that teachers could really organise because it would just be too awkward...

These are important concerns for school staff to be mindful of in light of the high rates of bullying towards LGBTQIA+ young people (Ministry of Education, 2015b, p. 16). When teachers seek to better implement young people's voices in relationship and sexuality education, according to the latest Ministry of Education (2015a, p. 23) guidelines, it is essential to consider how this can be done in a way which protects students' safety while equally valuing their knowledge and enabling them to share it in student-led educational contexts.

Most participants agreed that the emotional turmoil implicit in unchecked responsibilities of LGBTQIA+ youth could substantially be countered by greater societal awareness of ongoing issues for their community. InsideOUT is already seeking to do this through their educational services, resources and initiatives like the Day of Silence. Further to this end, the onus to reduce bullying towards LGBTQIA+ youth should fall on "allies" (heterosexual and cis-gendered people in the community who support LGBTQIA+ people). "I wish allies would [educate others] more...it's more taxing [for us] than it would be for allies" (FG2:B). In this respect, greater education of communities is needed about the issues facing LGBTQIA+ young people and how allies can support them. In the final discussion, I consider how a community based approach, which calls on allies and bystanders of harmful behaviour, could help to alleviate them of the current pressure they are under to educate others with no support for the time and energy it takes to do so. 


\subsection{Stereotypes, Uncertainty and Further Implications in Pressure to be 'Staunch'}

Extending on a school counsellor's conceptualisation of Sophie Elliot as "a perfectionist" who did not leave her relationship with Clayton Weatherston because she did not want to be seen as a failure, fears of failing are also very real for LGBTQIA+ young people in how they experience intimate relationships (IV3:A). This primarily involves how they perceive themselves through the eyes of others, in that to identify outside the gender binary and heteronormativity prompts a particular application of self-regulation to prove oneself to be queer enough to render their relationship legitimate in the first place. "There is just this constant sense of imposter syndrome [in being an 'out' LGBTQIA+ young person] - like what if I'm not X, what if I've been faking this entire time" one participant comments, extending on the first interviewee's description of how femmes might be scrutinised for not being "queer enough" (FG2:C; IV1). This sense of doubt which young LGBTQIA+ people might hold about their identities can be compounded by a perception from others that they may only be identifying in this way for superficial reasons. This was summarised by one participant as: "A lot of people say oh I'm gay, or lesbian or, oh I'm bi just to bring attention to themselves" (FG3:E).

The fear in identifying as LGBTQIA+ is heightened when there is increased scrutiny on these relationships, as one participant notes:

I know of a few couples at the school who are not heterosexual... and they get talked about a lot more. You just hear a lot more whisperings about them, and more questions posed but behind their backs... that's not something that tends to happen with heterosexual couples (FG1:E).

Fundamentally then, there is also pressure on LGBTQIA+ to simply prove to those around them that they can enter a relationship and navigate it successfully, and without the drama which curious peers seem to be looking out for. This pressure appears to be borne out of the continually persistent conservative stereotype that LGBTQIA+ people are more promiscuous than heterosexual people. The stereotype was described as rearing its head in others' understandings of relationships LGBTQIA+ have with each other. "[You're] cis-het until proven otherwise...the problem of queer stuff is that it's seen as inherently sexual... 'we' cannot tell children about 'them' ..." (FG2:C). Another participant echoes this in recalling meeting an adult lesbian couple when she was younger and not being told by her family that they were partners.

[I wondered] why do these two women live together - do they not have husbands? It was only a couple of months ago that I realised why these two women were living together... It's really interesting nobody told me because my family is relatively accepting. But they're accepting as in - they're not going to be hateful but they also don't really give a fuck (FG1:A).

Implicated within these responses may be a strain of moral conservatism about keeping young people sheltered from LGBTQIA+ couples. This stems from the second focus group 
participant's comment that there is still a perception of LGBTQUIA+ people as more "inherently" sexual than others. 'Some people's minds go to 'Oh God they are doing heinous sexual acts!' because that's the only way they can view it...but you talk about straight couples doing things you think, holding hands, going on dates, getting married" (FG2:C). This stereotype is also present in schools' treatment of non-heteronormative material in sexuality education. "Before [sexuality education] classes they always need a permission form saying that we'll be talking about gay people...why do my parents need to give me permission to listen to this stuff?" (FG2:D).

There appear to be two influential discourses impacting how LGBTQIA+ young people experience pressure to be staunch in their performance of identity and take responsibility for managing their intimate relationships successfully. Firstly, there is clearly still a morally conservative influence on the ways in which they are stereotyped as hyper-sexual and promiscuous. This stereotype is largely recognised for what it is, and it is actively being worked against through educational resources from InsideOUT, and dissecting gender and sexuality norms in SAPN sessions, as the first two interview participants have described. But it continues to fuel pressure on young LGBTQIA+ people to appear to others as authentic in their identity, proven through a 'successful' ongoing intimate relationship. Secondly, there is the more subtle presence of a depoliticised and individualised notion that it is up to individual LGBTQIA+ people to maintain successful relationships through making 'responsible' decisions - in this sense becoming like the ideal postfeminist and neoliberal subject described in Chapter 2: Theoretical Framework.

Pressure to maintain a successful appearance to others through intimate relationships, and to not appear as hyper-sexual: "That's like OK no, I'm not perpetuate that stereotype because it's wrong....and then you force yourself to stay in an unhealthy relationship" (FG2:B). Further, "because it's harder to find a relationship [when one is LGBTQIA+] you might try to tough through stuff that isn't working, when it would really just be better to break up" (FG2:C). The nature of abuse, control or power dynamics in LGBTQIA+ relationships is a key focus for future research in this area. From my interpretation of the data from this project, it appears that the pressure to be successful in these relationships, which may be as dangerous to persons' wellbeing as the feminised experiences of pressure to be successful in heterosexual relationships is, discussed in relation to the Sophie Elliot murder case (IV3:A). I elaborate further on this point in the following discussion of the third theme, Healthy Relationships, where I consider the participants' suggestions for reconceptualising, challenging and expanding current education and social discourses about what a healthy relationship looks like. 


\section{Chapter 6: Healthy Relationships}

\subsection{Perspectives on Healthy Relationship Education}

While every school appears to adopt sexuality and relationship programmes differently, as mentioned previously, I examine the healthy relationship programmes which do exist within some schools currently through exploring different participants' perceptions and evaluations of these programmes. The concept of 'healthy relationships' is fairly ambiguous, and is interpreted by participants in myriad ways. Terms used to describe the qualities of a healthy relationship by members of every focus group included "good communication", "honesty", "trust" and "love" (FG1:D, FG1:A, FG2:B, FG2:C, FG3:A, FG3:C). Referring to a variety of different Māori models which are regarded equally useful as hauora for conceptualising sexuality in teaching, the revised Sexuality Education Guidelines (Ministry of Education, 2015a, p. 9) indirectly define a healthy relationship as a "respectful and safe process"8. However, as I discuss below, some participants were concerned about what the term is commonly thought to encompass in dominant educational and social narratives. Beres (2017b, p. 3) argues that experiencing ideally 'healthy' relationships "is particularly challenging considering that adolescence can be a time period marked with exaggerated gender roles, and an acceptance of mythical notions of romance." This is echoed by several participants. I comment on how healthy relationships are perceived and how this is conceptualised in various sexual violence prevention programmes. I then consider how friendships and platonic relationships are valued by participants, before conveying their views on how gender norms affect young people's experiences of romantic relationships. Finally, I comment on the usefulness of the concept of community in this research area, building a bridge between this chapter and the previous two with the critical analysis given in the following chapter.

In the dyadic interview with the school counsellors, much time was spent discussing the Australian Loves-Me-Not programme which commenced in New Zealand after the murder of Sophie Elliot, and was primarily initiated and funded by Sophie's mother Leslie Elliot. The educational programme is rolled out for senior year groups across different schools in New Zealand, and takes place annually as an all-day workshop for students. Its main purpose is to "raise awareness [of the signs of an abusive relationship]... and supportive agencies outside of school as well as what we can do to help in school" (IV3:A). The long-term goal of Loves-Me-Not is also to call on bystanders to support healthy relationships. "It's about...widen[ing] that support network, that wrap-around network...where you can actually leave [an abusive

\footnotetext{
${ }^{8}$ For elaboration of these models, which include the Te Pae Mahutonga, Te Wheke, the Powhiri Model, Te Uruuru Mai a Hauora, the Waka model of whānau, hapū, and iwi health, and the Wero model, see the Ministry of Education's revised Sexuality Guidelines, 2015.
} 
relationship]... and people will support you" (IV3:B). The concept of this "wrap-around network" is significant for this critical analysis, and will be drawn on again in Chapter 7: Discussion of Findings.

Different students I spoke with were familiar with the Loves-Me-Not programme, and had differing views about it, and about the extent of their schools' sexuality education programmes more broadly. Every participant appeared to be in agreement that external programmes like Loves-Me-Not were very important for their peer groups, especially as they enabled more open discussion about navigating intimate relationships. This is an aspect of education which some school staff are hesitant to talk about. "It's like they don't want to touch it with a ten foot pole" (FG3:E). This may be especially the case when they do not have the extent of expertise on the area as external educators might. One young man shared how much he valued his participation in the Loves-Me-Not programme:

It tells you how to identify good and bad relationships...it was really helpful. We went into a lot more detail [than in school classes]...it was really interesting and gave quite a bit of insight into how to identify relationships...it applied to friend relationships, not just romantic ones, which was quite good (FG3:D).

The importance of friendships and platonic relationships in young people's lives was visible across a few interviews and focus group discussions, and I comment on this further below in relation to re-thinking and expanding on the concept of healthy relationships. This student's positive views about the value of the Loves-Me-Not programme echoed the counsellors' emphasis on the importance in focusing on community skills to provide support to victims of abusive relationships or violence.

Other students, while noting the positive impacts of the programme, were less excited about Loves-Me-Not because they felt that its focus did not adequately speak to their experiences as LGBTQIA+ young people.

FG1:B: It was entirely heterosexual.

FG1:D: Unless you asked very specific questions. And even then they just sometimes can't answer them. FG1:E: But it's compulsory for everyone, so we all went. But I don't know...it wasn't outrageous.

FG1:C: Even for heterosexuals, it wasn't great - like...

FG1:A: Because it was like they have a fear of going into the complexities of things.

When non-heterosexual students need to ask "very specific questions" to feel included in the discussion, this is not always easy or comfortable to do. Further, as one participant in McAllum's (2014, p. 82) research recalled, students who do not identify along heteronormative lines may not necessarily have come out, or they may not want to be identified in a certain way to their classmates. Attitudes about 'normal' sexual and romantic relations that ignore LGBTQIA+ 
people's existence can be reinforced when language, resources and examples are not thoughtfully selected (Beres, 2017b, pp. 9-10). Beres (2017b, p. 9) contends that "young people can disengage if they are not included in the messages" of these classes. Overlooking information and ideas about healthy relationships for non-heteronormative relationships contributes to the silence around LGBTQIA+ experiences in education and it also appears to naturalise femininity and masculinity as a heteronormative binary (Butler, 1990, pp. 151-152). As noted earlier, the Sexual Abuse Prevention Network tries to meet the needs of these students by using resources in their programmes which include more diverse examples of relationships, but it is difficult to find such resources, so they will sometimes make their own. This shows that acknowledgement of the needs of queer students may remain a relatively untouched area within school curriculums.

As presented above, one participant noted that the workshop "wasn't great" even for heterosexual people. In the context of this discussion, he appeared to be referring to the fact its key ideas were not probed far enough, and another participant clarified this: "They were also nervous to talk to us about sexual things" (FG1:B). There may continue to be fear and anxiety among educators and teachers about having these discussions with young people on a deeper level. It also might be true that "complexities" are simply brushed over because of time constraints of each session; certainly Loves-Me-Not delivers only a day-long workshop that occurs once annually for Year 12 students. Perhaps if there were more sessions that could be run over a few weeks, similarly to the layout of ACC's Mates and Dates programme about raising awareness of healthy relationships, more information could be made available to students ${ }^{9}$. Critically raised here though was the delivery of these sessions, and how comfortable educators appeared to be. Allen's (2005a, p. 89) research has shown that reluctance to expand on certain concepts has been a common historical trend in New Zealand classrooms, much to the dissatisfaction of young people. While the revised guidelines encourage more open communication between staff and students, and expansion of education on relationships and sexuality, educators can still be hesitant to delve into anything deemed too risky. A participant in another focus group agreed, claiming that "terms like lesbian and transgender are taboo...[educators] are visibly uncomfortable" (FG2:D).

Complicating these gaps in relationship education further, there needs to be more consideration around accommodating students who are not comfortable talking openly about sexuality, or who may require different forms of support from their community in this area (Beres, 2017b, p. 9). For example, this can include young people with diverse cultural or

\footnotetext{
${ }^{9}$ For more information about the Mates \& Dates programme, which can be delivered to high school students at all stages, visit https://www.matesanddates.co.nz/.
} 
religious backgrounds (see Allen, 2012, p. 461; Allen \& Quinlivan, 2016, p. 124). In my conversations, it appeared to be most pertinent for young people who identify as asexual. The participants described that overt emphasis on sex as the "normal" way to express romantic feelings makes them feel uncomfortable because it overlooks their identities:

FG1:C: As far as asexuality goes - if one person is and the other one isn't...that will be troubling [for the asexual person] because at least one person will feel that they are not doing enough for the other... so [overemphasising physical intimacy] can be kind of jarring.

FG1:B: And it can make you quite scared to enter a relationship because you're like, what if this person wants more from me than I can give?

These insights form necessary considerations for introducing the concept of sexuality in an informative yet inclusive and sensitive way. It follows that mindfully incorporating hauora into teaching young people about healthy relationships and sexuality would acknowledge the needs of these young people, by giving equal attention to non-physical ways of showing intimacy, for example, and including asexual identities in conversations about diversity.

Another important insight in relation to the overall collection of data for this project was articulated by the fifth interviewee, who described that engaging in critical conversation about gender norms and healthy relationships is a "privilege" for students who have access to these conversations, as not all schools offer educational workshops like this:

It's a privilege to be able to challenge [gender norms], and to question it... being able to read about it and learn about it and have an academic understanding that's class privilege, being able to do that (IV5).

The extract brings up a key limitation of my study, in its geographical restrictions to schools and communities of young people in the city. The counsellor works at a high decile state school, whose student population are from predominantly middle-class families. I reflect on this limitation through suggestions for further research later in the conclusion.

As an opportunity to implement the recently revised guidelines on sexuality education by the Ministry of Education (2015a), this counsellor's school holds annual "wellbeing days" for each senior year group, "where we cover gender...and cover different topics for every year [group], so they won't cover the same thing every year...we look at health holistically, talk[ing] about hauora" (IV5). A focus group participant whose school also offers wellbeing or hauora days affirms this, "at school we now talk about gender and relationships all the time. It's very clear...everyone really enjoys it and it's a safe environment...it's like a fun day where we all wear mufti and hang out and chill" (FG3:B).

It is pleasing to see this incorporation of hauora in talking about healthy relationships, following the directive of the revised guidelines, which I expand on in more detail in the final 
discussion (Ministry of Education, 2015a, p. 6). But I also share the fifth interviewee's concern about the "privilege" of receiving holistic education which takes place in schools that are visibly supportive of gender and sexuality diversity. The fact that it is regarded as a privilege by this participant indicates that many schools are still not fostering this education and support, and as other counsellors pointed out, some private schools might be potentially disadvantaging students by not providing opportunities for important discussions on gender, sexuality and relationships to take place. Further, some external support groups for LGBTQIA+ young people, like InsideOUT, are only based in one location which would be difficult for young people who live in further away suburbs to access.

\subsection{Rethinking the Concept of Healthy Relationships}

There was some variation across the ways in which interviewees and focus group participants regard education on healthy relationships. One school counsellor identified that what sexual violence prevention classes do have in common is an objective to raise young people's awareness of identifying and distinguishing between abusive and healthy relationships. "It's about having the skills to intervene and learn[ing] to become an active bystander" (IV3:A) In addition, the skills being taught are for students to reflect upon in their own relationships. "You do a bit of forward-gazing into an awesome healthy relationship and what that would look like" (IV3:A). The counsellor clarified that some students at her school are already having these kinds of relationships. "Some of the kids are in long-term, healthy relationships that are quite adult like" (IV3:A). Complicating this observation, some of the young people in focus groups questioned what the term 'healthy relationship' is thought to imply, and how this might affect their peers.

There was lengthy discussion about the concept of a 'healthy relationship' potentially becoming another source of pressure for young people, because of particular connotations the term was believed to hold:

There's the idea that you've got to give everything to your partner and be hopelessly in love with them every time you look at them....when it's not realistic to be head over heels, butterflies going everywhere once you've been with someone for a while (FG2:A).

Moreover, "Obviously some [relationships] are really unhealthy. But every relationship has its struggles and it doesn't necessarily mean it's an unhealthy relationship" (FG3:A). It was proposed that communication skills within relationships are key. It could be unclear for young people to distinguish between a resolvable issue within a relationship and an overall unhealthy or dysfunctional relationship when communication is not valued:

FG2:B: Healthy relationships look like good communication. 
FG2:C: Yeah I feel like that's a really important one...you can't get to the whole 'trust' and 'honesty', you know, unless you talk about it.

There was concern that the connotations of 'healthy relationship' are generally perceived as synonymous with a perfect relationship, where there can be considerable pressure to do romance in certain ways; subsequently there might be confusion and uncertainty when that feeling of initial excitement dissipates over time. A participant in the second focus group goes on to explain the ways in which this becomes a site of pressure on young people, extending on the notion of 'successful' relationships as discussed at the end of Chapter 5: Pressures and Responsibilities.

[Trying to achieve perfection is] a toxic way to look at [relationships]...it's made especially difficult for LGBTQ people, because they feel they have to validate their sexuality by being hopelessly head over heels for someone every time they look at them ...because otherwise how do they know that they're attracted to them - how do they know they're not straight? (FG2:A).

The participant and other members of the focus group she was in put the pressure of maintaining a flawless relationship down to a tendency within New Zealand's gendered culture: "people value heterosexual romantic relationships above platonic relationships" (FG2:D). The pressure to be in romantic relationships is believed to make people feel that aspects of their life are unsuccessful when they are not in a relationship, or when the relationship is not going well. "She had tons of friends, a prospering career, a house, cats and things. Everything was fine except - and she thought because of that [not being in a relationship] that her whole life was in tatters" (FG2:C). In the context of Focus Group Two's discussion, this phenomenon again appears to be connected to Butler's (1990, p. 151) conceptualisation of the heterosexual matrix, in that femininity and masculinity are "naturalised" as a binary and constructed as somewhat more complete identities via heterosexual relationships. "[Someone I know] ended up staying with a guy for six years who was the worst, because she was afraid of being alone" the participant recalls (FG2:C). The fear of ending the relationship, despite its problems, might be somewhat rooted in the person feeling that her performance of femininity would not be as fully realised, or as easily "proven" if she was not in a relationship with a male partner normatively performing masculinity (Butler, 1990, p. 151).

"Platonic" relationships and friendships are equally salient for young people, and undoubtedly influence navigations of relationships. One counsellor I spoke with cited issues with friendships as a main reason why many young people, especially in the junior years, make appointments with her: "Mostly its issues with friendships, particularly in year nine and ten...that's a big theme. I think there is an idea that people have a partner, but it's a lot less common than young people probably think" (IV5). It was widely agreed in the focus group 
discussions that friendship tends to be undervalued through pressure to be in an intimate heterosexual relationship. "High school relationships mess with your perception of other relationships...if you are in this straight cis-het relationship you're going to [think] friends aren't as important as significant others" (FG2:B). In accordance with the "naturalising" of heterosexual relationships described by Butler (1990, p. 152), this participant seems to imply that the under-valuing of friendships affects predominantly heterosexual, cis-gendered young people due to their gender-conforming identity. The participant may have found, from their experiences, that strong, significant friendships are more normalised for LGBTQIA+, who as described later, might experience more difficulty finding romantic partners. Participants from Focus Group Three describe how young people's friendships are overlooked in dominant romantic relationship discourse:

FG3:A: Friendships are really important because when the relationship fails, you're meant to fall back on your friend - I think friends are often overlooked. You know, friendships are often just like, yeah cool, we're friends ...but I think they're quite a central part of life.

FG3:B: Yeah...there's all this talk and all this education about healthy romantic and sexual relationships, but there's not a lot about actual friends and the stuff that goes on in between friendships.

These participants went onto describe that the lack of acknowledgement of friendships and platonic relationships is an issue: "I know more people who get mucked around by shitty friends than shitty relationships" (FG3:A). Strong friendships among young people are significant for providing the "wrap-around network" mentioned earlier, to form part of a cohesive community which collectively prevents sexual and relationship violence by challenging harmful gendered discourses (IV3:B). In this respect, it seems essential for the concept of 'healthy relationships' to explicitly include friendships too. This may already present in Loves-Me-Not, as Participant D of Focus Group 3 identified earlier, but perhaps needs to occupy a more central role in classroom discussion and the wider school culture.

Another participant in the third focus group agreed that friendships deserved more recognition in the conceptualising of 'healthy relationships', but articulated some uncertainty around how stronger friendships could be encouraged by schools, "if they brought into schools a class on how to be a good friend, I don't think it would be taken seriously" (FG3:C). The group appeared to concur with the idea that good friendships happen organically. "Learning about how to be good friends is done through experience" (FG3:A). One participant believed that friendships ought to be recognised as integral to good emotional health in a more substantive way, and she felt that this was not being adequately fostered by communities.

I think loneliness really contributes to our high youth suicide rate. Because social media has taken over our generation's lives, it's really hard to make meaningful 
connections with human beings...we just turn to our phones and we feel connected momentarily but that doesn't cut the surface (FG3:A).

I comment on the role of social media briefly in the conclusion, and how further research could be undertaken to follow up the point raised by this participant. I also discuss how school cultures can visibly and tangibly adopt emancipatory, inclusive and compassionate values to support social connections between young people in Chapter 7: Discussion of Findings; informed by contextualising our poor mental health rates as an issue partly implicated in New Zealand's gendered culture. Building up community support around young people may be particularly significant for addressing the "loneliness" which this participant has described.

\subsection{Gender Norms, Relationships and Communities}

Extending on analysis of concerns about young New Zealanders' comparatively poor mental health, Focus Group Two members refer to values underpinning 'bro culture' and how these can further reinforce the hegemony of the gender binary. A participant observed that male peers' behaviour changes noticeably when they are with their male friends, versus with their girlfriends: "they become kind of two-faced - they're really mean and manly with their friends, but maybe nicer to their girlfriend" (FG2:D). As noted in Focus Group One's discussion of "bro culture', young men can appear to interact in a more disruptive and intimidating way in their male mateship groups (see page 43). Focus Group Two members noted that it is easy to perceive this behaviour as a performance of competitive and macho masculinity because of the visible contrast in these same young men's behaviour when they are with girlfriends, "[there is a perception that] men don't need hugs except from their girlfriends" (FG2:C).

It was not implied that men were necessarily emotionally open in their relationships with women, however. Rather, one participant believed that in every heterosexual relationship, male partners face pressure to prove their masculinity. "To be the man in the relationship, they've got to be strong...even if it's not an explicitly unhealthy, sexist relationship...they've [still] got to be the macho man" (FG2:A). The 'Kiwi bloke' masculinity, as I discussed with regard to bro culture, continues to be visible, despite some instances of departure, like in the fourth interviewee's description of a young man known to her: "he's adopted this cool, calm, collected way where he's outwardly affectionate to his [male] friends" (IV4). Being 'macho' in the context of an intimate relationship is summarised as: "they're possessive [of girlfriends] because they are the only person you ever hug...men can't have strong feelings and if they do, then they should hide them and not burden the girlfriend with them" (FG2:A). Further, "there's not a lot of physical affection there, which means men are always bottling things up and they can't properly identify their emotions (FG2:C). This claim is of course complicated by the tendency for young men with poor mental health issues to be dependent on limitless support and care from 
girlfriends and ex-girlfriends, as the fifth interviewee described in Chapter 5: Pressures and Responsibilities.

The heterosexual matrix is visible through the ways in which young men are perceived to talk about young women in their peer groups, who are assumed to be primarily available for entering intimate relationships or interacting with sexually. This happens through stigma around platonic friendships, where the term 'friend-zoning' is used by young men to describe young women who decline their offers of a romantic or sexual relationship with them. "I've listened to [young men known to participant] talk about this all the time...they'll be like 'oh this girl friend-zoned me'...[but they] want to date every girl they talk to" (FG2:D). According to the participant, these young men would appear surprised or personally insulted when the young woman told them she did not want to go out with them:

They go, 'oh she went out with this other guy even though I was so nice to her' and I was like you know, 'just be happy - make friends with someone [instead]'. They'd be like 'Oh that's not manly' or something (FG2:D).

The concept of being 'friend-zoned' seems to naturalise heteronormative relationships and reinforces the idea that masculinity and femininity are fundamentally different: "there's that thing of, can men and women really be friends?" (FG2:A). These participants were particularly critical of the ways in which 'friend-zoning' de-naturalises and overlooks friendship; as exemplified in Participant D's quote above, where the young men they spoke about regarded platonic friendship (presumably with women) as not "manly" enough. This attitude was explicitly challenged for its reductive view of women by another participant: "she may have friend-zoned you, but you girlfriend-zoned her first!" (FG2:B).

It is clear then, that friendships form each young person's "wrap-around network", and are significantly weighted with potential to challenge pre-existing harmful discourses, which can be seen in the initiative taken by some students in Focus Group One to collectively break the silence in their school on issues affecting LGBTQIA+ young people through the annual Day of Silence. They described another aspect of this initiative which engaged the school as a collective:

FG1:D: We covered an entire wall with-

FG1:A: Brown paper.

FG1:D: Yeah brown paper, and drew pink silhouettes of people...

FG1:A: ....and we'd paint and write notes and messages on them.

The participants regarded this as a particularly helpful activity for educating others because the act of contributing to a large piece of artwork made each student think carefully about what they wanted to contribute, and helped them to articulate their role in supporting an inclusive 
community. In addition, the 'hauora' days appear to elicit positive outcomes for including students' voices: "We ask them what they think is missing [from education curriculums and the school culture] and what people at different ages need" (IV5). Loves-Me-Not, despite some constraints in its accessibility to non-heterosexual students, appears to also be carried out in a way which calls on community engagement. "We have a training day for...the community agencies, school teachers and police [who] are in the classroom with students...we also run a parent evening [to give more information to parents and answer questions]" (IV3:A). It is exciting to see that there are substantive community youth development approach measures in place to counter the loneliness felt by some young people, described by Focus Group Three Participant A.

There is still noticeable pervasiveness of the gender binary in young people's lives, which was described at length by all the participants in different contexts in each findings chapter. But this pattern further strengthens the position of the general manager at SAPN, that effective educational approaches are gender-transformative: "We dissect gender norms and roles...[and talk about] genders and sexualities that don't fit into a traditional binary" with a view to "prevent sexual violence through identifying gender norms...as one of its underlying causes" (IV2). In the next chapter, I consider the ways in which academics and communities can respond to these issues raised here, in ways which continue with already existing helpful and inclusive initiatives that integrate hauora into schools and communities more fully. 


\section{Chapter 7: Discussion of Findings}

\subsection{Critical Perspectives on Idealising 'Staunch' Performances of Gender}

Towards the end of Chapter 4: The Gender Binary and "Bro Culture", I commented on the ways in which some of my participants viewed the 'staunch' femininity evident in their descriptions of young women who visibly resist against gender-based bullying and sexual harassment. Considering the implications of being staunch, or resilient through experiences of victimisation, I demonstrate that the discourses implicated in this are highly significant and salient, and should be probed further. It is imperative to theorise on this area, in its situated contexts within Aotearoa New Zealand, in order to fully understand and re-think the ways in which gender norms are analysed, critiqued and transcended.

I identified that being staunch seemed to indicate an ideal way to perform femininity in the context of the city schools I engaged with through the interviews and focus groups. The interview participants who had direct experience working in schools told me that they had recently observed growing confidence among girls to put up barriers to bullying or sexual harassment from their male peers. Compared to previous years, according to the participants, there was also less tolerance for sexism and misogyny among students across these schools. A protest was organised by many students earlier this year in response to the exposed online comments made by a small group of male students about raping young women. This resistance can be considered in the context of a resurgence of feminist activism currently and in recent years (Tennent \& Jackson, 2017; Gill, 2016). I come back to thinking about this in the context of communities and solidarity later in this chapter.

In addition to this, being staunch constitutes a pressure on young people in this study to appear unaffected by ongoing oppression. It may illustrate the depoliticised notion of empowerment that Gavey (2012, pp. 719-720) critically describes. For instance, the pressure to be seen as successful subjects in fulfilment of their identities means there is little room for critical acknowledgement of ongoing issues which young LGBTQIA+ people do face. InsideOUT has responded to this through their Day of Silence initiative, which draws attention to how these people are often compelled to be silent about their experiences. The subjectivity of young LGBTQIA+ people who experience their identity in this way is reminiscent of McRobbie's (2009, p. 18) description of the depoliticised and uncritical postfeminist subject who "is called on to be silent" about issues of injustice. Many participants who identified as part of the LGBTQIA+ community problematized these pressures to be staunch as implicated in expectations of their individual responsibility to reduce bullying or misunderstanding from others. 
This perception of being staunch - as implicated within heightened pressures to conform to gender norms and be perceived by others as successful- is connected to reinforcements of New Zealand's gendered culture. The fourth interview participant noted that gender norms in rural New Zealand culture appeared to construct young women equally as "headstrong" as young men, and according to her experience as a youth worker, this quality appears to be adopted by young people in cities too. She conceptualised the resurgence of feminism I mentioned before in terms of young women being encouraged to show that they are on an equal footing with young men by adopting the same qualities as them, and believed that this indicated gender equality was being achieved. In light of this, it is necessary to trace what those qualities of the staunch individual are, and consider how they are negotiated by people of diverse genders.

Earlier in the thesis, I described New Zealand masculinity as historically rooted in the normative figure of a pioneering, hard-working self-made man (Phillips, 1987, p. 5). There is, as participants in Focus Group One raised in their descriptions of "bro culture" and "DIY culture", some presence of individual responsibility in these constructions. Of course, the strong values of male mateship also characterise masculinity in Kiwi terms, which would complicate claims that dominant constructions of New Zealand masculinity are entirely hinged on uninhibited individualism in the capitalistic sense that Kimmel (2005, p. 37) describes of traditional white American masculinity. With this in mind, the data still seemed to show that individualism is relevant to how staunchness is valued by young men in New Zealand. This is visible through the imperative to prove one's masculinity through physical strength, rejecting sentimentality as effeminate and therefore off-limits, and to demonstrate entrepreneurial abilities by being innovative and successful (Markula \& Pringle, 2006, p. 93). This phenomenon was summarised succinctly in the first focus group's descriptions of 'bro culture' among New Zealand's young men, and the "do-it-yourself" (DIY) imperative within this.

From some participants' description of the characteristics of feminised personal responsibilities, it appears that notions of stoicism, independence and implicit rejections of emotionally-based critiques of the status quo are equally taken on by young women.

Staunchness in this respect seems to imply an expectation that young women, and members of other marginalised groups might appear relatively unaffected or distanced from sexism or gender-based bullying, to a point where they no longer need to critique it openly at all. There is a discourse within this data which assumes that for young women to demonstrate that they are truly liberated from sexism, they should ignore, minimise or be silent about it (McRobbie, 2015, p. 8; Harris \& Dobson, 2015, pp. 150-151). The critical observations in McRobbie's (2004, p. 256) earlier work on the concept of the double entanglement are supported here, because the 
discourse of 'empowerment' reinforces the notion that gender equality is already achieved, and to suggest otherwise is to deviate from the status quo and potentially invite criticism and judgement from others in society. In relation to Stringer's (2014, p. 11) theorising on neoliberal victim theory, which I unpack further later, the characterisation of the 'power-victim' strengthens this point. The power-victim is distrusted and outcast for publicly articulating the grievances of their experience as a victim, and might be framed in an especially unfavourable light if their experience drives them to advocate for radical systemic or social change (Stringer, 2014, pp. 10-11).

Before elaborating on the critical implications of staunch femininity and dominant constructions of victims, I will consider the ways in which the concept of being staunch can be thought about in relation to the ladette figure. The ladette is a culturally-specific phenomenon in the United Kingdom, as studies around the concepts of "lads" and "ladettes" most often take place in the UK and employ the local terminology of "ladette" to describe young women who seem to adopt the behaviour, persona and mannerisms of loud, disruptive and brash young men (Jackson, 2006, p. 346). The unruly nature of ladettes is not entirely descriptive of New Zealand's staunch femininity performed by young people, but the concept can in part be drawn on here, because of staunch girls' potential focus on adopting the same qualities visible in staunch masculinity. This appears to contribute to the constructing of an image of idealised femininity among young people in urban New Zealand. The fierceness implied in participants' descriptions of contemporary young women as "strong and independent" bears relation to the cultural legitimation of these young women's adoption of what could be perceived as traditionally masculine values; being carefree, entrepreneurial and driven to create their own pathways to success, which are also seen in the self-made characteristic described in literature on Pākehā masculinity (Phillips, 1987, p. 36; Markula \& Pringle, 2006, p. 93).

Significantly, by young women "becoming like their male counterparts" through their staunchness via their independence from male peers, the silencing effect of this hegemonic gender norm is less visible from critique (McRobbie, 2009, p. 83). If young women's liberation is talked about in a way which universalises the experiences of all young women, critical feminist theorists may risk losing sight of ongoing experiences of oppression. In overemphasising this liberation, there is danger in missing out seeing what it means to not identify with the 'staunch' imperative, as a couple of Focus Group One participants spoke about (see Chapter 4: The Gender Binary and "Bro Culture"). Further, there are also key differences between 'ladette' femininity and 'staunch' femininity, as the data from this study indicates.

While the ladette is described by McRobbie (2009, pp. 83-84) as a girl who does not appear to have meaningful relationships with other girls, instead joining male mateship circles 
as 'one of the boys', quite the opposite appeared to be true in the participants' conversations about the increasing visibility and importance of staunchness among young women in New Zealand. With respect to the ways in which they stood up against gender-based bullying, sexual harassment and rape culture online, many young women, feminine people, and their supportive peers of other genders were described as a collective, or as a cohesive community. The march mentioned earlier was organised between students of different schools, who communicated with each other about their intolerance for the misogyny and sexual violence as a normalised expression of heterosexual relations. Gender norms as binary and hierarchical were challenged not only by the nature of the protest but also by each interaction of solidarity among the students. These interactions initiated the idea of publicly protesting against sexual violence and its rhetoric in the first place.

Further to this, multiple participants noted the often over-looked significance of friendships in their lives as high school students. This indicates the need for expansion and depth in education on healthy relationships, and the need for further research into how friendships among young people in New Zealand navigate gender norms. The importance of friendship in young people's lives calls on critical feminist researchers in this area to be cautious not to exaggerate the presence of individualism in hegemonic expressions and performances of gender and sexuality. Friendship and community are also significant for understanding young people's views and experiences of gender norms in my study. These concepts are interesting to think about in relation to staunch femininity and the ways in which this gets framed in young people's lives. While there may be potentially concerning reproductions of New Zealand's gendered culture and neoliberal individualism implicated in the discourse of staunchness, there is equally room for thinking about how collective staunchness can provide substantive ethical regulations for what kind of behaviour and attitudes are and are not acceptable in society. Understanding young people's friendships better in the context of New Zealand's gendered culture and resistance to it forms a useful and important area for future research.

As explored in Chapter 2: Theoretical Framework, Gavey (2012, p. 719) argues that when research participants report being "empowered" from the constraints of sexism, it is imperative for researchers to recognise that these claims are situated, mediated and not necessarily indicative of an end to gender oppression. For the purpose of probing and interpreting 'staunch' further, I consider this in relation to my participants' descriptions of "strong and independent", "headstrong", "resilient" and "staunch" young women. Of course critical feminist researchers, in accordance with the critical feminist protocol established in Letherby's (2003, pp. 72-73) work, should not dismiss participants' claims to subjectivity and agency simply as a sign of being duped by the workings of some all-encompassing oppressive structure which they are merely 
"carriers of" (Hays, 1994, p. 62). But Gavey (2012, pp. 719-720) notes that it is also imperative to maintain critical scrutiny on words like empowerment, especially when the term is used to refer to individual liberation only. I concur with this critique of the simplification of the term 'empowerment' as an uncritical and vague buzzword, and propose that the same precaution should apply to theorising on stanchness, so that it does not become used in a way which is void of substantive meaning to affect change.

One of my main concerns about the apparent hegemony of being a staunch individual regardless of one's gender identity, is that I am doubtful about the extent to which it actually challenges and resists harmful tropes about masculinity in a New Zealand context. I am not only doubtful about the full extent of its usefulness to people of marginalised gender identities in aiding their resistance to the status quo - especially when dominant cultural interpretations of staunchness may illustrate it in terms of the unaffected resilience of individuals, rather than groups. It also may form a conceptual framework (one which requires more rigorous theorising in future research) for thinking about the high rates of poor mental health in New Zealand, which are particularly high among young men. As the second interview participant noted, it is still mostly men who do sexual violence. It is also young men who appear to be missing out on important education on healthy relationships, because of an implicit heteronormative and gender-normative belief among staff at boys' schools that 'relationships' are feminine territory.

There needs to be more critical enquiry into why New Zealand's young men are less likely to receive this education, and to what extent a lack of diverse representation of gender in young men's lives might fuel pressures to live up to heteronormative ideals of masculinity. As some focus group participants discussed in relation to thinking about heterosexual relationships, the factors contributing to young men's possessiveness or emotional distancing from girlfriends may provide some insight to their high rates of poor mental health. Unrelenting pressure to be staunch in all areas of life can have severe emotional impacts, as Shafer and Wendt (2015, pp. 105-106) note in their study of men's experiences of mental health problems. Connell and Messerschmidt (2005, p. 834) have also identified that the hegemony of staunchness, in the context of physical contact sports such as rugby, can cause "emotional [as well as] physical damage" because of the cultural normalisation of this stereotype of being a man. While not every young man in New Zealand plays rugby, and while the game of rugby itself is not to blame for this, the culture of toughness, physical prowess and emphasis on individual stamina is visible in young Kiwi men's attitudes and interactions off the field with their peers in school settings.

The fifth interview participant observed a common tendency for young men with mental health issues to be dependent on young women for support, often those whom they are or have 
been in a romantic relationship with. There may be not enough support services equipped to understand and address young men's mental health problems, but there is also likely to be stigma around young men seeking publicly available counselling or therapy (Shafer \& Wendt, 2005, p. 105). Instead, young men may offload emotional stress onto girlfriends or female peers, as doing so keeps their struggles within the private, rather than public sphere. This therefore helps them to avoid potential ridicule (or fear of ridicule) from other men. According to this interview participant, this can result in the heightening of the "caretaker" role of young women, adding to other academic, social and gendered pressures they may experience.

Further research into staunchness within people's experiences of gender would do well to focus energy towards understanding how staunchness is experienced and perceived by young Kiwi men. 'Bro culture' as a framework for theorising New Zealand masculinity also requires further historical and situational conceptualisation to account for how young men of diverse genders, ethnicities, sexual orientations, ages and abilities perceive and interact with it. Understanding men's experiences of masculine pressures in a multi-faceted and ongoing way is a crucial first step towards transcending the binary meaningfully for men and masculine people. It is essential to note the ruptures and lines of flight which are also made by young men who behave subversively in relation to the archetypical hardened 'Kiwi bloke' manhood described by participants. This was hinted at in the fourth interviewee's discussion about young men who outwardly express fondness and affection for their male friends, with no apparent concern for accusations of being less manly in doing so (see page 44). Exploring these sorts of observations further is imperative for documenting complexities in resistance to the status quo among young people, which would give critical feminist theorists greater insight to the ways in which ruptures are taking place. Noting the ways in which resilience, subversion and moments of deterritorialization are taking place avoids painting the picture of staunchness as nothing but problematic for New Zealand's gendered culture, and provides critical feminist researchers with wide and nuanced understandings of what emancipatory social change can look like.

\subsection{Unpacking 'Victim' Identity}

Describing the various meanings and significance of staunchness as a concept enables me to consider how victimisation is implicated in this. According to Stringer (2014, p. 18), there has been a tendency over the last two decades for some popular feminist accounts of women's liberation from sexism to strongly, and at times disdainfully, refuse to conceptualise the suffering of women as a marginalised group as victims. These accounts, albeit with some points of difference, convey a dichotomy between an individual-focused empowerment feminism and a "resentment" or victim-centred feminism (scholars who refer to and construct this dichotomy in their work include Sommers, 2000, Roiphe, 1993, and Paglia, 1994). The former, as critically 
summarised by Stringer (2014, p. 21), assumes that patriarchy in the West is "dying", therefore assuming that feminism focused on structural change is no longer relevant for already liberated women. This discourse, which has resonance with McRobbie's (2004, pp. 256-257) and Gill's (2007, pp. 148-150) descriptions of postfeminist sensibilities, conceptualises women as capable agents who are empowered through equal opportunity to participate in a free-market workforce and social institutions (and by extension, a society supposedly "free" of real gender inequality).

On the other hand, victim-feminism is constructed by proponents of this dichotomy as an ideological fiction of ongoing structural inequality where women are encouraged to buy into a 'myth' of dominant masculine values which subordinate them, and to wallow in their victimhood to a never-ending patriarchy (Stringer, 2014, pp. 22-23; Mardorossian, 2002, pp. 748-750). This dichotomy is evidently critiqued by Stringer and other scholars (see Van Dijk, 2009; Katz \& Rich, 2017; Mardorossian, 2002), for the ways in which it blurs the distinctions between critical feminist perspectives which explore victimhood through describing them with the umbrella term 'victim-feminism'. Significantly in this discussion, there are overlaps between the insistence of women as staunch, empowered, rational individuals within the literature, and the pervasiveness of neoliberal victim theory which I introduced in Chapter 4: The Gender Binary and "Bro Culture". In her critique of Paglia's polemic arguments against collectivefocused feminism in favour of 'feminist' discourse which emphasises personal responsibility, hooks (1994, p. 86) maintains that this dichotomy, both in academia and in popular culture, ignores all the qualities and experiences that feminists can have. According to hooks (1994, pp. 86-87), feminists should not be theorised in a one-dimensional way, and there needs to be greater accounting for how personal responsibility, oppression and victimisation can all co-exist in people's lives. Recalling Trnka and Trundle's (2017) argument, imperatives to care for others might also play a crucial role here.

Neoliberal victim theory is formed via citizens' heightened personal responsibilities under neoliberal governance (Stringer, 2014, p. 40). Sympathy for victims of stalking, as one participant experienced, or other forms of sexual violence is "eroded" via a popular perception that individual "agency is a mandate, even for the powerless" (Katz \& Rich, 2017, p. 79). BayCheng (2015, p. 286) argues that there is no acceptance of personal failure under the logic of neoliberal social hegemony. In this way, neoliberal victim theory is defined as "a victim-blaming conception of victimisation as subjective and psychological rather than social and political" (Stringer, 2014, p. 9). Victims are regarded as having personality which are "incompetent at managing risks and avoiding negative outcomes" (Stringer, 2014, p. 9; Katz \& Rich, 2017, p. 79). The construction of victim-identity in a society which is largely organised by the logic of 
neoliberal self-governance in part results from this shift. As I mentioned earlier, with reference to common dualistic interpretations of 'victim' as either "compliant" or one who is playing the victim, it is implied that people who self-identify as a victim are socially deviant, and their narrative is pathologised as fraudulent or power-seeking (Stringer, 2014, pp. 10-11). The pervasiveness of these representations of victims, according to the logic of neoliberal victim theory, should be of critical concern to scholars in this area because of how it makes invisible the social conditions which enable suffering. Removing focus on structural, institutional and cultural discourses also removes the ability to "explain suffering sociologically", meaning that notions of personal responsibility and pressure to be 'staunch' must become areas of scrutiny in this research field (Stringer, 2014, p. 41).

Pathologising victims' experiences is not new. There is a strong moral mandate for individuals to demonstrate power and success, and blaming victims is a historically documented "well known defence mechanism" from those comprehending others' victimisation (Ryan, 1971 as cited in Van Dijk, 2009, p. 13). The status quo is maintained whereby "we prefer to avert our eyes from those who persist in reminding us of the wrongs they have suffered...[they] are disturbers of the peace; we wish they would take their memory away to a church, a cemetery, a psychiatrist's office" (Jacoby, 1983, as cited in Van Dijk, 2009, p. 13). Van Dijk (2009, pp. 13-14) and Katz and Rich (2017, pp. 79-80) both cite Lerner's (1980) 'Just World Hypothesis' for explaining ongoing blame of victims; where blame is used by dominant groups to "reassure" themselves that they live in a just world, and that experiences which contradict this can be put down to the ineptitude of individuals. There is similarity in the critical language deployed in this literature to that of Oakley's (1981) argument for the necessity of feminist research in the academy. It demonstrates that what is perceived as a just world" by the dominant groups that this research concerns, is our gendered culture underpinned by hegemonic masculine values.

Neoliberal victim theory represents victim identity in a way which determines societies' perceptions of victims and perpetrators. Women are perceived as victims of men's harmful behaviour (Stringer, 2014, p. 10). Within this binary, there does not appear to be space for conversation about men's experiences as victims, apart from in the context of reversing who the "real victims" are when victims are regarded as defaming the character of (male) perpetrators, and attempting to destroy their reputation (Stringer, 2014, p. 11). The dualistic representation of victim identity builds a construct of victims which is far removed from lived realities.

Reifying gender as a binary through neoliberal victim theory's constructions of victims as either deserving or undeserving also may contribute to the silencing of oppression and violence experienced by members of LGBTQIA+ communities. There appears to be no representation of LGBTQIA+ people within the typical gendered narratives of constructions of 
victims. In this research, young people who identified as LGBTQIA+ were often anxious to appear as successful in their consolidation of their non-heteronormative identity. It appeared that publicly acknowledging experiences of oppression was not an option for these young people, because doing so might demonstrate they were failing to enact personal responsibility and staunchness. This forms an important area for further empirical research; understanding how members of the LGBTQIA+ community perceive, navigate and experience victim identity in the context of pressure to be seen as staunch and individually empowered.

Some discussion about resilience from the fifth interview transcript has remained significant for thinking about these ideas throughout analysing the findings in this project. The interviewee noticed in her counselling experience that substantive resilience among young people can come through learning that they are different to their peers, by adopting a nonheterosexual or gender-non-conforming identity. From here, they perceive the world from an external "outsider" position in addition to their usual participation in social life. They may have insightful observances about what would need to change in order for oppression or inequality to be reduced. Further, it is through adults' understanding and acknowledgement of these young peoples' knowledgeable positions that can foster student-led community development initiatives such as the Day of Silence.

Considering more closely how vulnerable people and victims have epistemic agency through their experiences of oppression is integral to developing complex and rich theory and activism. In this context, this involves troubling the underpinnings of New Zealand's gendered culture, in its current manifestation of staunchness and individualist values akin to neoliberal governance. The dichotomising of victims and agents within some scholars' simplistic criticism of so-called victim-feminism, and the dualistic conceptions of victims of neoliberal victim theory reinforce normative views of femininity and masculinity. In this study, it appears that part of the lived reality of marginalised groups, particularly members of the LGBTQIA+ community, substantively resists against being framed in this dichotomy. Thinking about the ways in which these people possess valuable knowledge about the nature of oppression, social interactions and dominant discourses, dichotomising and harmful ideas about victims are deconstructed. Through engaging with this deconstruction, we will be able to begin formulating an alternative reading of victimisation.

\subsection{Thinking about Community}

Following my brief description of some of the issues with critical feminist researchers' engagement with the concept of friendship in Chapter 3: Methodological Framework, I proposed that 'community' was a more suitable term to describe the relationship I had as a researcher 
with my participants over the course of this project. I justified this with the fact that we all broadly shared an interest in the research topic, and viewed gender norms in a particular way (as binary, oppressive, hierarchical and imbued with cultural meaning specific to New Zealand). To be consistent with this, I am giving my participants access to a summary of the research findings, so they can continue considering these ideas from our conversations with their peers and colleagues and in their schools and workplaces.

Many of my participants identified belonging to a community through the ways in which they spoke about the young people they support, the peers they interact with on a daily basis, or the ways in which they, as young people, communicate with the adults around them about their needs. I draw on the concept of an "imagined community" where members "will never know most of their fellow-members, meet them or even hear of them, yet in the minds of each lives the image of their communion" to think about the ways in which my participants spoke about their communities (Anderson, 2006, p. 6). Their communities were both broad and localised, and defined through some form of shared identity. The broadness of the participants' imagined communities was "inherently limited" because of the specific attention on New Zealand's gendered culture in this study (Anderson, 2006, p. 7). This was implied through generic verbal gestures to others who shared some common-ground with the participants, which might have encompassed attending the same school, but could also simply refer to other New Zealanders. For example, broader imaginings of community happened when participants referred generally to people in wider society expressing dominant attitudes about bro culture, or made comments about the effects of the values of this culture on non-specific individuals. More specific situated imaginings of community took place when participants described the experience of interacting with others during educational workshops, such as Loves-me-not and Day of Silence, and considered the impacts of expanding these initiatives in different schools where student-led education may not be so easy to implement in a supported way.

Sometimes, communities are politically established "by the style in which they are imagined" (Anderson, 2006, p. 6). Through shared experience as LGBTQIA+ for example, some members used the term "rainbow community" to refer to others who identify along LGBTQIA+ lines within New Zealand. In this respect, the rainbow community appeared to encompass LGBTQIA+ people across New Zealand, not all of whom the participants will have met before. Their shared experience as outsiders to heteronormative gendered culture enables the term 'rainbow community' to refer to an imagined community which holds specific meanings and identities. More specifically, there are imagined communities for each identity within and beyond what is included the 'LGBTQIA+' acronym. For example, three of my participants identified as asexual, and another three identified as non-binary. When they referred to their 
experiences, they spoke about wanting change in their schools and in education generally to be more inclusive of others who shared their identities.. This indicated their solidarity with and concern for the wellbeing of others whom they had not necessarily met, which showed the political character of their communities to seek social change that reached out beyond their own schools and immediate networks.

Most participants valued the support of their closer communities as imperative for fostering empathy for experiences of diversity and marginalisation. The first interview participant who was the founder of InsideOUT sought to tackle the issue of femmephobia within the rainbow community through challenging toxic masculinity internalised by masculine LGBTQIA+ people. But she also saw femmephobia as implicated within a system of structural discrimination against women, femininity and femmes in Aotearoa New Zealand. What could be perceived as an inter-community issue may also come from hegemonic discourses about gender from the wider imagined community. Multiple interview participants spoke about community development approaches for current and future educational initiatives for young people which may make a long-term and substantive impression on their social learning about relationships. Staff, students, parents, external educators, counsellors and police were all involved, depending on the programme. Most focus group participants endorsed these initiatives. Some wanted more out of them, like more discussion of non-heteronormative relationships and friendships.

It is clear that for substantive social change to take place, members of both local and wider communities need to be engaged. Dominant cultural discourses obviously do not change overnight, but there are steps which can be taken and are already being taken to challenge New Zealand's gendered culture, and construct inclusive alternatives. Change can be sought through policy and leadership roles within schools and across Aotearoa New Zealand to re-frame how we understand gender, staunchness, responsibility and relationships as influential social organising principles in people's lives. The protest earlier this year was a real-life example of critical feminist activism bringing sexual violence, typically considered a private, individuallyexperienced issue, to public conversation. The young people collectively demonstrated intolerance for the violence shown toward women in the online comments advocating rape, demanding not only accountability from the commenters but also envisioning critical questioning of the gendered status quo.

Researchers should value communities as endowed with potential to seek social change. Individual participants were both distinct from and tied to their communities. To overemphasise the hegemony of individualism in New Zealand's gendered culture would be to overlook how people identify as members of communities at the same time as, and in contrast to, the self-focused pressures about their own performances of gender. Sharon Hays (1994, p. 
61) notes that "structures not only limit us, they also lend us our sense of self and the tools for creative and transformative action, and thereby make human freedom possible". In the context of this research, the social stratification of the gender binary and its manifestation in cultural discourses about staunchness do not necessarily mean that people identify as oppressed and powerless to this imperative at all times. Rather, the experience one might have of powerlessness, or victimisation can enable them to recognise and push beyond the boundaries of "language....what is possible to think and how it is possible to think it" (Hays, 1994, p. 61).

While maintaining a critical eye on hegemonic gendered discourses is essential, critical feminist theorists could look further into the ways in which community action complicates these discourses. Community has appeared to be a significant concept here, because of the researcher relationship I have with my participants, and because of the ways in which the participants talked about gender norms and expressions of resistance in their own lives and experiences. There are multiple aspects of this research which open up more important questions to be asked about how people navigate and subvert New Zealand's gendered culture. 


\section{Chapter 8: Conclusion}

Motivated by the perspective that there needs to be greater theoretical understanding of young people's views and experiences of gender norms and relationships, I propose ongoing scholarly inquiry into individualised and collective notions of being staunch in relation to expressions of gender. I presented and analysed some of my key findings, which I gathered through interviewing professionals who support young people and facilitating focus groups with young people. The data has been categorised in three key themes to consider the myriad ways in which my participants' views and experiences of New Zealand's gendered culture contribute to knowledge on this area. I argue that focus should be maintained on staunchness as a cultural imperative, and what this imperative might mean for New Zealanders' ability to transcend an oppressive gender binary. In this final chapter, I summarise the preceding chapters, further noting the ways in which the data extends on and diverges from theory. I then highlight essential areas requiring further research and provide brief commentary on some recommendations for policy focus. Finally, I make some concluding comments about the extent to which the research journey has enabled me to meet my initial research aims and critical perspective.

\subsection{Summary}

In Chapter 2: Theoretical Framework, I briefly discussed the sociological conceptualisation of New Zealand society as shaped by what James and Saville-Smith (1994, pp. 11-12) term a gendered culture. I have adopted this concept in my discussion throughout the thesis as a heuristic device for thinking broadly about the ways in which hegemonic gender values are embedded in everyday interactions and institutions. This established some background context for thinking about New Zealand's gendered culture and the implications of it for young people's relationships. I discussed idealised expressions of gender in literature on postfeminism and considered salient issues for less powerful young people in New Zealand classrooms; illustrating the harms of a gendered culture for enabling bullying or sexual violence through pressure on some young people to remain silent about these issues.

In Chapter 3: Methodological Framework, I unpacked what I mean by 'critical feminist research' and described how I engage with this. Extending on Oakley's (2016, p. 209) work on feminist methodology, I framed my relationship with participants as part of a community. I commented on cultural conceptualisations of feminism, and my research journey and experience. Before describing my use of Braun and Clarke's (2006) guide to thematic analysis for organising and analysing research data, some personal and practical limitations of the project were considered too. 
In Chapter 4: The Gender Binary and 'Bro Culture', Chapter 5: Pressures and Responsibilities and Chapter 6: Healthy Relationships, I presented some of my richest findings. Staunchness as a key concept for characterising New Zealand's gendered culture stood out as significant for subsequent unpacking in Chapter 7: Discussion of Findings. This was discussed with respect to dominant perceptions of victims of harassment or violence. In Chapter 5, I identified the feminisation of personal responsibility with regard to how heightened emphasis on individual empowerment is implicated in staunchness. Adding another layer to this, I also presented findings which demonstrate the accountability of young LGBTQIA+ people to educate others and to be seen as 'successful' in maintaining non-heteronormative relationships. In Chapter 6, I comment on the ways in which my participants critique and extend on what the term 'healthy relationship' is thought to encompass; analysing how various educational initiatives respond to their needs.

In Chapter 7: Discussion of Findings I elaborate on the significance of the concept of being staunch from a critical feminist perspective, and critique dominant constructions of victims, drawing on neoliberal victim theory. I observed the value of community in young people's lives, with their friends, peers, adults around them, and wider New Zealand society. I drew on a protest against rape culture to think about how community action challenges harmful manifestations of gender norms. In this way, the relationship participants had with one another and with me as a researcher complicates Bauman's (2007, p. 3) assertion that there is no longer a tangible sense of community and instead there are just "random" networks of individuals in neoliberal societies. Further, while the pervasiveness of neoliberalism as a social hegemony is relevant for conceptualising individualised discourses of staunchness within a gendered culture, it may not fully account for the ways in which personal responsibility can carry motives beyond the self. The ways in which young people take initiative to educate others, whether individually or with a supportive network behind them, also demonstrates their recognition of the impact of their interactions with others in their community. These actions are also arguably motivated by a desire to make meaningful connections with others. I considered this in the context of Andersen's (2006) concept of 'imagined communities', where solidarity is realised by young people through shared intolerance to misogyny - as evidenced through young people's collective response to leaked online comments endorsing the rape of young women.

\subsection{Suggestions for Further Research}

In the previous chapter, I made the case that critical feminist researchers and sociologists in this area should further probe what it means for young people to negotiate the hegemony of staunchness in everyday life in Aotearoa New Zealand, with the aim to more fully theorise the concept. There will be myriad, and possibly contradictory ways in which 
staunchness can be thought about which my project has not accounted for. While some young people might internalise the imperative to be staunch and come to expect similar behaviour from their peers, my conversations with some of the participants in this project suggested that through identifying attitudes of staunchness as associated with bro culture, the social pressure to be staunch was identified as such and critiqued.

In turn, I argued that understanding how young people experience and navigate victim identity is essential for critical feminist theorists. Gender norms in New Zealand appear to carry significant attachment to notions of staunchness and to be a victim is vilified within these discourses. Not only would unpacking the ways in which people perceive victimisation help scholars to understand and theorise experiences of gender norms and the hegemony of staunchness closely, this focus pushes the boundaries of conventional feminist conversations about empowerment.

My focus has largely been on the experiences of young women and normative femininity. This is due in part to the literature I have focused on, the fact that more of my participants identified with feminine and non-binary identities rather than masculine identities, and the fact that feminist research tradition tends to focus on issues particularly salient in women's lives. I do not have the capacity here to give adequate attention to how young men are implicated in notions of staunchness - as part of 'bro culture' and victimisation, and how masculinity is being subverted by some young men. Given that many participants pointed to the poor mental health experienced by many young men in New Zealand, and to the fact that young men at single-sex schools may be more likely to miss out of sexual violence prevention programmes, it is important that their experiences are documented more closely in future research on this area.

One direction this can take is to look at how young men resist the status quo, whether in explicit ways or through subtle ruptures in their daily interactions. Recognising and theorising these forms of resistance could help disempowered young men continue challenging harmful tropes of bro culture. A participant in Edley \& Wetherell's (1997, p. 210) study felt at odds with "macho" masculinity and positioned himself as a "pacifist wimp" compared to confrontational and violent men. When asked to elaborate on this self-identification with the term "wimp", he had no qualms about describing his tendency to avoid conflicts with other men, perceiving himself as "physically less able". Complicating this, he noted that perhaps he is not a wimp after all, because he clarified “I don't think I'm mentally weak as in I can't stand up for myself verbally" (Edley \& Wetherell, 1997, p. 211). In this way, the participant identifies as both resisting violent hegemonic masculinity yet conforming to it in a different way where toughness is exhibited through mental and verbal capacity. The ability to capture this complexity in further 
research with young masculine people is essential as it paints a richer picture of the nature of hegemony and gives insight into subtle exercising as well as subverting of power.

It is equally salient to undertake further research on the experiences exclusively of people who identify with different identities covered and beyond the LGBTQIA+ acronym. While actions to disestablish heteronormativity within the institution of education would be beneficial for all young people, it is also useful to focus on the views and experiences of those who identify in a particular way. McAllum's (2014) research with young women who identify as bisexual does this well, by elucidating the ways in which bisexual perspectives, among others that do not conform to heterosexual or homosexual, are routinely dismissed and marginalised in school cultures. This was also highlighted by three members of the same focus group identifying as asexual, who felt that their identities are not accounted for in current relationship education. They described feeling stressed about not wanting to engage in intercourse, and what this could mean for their romantic relationships. This extends on Allen and Quinlivan's (2016, p. 124) argument that diverse understandings of relationship characteristics need to more fully inform the delivery of these lessons. Doing further research with young people who identify as asexual on their views about this education would shed light on how greater inclusivity can be fostered.

One participant's comments about the pervasiveness of social media in Chapter 6: Healthy Relationships also raises a key area for ongoing research focus. The online world is a significant space where young people consolidate and navigate gender norms. Discourses about staunchness in social media spaces and in relation to popular culture are undoubtedly influential for young people. Not only does online media constitute a sphere of influence, it can also be a central space for communication, education and resistance against the status quo. Studying social media activism is useful for extending on theorising on community through solidarity among oppressed groups, as Rentschler (2017, p. 571) argues. Further, pornography is largely accessible online and can be a key site of learning for young people as its tropes influence the sexualisation of other media that young people consume (Gill, 2012, p. 736; Baker, 2016, p. 214). While sociologists do undertake interdisciplinary research in this area, gender discourses in popular culture and media is conventionally researched by media studies, cultural studies and social psychology scholars (McRobbie, 2015; Gill, 2016; Tasker \& Negra, 2007; Jackson \& Vares, 2015; Gavey, 2012). In this thesis, my focus has been on understanding contemporary manifestations of New Zealand's gendered culture as articulated in societal realms. I have not had the space to analyse these key sites where gender norms are articulated, but I hope to be able to look into these in future research.

As I discussed earlier, a limitation of my project is that I did not cover a broad geographic or socio-economic context. If researchers can access private, religious or integrated 
schools, it would be highly beneficial to speak with educators, counsellors and students in these schools about how they navigate gender norms and relationships. These schools typically get constructed as morally conservative institutions through being unsupportive of gender and sexuality diversity. What may be missing from this narrative is whether and how students in these schools (or their support staff) subvert the status quo, despite possibly tighter restrictions on what kind of gender or sexual identities are accepted in the school. As an interview participant noted, an educational outlook imbued with the principles of hauora is deemed a "privilege", as some schools are apparently much slower than others to implement the revised guidelines on sexuality education.

Further research should reach lower socio-economic schools and those outside of the city too. Gender norms are likely to hold different meanings within contexts where there may be more deprivation and/or poverty. It was not practical for me to get to these schools due to transport limitations. However, I hope to continue this research with a more specific focus on lower decile schools in the future. Accessing different sorts of schools may also enable researchers to work with schools to recommend steps the school could take to better value the voices of its students and centre hauora principles through effective initiatives appropriate to the school's culture.

In December 2017 I took part in an introductory workshop on teaching young people about negotiating consent. We learnt about the educational objectives of teaching young people of different ages. Paired with another attendee, we simulated a session from the Mates \& Dates syllabus, and other people at the workshop pretended to be the students we were delivering to. Both exercises provided some insight into the myriad task management skills of educators when facilitating these sessions. Not only do educators need to deliver the prepared session and ensure good time management in carrying it out, they have to continuously engage with the class to make sure everyone is participating, be able to address any potentially disruptive or unrelated conversations, and be equipped with the skills to listen to and assist students who make disclosures of sexual abuse. While delivering these sessions might become easier over time, there is hefty responsibility on the shoulders of these educators. The workshop leader described the work as "challenging" and "full-on", yet "rewarding". It would be useful to ask professionals and educators, like those who participated in this study, how they manage the multiple responsibilities they seem to be endowed with. This could shed light on whether they feel they need greater support from schools and, if so, what forms this support could take. 


\subsection{Recommendations}

While my research focus here has been largely theoretical in relation to conceptualising New Zealand's contemporary gendered culture in a complex way, there are some general recommendations that can be made for broad or local policy in this area. Because my findings are complex and non-conclusive, making policy recommendations is not straightforward. Equally, because I am only dealing with the findings of one study, my suggestions are modest. However, in the tradition of critical feminist research, it is essential that I consider my participants' insights with a view to enact positive social change. Accordingly, I suggest four interventions that could be considered by policy analysts and researchers for government departments, particularly the Ministry of Education, and by staff and students to incorporate within schools.

Firstly, as mentioned earlier, Beres (2017a, p. 2) has argued that teaching about consent in its own right does not "fully address the ways in which sexual behaviour is socially constructed". Teaching in this area needs to accompany a focus on the wider gendered culture around young people, and greater awareness of the interrelated nature of gender norms and negative relationships and sexual experiences. Effective approaches to reducing sexual violence are gender-transformative; that is, attention is given to gender norms and how these can normalise or mystify sexual violence (Beres, 2017b, p. 10). In a classroom, it would be useful to introduce these norms as they exist in small everyday manifestations, as well as more broadly. Schools committing to inclusive, emancipatory values which deconstruct hegemonic gender norms across the wider school environment would be a substantive and meaningful approach. This can take place in myriad ways; through professional development training for staff (SAPN offer programmes for adults and bystanders), reviewing class resources for their representation of gender and sexuality, and having mixed gender classes and groups for all activities.

Secondly, Beres (2017b, p. 10) endorses ACC's 'Mates \& Dates' programme because it is informed by international evidence of effective sexual violence prevention programmes and input from young people and their families and communities. The significance of engaging with the community to inform the construction of this programme is key here. Ongoing and increasing government funding, and regular reviews and revisions to this programme, are also necessary to maintain its relevance and educational potential. Extending on this, it was pleasing to see SAPN create their own resources for the sessions they carry out, and gather feedback about them, to ensure that they are culturally and socially relevant and inclusive of a wide range of young people. 
Thirdly, for the purpose of strengthening community support, continual efforts are needed to implement the concept of hauora into education about understanding gender norms and relationships. Both students and staff of schools who organised a hauora day or implemented the tikanga of hauora throughout their curriculum saw positive impacts on year groups in gaining more knowledge on the interrelated nature of gender, sexuality, relationships and wellbeing. There are certainly ways in which this initiative could be expanded on. One example which stood out from this project was students' reported need for in-class conversations about healthy relationships to include friendships as well as romantic relationships. This was especially significant given the focus on community development in a hauora approach to education. Valuing friendships in this way would not only would strengthen the position of bystanders and the social network around intimate relationships, but may also help to counteract the presence of a heterosexual matrix, the gender normativity implied within this, and general social pressure to enter into a relationship at high school.

Fourthly, Beres (2017b, p. 15) has noted that while schools can do a great deal to establish a safe environment for young people, wider community involvement in their development is also helpful. She references the anti-domestic violence campaign 'It's Not OK', which engaged communities through getting them to put forward local "champions" to advocate for non-violent communication in relationships. These champions are not necessarily famous individuals; they have involved "a group of secondary school students from the Clutha region" for example (Beres, 2017b, p. 15). Initiatives like this could potentially involve a diverse range of young people from this region. This would not only extend on student-led educational approaches within schools to affect wider communities, it could also be a useful way to realise Connell's (2005b, p. 1807) point about constructing "positive" hegemonies of gender, if the campaign is articulated in ways which reflect on and critique normalisation of harmful discourses through behaviour and attitudes of the dominant group (Oakley, 1981, p. 39).

\subsection{Concluding Comments}

According to many participants, gender norms constitute a significant and central part of young people's lives; echoing James \& Saville-Smith's (1994, p. 14) claim that gender is a distinct organising principle of social life in New Zealand society. The young people described myriad pressures to conform to gender normative ideologies; I focused on this with particular attention to the imperative to exercise 'staunchness' as a way of demonstrating liberation from oppression. The aspect of care for others and desire to build meaningful connections with others appeared to underpin some of the motivations behind being a responsible neoliberal subject. These were touched on in order to convey a more complex picture of theorising contemporary manifestations of a gendered culture and for thinking about community 
solidarities, action and resilience. The scrutiny of victims also highlighted an enormously significant area for critical feminist attention. Documenting victims' experiences of a gendered culture may begin to respond to Stringer's (2014, pp. 159-160) call for developing a more nuanced and reflexive account of victimisation for feminist theory - where victim identities are "reclaimed" as resilient, meaningful and radical.

This research has provided platforms for further scholarly and policy-focused thought. Undertaking this project has enabled me to contribute to knowledge in this area through offering some insights about the significance of staunchness, victim identities and the importance of communities for the context of Aotearoa New Zealand's gendered culture. I hope to pick up on some of these key areas in future critical feminist research, to continue thinking about emancipatory social change. 


\section{References}

Allen, L. (2005a). Sexual Subjects: Young People, Sexuality and Education. Hampshire: Palgrave MacMillan.

Allen, L. (2005b). 'Say everything': exploring young people's suggestions for improving sexuality education. Sex Education, 5(4), 389-404.

Allen, L. (2007). Doing 'it' differently: relinquishing the disease and pregnancy prevention focus in sexuality education. British Journal of Sociology of Education, 28(5), 575-588.

Allen, L. \& Quinlivan, K. (2016). A Radical Plurality: Re-thinking Cultural and Religious Diversity in Sexuality Education in Aotearoa, New Zealand (pp. 115-129). In V. Sundaram \& Sauntson, H. (Eds.), Global Perspectives and Key Debates in Sex and Relationships Education: Addressing Issues of Gender, Sexuality, Plurality and Power. Hampshire: Palgrave MacMillan.

Anderson, B. (2006). Imagined Communities: New Edition. London: Verso.

Andrewes, F. (1999). The Man in the Grey Flannel Suit: White-Collar Masculinity in Post War New Zealand (pp. 191-212). In Daley, C. \& Montgomerie, D. (Eds). The Gendered Kiwi. Auckland: Auckland University Press.

Baker, K.E. (2016). Online pornography - Should schools be teaching young people about the risks? An exploration of the views of young people and teaching professionals. Sex Education, 16(2), 213-228. doi:10.1080/14681811.2015.1090968

Baum, B. (2015). Decolonizing Critical Theory. Constellations, 22(3), 420-434. doi:10.1111/1467-8675.12169

Bauman, Z. (2007). Liquid Times: Living in an Age of Uncertainty. Cambridge: Polity Press.

Bay-Cheng, L. Y., Livingston, J. A. \& Fava, N. M. (2011). Adolescent Girls' Assessment and Management of Sexual Risks: Insights from Focus Group Research. Youth and Society, 43(3), 1167-1193. doi:10.1177/0044118X10384475

Bay-Cheng, L.Y. (2015). The Agency Line: A Neoliberal Metric for Appraising Young Women's Sexuality. Sex Roles, 73(7), 279-291. doi:10.1007/s11199-015-0452-6

Belich, J. (2007). Making Peoples: A History of the New Zealanders From Polynesian settlement to the end of the nineteenth century. North Shore: Penguin Books.

Beres, M. \& Farvid, P. (2010). Sexual Ethics and Young Women's Accounts of Heterosexual Casual Sex. Sexualities, 13(3), 377-393. doi:10.1177/1363460709363136

Beres, M. (2014). Rethinking the concept of consent for anti-sexual violence activism and education. Feminism \& Psychology, 24(3), 373-389. doi:10.1177/0959353514539652

Beres, M. (2017a). What does faking orgasms have to do with sexual consent? Sexualities, 0(0), 1-4. doi:10.1177/1363460717708151

Beres, M. (2017b). Preventing adolescent relationship abuse and promoting healthy relationships. New Zealand Family Violence Clearinghouse, 12, 1-21. Retrieved from https://nzfvc.org.nz 
Braun, V. \& Clarke, V. (2006). Using thematic analysis in psychology. Qualitative Research in Psychology, 3(2), 77-101.

Brickell, C. (2012). Men Alone, Men Entwined: Reconsidering Colonial Masculinity. Journal of New Zealand Studies, 13, 11-33.

Brown, W. (2006). American Nightmare: Neoliberalism, Neoconservatism, and De Democratization. Political Theory, 34 (6), 690-714.

Budgeon, S. (2011). The Contradictions of Successful Femininity: Third-Wave Feminism, Postfeminism and 'New' Femininities (pp. 279-292). In Gill, R. \& Scharff, C. (Eds). New Femininities: Postfeminism, Neoliberalism and Subjectivity. Hampshire: Palgrave MacMillan.

Bunkle, P. (1980). The Origins of the Women's Movement in New Zealand: The Women's Christian Temperance Union 1885-1895 (pp. 52-76). In Bunkle, P. and B. Hughes (Eds.) Women in New Zealand Society. Sydney: George Allen \& Unwin.

Butler, J. (1990). Gender Trouble: Feminism and the Subversion of Identity. New York: Routledge.

Campbell, H. (2000). The Glass Phallus: Pub(lic) Masculinity and Drinking in Rural New Zealand. Rural Sociology, 65(4), 562-581.

Clarke, J. (2001). Sex Education in the New Zealand Primary School: A tangled skein of morality, religion, politics and the law. Sex Education, 1(1), 23-30.

Connell, R.W. (2005a). Masculinities: Second Edition. New South Wales: Allen \& Unwin.

Connell, R.W. (2005b). Change among the Gatekeepers: Men, Masculinities, and Gender Equality in the Global Arena. Signs, 30(3), 1801-1825.

Connell, R.W. \& Messerschmidt, J.W. (2005). Hegemonic Masculinity: Rethinking the Concept. Gender \& Society, 19(6), 829-859.

Cuklanz, L. M. (2000). Rape on Prime Time: Television, Masculinity, and Sexual Violence. Philadelphia: University of Pennsylvania Press.

Davis, K. (2007). Reclaiming women's bodies: Colonialist trope or critical epistemology? The Sociological Review, 55(1), 50-64. doi:10.1111/j.1467-954X.2007.00692

Department of Education. (1977). Report of the Committee on Health and Social Education, Growing, Sharing, Learning. Wellington: Department of Education.

Deleuze, G. \& Guattari, F. (1987). A Thousand Plateaus: Capitalism and Schizophrenia. Minneapolis: University of Minnesota Press.

Dobson, A.S. (2014). “Sexy” and “Laddish” Girls. Feminist Media Studies, 14(2), 253-269.

Duncombe, J. \& Jessop, J. (2002). 'Doing Rapport' and the Ethics of 'Faking Friendship' (pp. 107 122). In Mauthner, M., Birch, M., Jessop, J. \& Miller, T. (Eds). Ethics in Qualitative Research. London: Sage Publications.

Elliot, S. (2014). “Who's to Blame?” Constructing the Responsible Sexual Agent in Neoliberal Sex Education. Sexuality Research and Social Policy, 11(3), 211-224.

doi:10.1007/s13178-014-0158-5 
Fenwick, P. (1980). Fertility, Sexuality and Social Control over Women in New Zealand (pp. 7798). In Bunkle, P. and B. Hughes (Eds.) Women in New Zealand Society. Sydney: George Allen \& Unwin.

Fereday, J. \&. Muir-Cochrane, E. (2006). Demonstrating Rigor Using Thematic Analysis: A Hybrid Approach of Inductive and Deductive Coding and Theme Development. International Journal of Qualitative Methods, 5(1), 80-92.

Finch, J. (1984). 'It's great to have someone to talk to': The ethics and politics of interviewing women (pp. 70-87). In Bell, C. \& Roberts, H. (Eds.) Social Researching: Politics, Problems, Practice. London: Routledge.

Fine, M. \& McClelland, S. (2006). "Sexuality education and desire: Still missing after all these years". Harvard Educational Review, 76(3), 297-338.

Fraser, N. (1987). What's Critical about Critical Theory? (pp. 31-55). In Benhabib, S. \& Cornell, D. (Eds). Feminism as Critique. Cambridge: Polity Press.

Gavey, N., McPhillips, K. \& Braun, V. (1999). Interruptus Coitus: Heterosexuals Accounting for Intercourse. Sexualities, 2(1), 35-68.

Gavey, N. (2012). Beyond 'Empowerment'? Sexuality in a Sexist World. Sex Roles, 66, 718-724. doi:10.1007/s11199-011-0069-3

Genz, S. \& Brabon, B. (2009). Postfeminism: Cultural Texts and Theories. Edinburgh: Edinburgh University Press.

Gill, R. (2007). Postfeminist Media Culture: Elements of a Sensibility. Cultural Studies, 10(2), 147-166. doi:10.1177/1367549407075898

Gill, R. (2012). Media, Empowerment and the 'Sexualisation of Culture' Debates. Sex Roles, 66(11), 736-745. doi:10.1007/s11199-011-0107-1

Gill, R. (2016). Post-postfeminism?: new feminist visibilities in postfeminist times. Feminist Media Studies, 16(4), 610-630. doi:10.1080/14680777.2016.1193293

Hammersley, M. \& Traianou, A. (2012). Ethics in Qualitative Research: Controversies and Contexts. London: Sage.

Haraway, D. (1991). Simians, cyborgs, and women: the reinvention of nature. London: Free Association Books.

Harris, A. \& Dobson, A. S. (2015). Theorizing agency in post-girlpower times. Continuum, 29(2), 145-156. doi:10.1080/10304312.2015.1022955

Harvey, D. (2005). A brief history of neoliberalism. Oxford: Oxford University Press.

Hays, S. (1994). Structure and Agency and the Sticky Problem of Culture. Sociological Theory, 12(1), 57-72.

Hennessey, R. (1994). Queer Theory: A Review of the "Differences" Special Issue andWittig's "The Straight Mind". Signs, 18(4), 964-973.

Herman, D. (1984). The Rape Culture. In Freeman, J. (Ed.) Women: A FeministPerspective. California: Mayfield. 
Hesse-Biber, S.N. (2007). Feminist Research: Exploring the Interconnections of Epistemology, Methodology, and Method (pp. 2-26). In S.N. Hesse-Biber (Ed.) Handbook of Feminist Research: Theory and Praxis. California: Sage Publications.

hooks, b. (1994). Outlaw Culture: Resisting Representations. New York: Routledge.

Humpage, L. (2017). The Land of Me and Honey? New Zealand Society under Neoliberalism (pp. 121-133). In Bell, A., Elizabeth, V., McIntosh \& M. Wynyard (Eds.) A land of milk \& honey? Making sense of Aotearoa New Zealand. Auckland: Auckland University Press.

Hutchings, J. (2005). Mana wahine me te raweke ira: Maori feminist thought and genetic modification. Women's Studies Journal, 19(1), 47-65.

InsideOUT. (2017). Day of Silence. Retrieved from:

https://insideout.org.nz/projects/day-of-silence/

Jackson, C. (2006). 'Wild' girls? An exploration of 'ladette' cultures in secondary schools. Gender and Education, 18(4), 339-360.

Jackson, S. \& Weatherall, A. (2010a). Dilemmas of Delivery: Gender, health and formal sexuality education in New Zealand/Aotearoa classrooms. Women's Studies Association of New Zealand, 24(1), 47-59.

Jackson, S. \& Weatherall, A. (2010b). The (Im)possibilities of A Feminist School Based Sexuality Education. Feminism \& Psychology, 20(2), 166-185. doi:10.1177/0959353509349603.

Jackson, S. \& Vares, T. (2015). 'Too many bad role models for us girls': Girls, female pop celebrities and 'sexualization'. Sexualities, 18(4), 480-498.

Katz, J. \& Rich, H. (2017). Intimate Partner Violence, Neoliberal Ideologies, and Controversies about Victimhood (pp. 75-87). In C. Robertson (Ed.), Routledge Handbook on Victims' Issues in Criminal Justice. Retrieved from http://ebookcentral.proquest.com

Kelsey, J. (2014). The FIRE Economy: New Zealand's Reckoning. Wellington: Bridget Williams Books.

Kenway, J. \& Willis, S. (1997). Answering Back: Girls, Boys and Feminism in Schools. New South Wales: Allen \& Unwin.

Letherby, G. (2003). Feminist Research in Theory and in Practice. Buckingham: Open University Press.

Letherby, G. (2011). Feminist Methodology (pp. 62-79). In Williams, M. \& Vogt, W. P. (Eds.) The Sage Handbook of Innovation in Social Research Methods. London: Sage.

Lindsay, J. (2005). Don't Panic! Young People and the Social Organisation of Sex (pp. 85-101). In Hawkes, G. \& Scott, J. (Eds.) Perspectives in Human Sexuality. Victoria: Oxford University Press.

Lovaas, K.E., Elia, J.P. \& Yep, G.A. (2006). Shifting Ground(s): Surveying the Contested Terrain of LGBT studies and Queer Theory. Journal of Homosexuality, 52(1-2), 1-18. 
Mardorossian, C. M. (2002). Towards a new feminist theory of rape. Signs: Journal of Women in Culture and Society, 27(3), 743-775.

Markula, P. \& Pringle, R. (2006). Foucault, Sport and Exercise: Power, Knowledge and Transforming the Self. Routledge: London.

Maynard, M. (1994). Methods, Practice and Epistemology: The Debate about Feminism and Research (pp. 10-26). In Maynard, M. \& Purvis, J. (Eds.) Researching Women's Lives from a Feminist Perspective. London: Taylor \& Francis.

McAllum, M. (2014). “Bisexuality Is Just Semantics...”: Young Bisexual Women's Experiences in New Zealand Secondary Schools. Journal of Bisexuality, 14(1), 75-93. doi:10.1080/15299716.2014.872467

McRobbie, A. (2004). Post-feminism and popular culture. Feminist Media Studies, 4(3), $255-246$.

McRobbie, A. (2009). The aftermath of feminism: gender, culture and social change. London: SAGE Publications.

McRobbie, A. (2015). Notes on the Perfect: Competitive Femininity in Neoliberal Times. Australian Feminist Studies, 30(83), 3-20. doi:10.1080/08164649.2015.1011485.

Measor, L., Tiffin, C. \& Miller, K. (2000). Young People's Views on Sex Education: Education, Attitudes and Behaviour. London: Routledge Falmer.

Ministry of Education. (2015a). SEXUALITY EDUCATION: A guide for principals, boards of trustees, and teachers. Wellington: Ministry of Education.

Ministry of Education. (2015b). Bullying prevention and response: A guide for schools. Wellington: Ministry of Education.

Ministry of Health. (2001). Sexual and Reproductive Health Strategy. Wellington: Ministry of Health.

Ministry of Health. (2017). A Strategy to Prevent Suicide in New Zealand: Draft for public consultation. Wellington: Ministry of Health.

Morgan, D.L., Ataie, J., Carder, P. \& Hoffman, K. (2013). Introducing Dyadic Interviews as a Method for Collecting Qualitative Data. Qualitative Health Research, 23(9), 1276-1284. doi:10.1177/1049732313501889

Oakley, A. (1981). Interviewing Women: a contradiction in terms. In Roberts, H. (Ed.) Doing Feminist Research. London: Routledge.

Oakley, A. (1998). Gender, Methodology and People's Ways of Knowing: Some Problems with Feminism and the Paradigm Debate in Social Science. Sociology, 32 (4), 707731.

Oakley, A. (2016). Interviewing Women Again: Power, Time and the Gift. Sociology, 50(1), 195213. doi:10.1177/0038038515580253

Oliver, K. (2016). Hunting Girls: Sexual Violence from the Hunger Games to Campus Rape. New York: Columbia University Press. 
Paglia, C. (1994). Vamps and tramps: New essays. London: Viking.

Pearson, D. (2004). Rethinking Citizenship in Aotearoa New Zealand. In Spoonley, P., Macpherson, C. \& D. Pearson (Eds.) Tangata Tangata: The Changing Ethnic Contours of New Zealand. Victoria: Thomson Dunmore Press.

Phillips, J. (1987). A Man's Country? The image of the Pakeha Male: A History. Auckland: Penguin Books.

Projansky, S. (2007). Mass Magazine Cover Girls: Some Reflections on Postfeminist Girls and Postfeminism's Daughters (pp. 40-72). In Tasker, Y. and Negra, D. (Eds.) Interrogating Postfeminism: Gender and the Politics of Popular Culture. Durham: Duke University Press.

Renold, E. \& Ringrose, J. (2008). Regulation and rupture: Mapping tween and teenage girls' resistance to the heterosexual matrix. Feminist theory, 9(3), 313-338.

Rentschler, C.A. (2017). Bystander intervention, feminist hashtag activism, and the anti carceral politics of care. Feminist Media Studies, 17(4), 56-584. doi:10.1080/14680777.2017.1326556

Rexhepi, J. \& Torres, C.A. (2011). Reimagining Critical Theory. British Journal of Sociology of Education, 32(5), 679-698.

Ringrose, J. \& Barajas, K. E. (2011). Gendered risks and opportunities? Exploring teen girls' digitized sexual identities in postfeminist media contexts. International Journal of Media and Cultural Politics, (7)2, 121-138. doi:10.1386/macp.7.2.121_1

Ringrose, J. (2012). Postfeminist Education? Girls and the Sexual Politics of Schooling. New York: Routledge.

Rose, N. (1996). The death of the social? Re-figuring the territory of government. Economy and Society, 25(3), 327-356.

Roiphe, K. (1993). The morning after: Sex, fear and feminism. London: Hamish Hamilton.

Ryan, K. M. (2011). The Relationship between Rape Myths and Sexual Scripts: The Social Construction of Rape. Sex Roles, 65, 774-782. doi:10.1007/s11199-011-0033-2

Simmonds, N. (2011). Mana Wahine: Decolonising Politics. Women's Studies Journal, 25(2), $11-25$.

Silverman, D. (2011). Interpreting Qualitative Data: $4^{\text {th }}$ Edition. London: SAGE Publications.

Shafer, K. \& Wendt, D. (2015). Men's Mental Health: A Call to Social Workers. Social Work, 60(2), 105-112. doi:10.1093/sw/swu061

Smith, D.E. (1988). The Everyday World as Problematic. Milton Keynes: Open University Press.

Smith, L.T. (1992). Maori Women: Discourses, Projects, and Mana Wahine (pp. 33-51). In Middleton, S. \& Jones, A. (Eds.) Women and Education in Aotearoa 2. Wellington: Bridget Williams Books. 
Smith, L.T. (2012). Decolonising Methodologies: Research and Indigenous Peoples. $2^{\text {nd }}$ Edition. London: Zed Books.

Smyth, H. (2000). Rocking the Cradle: Contraception, Sex and Politics in New Zealand. Wellington: Steele Roberts Ltd.

Sommers, C.H. (2000). The way on boys: How misguided feminism is harming our young men. New York: Simon \& Schuster.

Stanley, L. \& Wise, S. (1993). Breaking Out Again: Feminist Ontology and Epistemology. London: Routledge.

Stewart, D.W., Shamdasani, P.N. \& Rook, D.W. (2007). Focus Groups: Theory and Practices (second edition). Thousand Oaks: Sage Publications.

Tasker, Y. \& Negra, D. (2007). Introduction: Feminist Politics and Postfeminist Culture (pp. 126). In Tasker, Y. and Negra, D. (Eds.) Interrogating Postfeminism: Gender and the Politics of Popular Culture. Durham: Duke University Press.

Te Awekotuku, N. (1991). Mana Wahine Maori: Selected Writings on Maori Women's Art, Culture and Politics. Auckland: New Women's Press.

Tennent, E. \& Jackson, S. (2017). "Exciting” and "borderline offensive": bloggers, binaries, and celebrity feminism. Feminist Media Studies. doi:10.1080/14680777.2017.1391858

Tolley, P. (2016, 31st July). Insight: The Horror of NZ's Suicide Rates. RNZ. Retrieved from: http://www.radionz.co.nz/national/programmes/insight/audio/201809993/in sight-the-horror-of-nz-s-suicide-rates.

Toynbee, C. (1978). Class and Social Structure in Nineteenth-Century New Zealand (pp. 65-82). In Hamer, D.A. (Ed.) New Zealand Social History: Papers From the Turnbull Conference on New Zealand Social History - 1978. Auckland: University of Auckland.

Trotter-Simons, B.E. (2016). Sexuality Education in Aotearoa New Zealand: A Feminist Issue. Unpublished Honours Dissertation, Victoria University of Wellington, Wellington.

Trnka, S. \& Trundle, C. (2017). Competing Responsibilities: The Ethics and Politics of Contemporary Life. Durham: Duke University Press.

Van Dijk, J. (2009). Free the victim: A critique of the western conception of victimhood. International Review of Victimology, 16(1), 1-33.

Venugopal, R. (2015). Neoliberalism as concept. Economy and Society, 44(2), 165-187.

Wilkinson, S. (1999). Focus Groups: A Feminist Method. Psychology of Women Quarterly, 23(2), 221-244. 


\section{Appendix 1: Interview Participant Information Sheet}

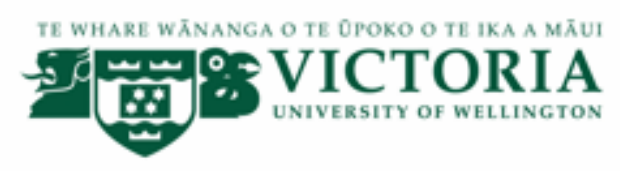

\section{How do gender and sexuality norms influence young people's understandings of relationships?}

\section{INFORMATION SHEET FOR PARTICIPANTS}

Thank you for your interest in this project. Please read this information before deciding whether or not to take part. If you decide to participate, thank you. If you decide not to take part, thank you for considering my request.

\section{Who am I?}

My name is Bonnie-Estelle Trotter-Simons and I am a Masters student in Sociology at Victoria University of Wellington. This research project is work towards my thesis.

\section{What is the aim of the project?}

This project will examine the ways in which gender and sexuality norms impact on young people's understandings of relationships. I am interested in learning about your work with young people in these areas, and discussing your views on gender and sexuality related issues for young people.

This research has been approved by the Victoria University of Wellington Human Ethics Committee [0000024493].

\section{How can you help?}

If you agree to take part I will interview you in a seminar room in the University library at Kelburn Campus, or at a location of your choice or convenience. Morning or afternoon tea will be provided in the interview. I will ask you questions about your professional view on young people's relationships. The interview will take one hour. I will record the interview and write it up later. You can stop the interview at any time, without giving a reason. You can withdraw from the study by contacting me at any point in the four weeks following the interview. If you withdraw, the information you provided will be destroyed or returned to you.

\section{What will happen to the information you give?}

You will not be named in the final report but your organisation will be named (provided you have the authority to agree to this on behalf of the organisation). If you would prefer the organisation not to be named, you will only be identified by your professional role (e.g. counsellor). 
Only my supervisor and I will read the notes or transcript of the interview. The interview transcripts, summaries and any recordings will be kept securely and destroyed four years after the research ends.

\section{What will the project produce?}

The information from my research will be used in my Masters report.

\section{If you accept this invitation, what are your rights as a research participant?}

You do not have to accept this invitation if you don't want to. If you do decide to participate, you have the right to:

- choose not to answer any question;

- $\quad$ ask for the recorder to be turned off at any time during the interview;

- withdraw from the study before the end of three weeks after the interview;

- ask any questions about the study at any time;

- receive a copy of your interview recording;

- $\quad$ agree on another name for me to use rather than your real name;

- be able to read any reports of this research by emailing the researcher to request a copy.

If you have any questions or problems, who can you contact?

If you have any questions, either now or in the future, please feel free to contact either:

\section{Student:}

Name: Bonnie-Estelle Trotter-Simons

University email address:

Bonnie.Trotter-Simons@vuw.ac.nz

\section{Supervisor:}

Name: Rhonda Shaw

Role: Associate Professor in Sociology

School: Social and Cultural Studies

Phone: (04) 4636134

Rhonda.Shaw@vuw.ac.nz

\section{Human Ethics Committee information}

If you have any concerns about the ethical conduct of the research you may contact the Victoria University HEC Convener: Associate Professor Susan Corbett. Email susan.corbett@vuw.ac.nz or telephone +64-4-463 5480. 


\section{Appendix 2: Interview Participant Consent Form}

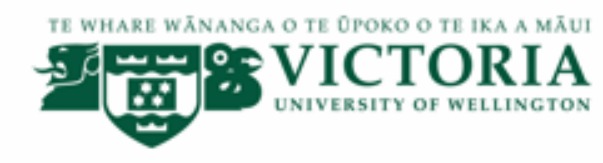

\section{How do gender and sexuality norms influence young people's understandings of relationships?}

\section{CONSENT TO INTERVIEW}

This consent form will be held for four years.

Researcher: Bonnie-Estelle Trotter-Simons, School of Social \& Cultural Studies, Victoria University of Wellington.

- I have read the Information Sheet and the project has been explained to me. My questions have been answered to my satisfaction. I understand that I can ask further questions at any time.

- I agree to take part in an audio recorded interview.

I understand that:

- I may withdraw from this study at any point before the end of three weeks after the interview without giving any reason, and any information that I have provided will be returned to me or destroyed.

- The information I have provided will be destroyed four years after the research is finished.

- $\quad$ Any information I provide will be kept confidential to the researcher and the supervisor. I understand that the results will be used for a Masters report and a summary of the results may be used in academic reports and/or presented at conferences.

- I consent to information or opinions which I have given being attributed to my organisation in any reports on this research. If I tick no, this information will only be attributed to my professional role (i.e. counsellor)

- I would like a copy of the transcript of my interview Yes $\square \quad$ No $\square$ I would like to receive a copy of the final report and have added my email Yes $\square$ No address below.

Signature of participant:

Name of participant:

Date:

Contact details: 


\section{Appendix 3: Focus Group Participant Information Sheet}

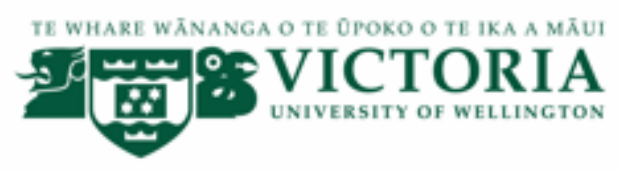

\section{How do gender and sexuality norms influence young people's understandings of relationships?}

\section{INFORMATION SHEET FOR FOCUS GROUP PARTICIPANTS}

Thank you for your interest in this project. Please read this information before deciding whether or not to take part. If you decide to participate, thank you. If you decide not to take part, thank you for considering my request.

Who am I?

My name is Bonnie-Estelle Trotter-Simons and I am a Masters student in Sociology at Victoria University of Wellington. This research project is work towards my thesis.

What is the aim of the project?

This project will examine the ways in which gender and sexuality norms impact on young people's understandings of relationships. I am interested in learning about your understandings of gender and sexuality norms, and how these norms shape your views on relationships.

This research has been approved by the Victoria University of Wellington Human Ethics Committee [0000024493].

\section{How can you help?}

If you agree to take part in the focus group discussion, I will facilitate the discussion in a location of your convenience or in a seminar room in the University library at Kelburn Campus. Snacks and tea will be provided during the discussion, and you will receive a movie voucher for your participation. I will ask the group open-ended questions about gender, sexuality and relationships. The focus group discussion will be roughly one hour. I will record the discussion and write it up later. You can withdraw from the discussion at any time prior to or during the discussion by contacting me at any point, without giving a reason. You may not withdraw your responses once the discussion has taken place because of the interactive nature of focus groups.

\section{What will happen to the information you give?}

This research is confidential. This means that the researchers named below will be aware of your identity but the research data will be aggregated and your identity will not be disclosed in any reports, presentations, or public documentation. 
Only my supervisor and I will read the notes or transcript of the interview. The interview transcripts, summaries and any recordings will be kept securely and destroyed four years after the research ends.

\section{What will the project produce?}

The information from my research will be used in my Masters report.

\section{If you accept this invitation, what are your rights as a research participant?}

You do not have to accept this invitation if you don't want to. If you do decide to participate, you have the right to:

- choose not to answer any question;

- withdraw from the study before the discussion commences or during it;

- ask any questions about the study at any time;

- $\quad$ agree on another name for me to use rather than your real name;

- be able to read any reports of this research by emailing the researcher to request a copy.

If you have any questions or problems, who can you contact?

If you have any questions, either now or in the future, please feel free to contact either:

Student:

Name: Bonnie-Estelle Trotter-Simons

University email address:

Bonnie.Trotter-Simons@vuw.ac.nz

\section{Supervisor:}

Name: Rhonda Shaw

Role: Associate Professor in Sociology

School: Social and Cultural Studies

Phone: (04) 4636134

Rhonda.Shaw@vuw.ac.nz

\section{Human Ethics Committee information}

If you have any concerns about the ethical conduct of the research you may contact the Victoria University HEC Convener: Associate Professor Susan Corbett. Email susan.corbett@vuw.ac.nz or telephone +64-4-463 5480.

\section{Helplines/Support Services}

- HELP Wellington main phone number: 044997532

$24 \mathrm{hr}$ phone counselling service: 048016655 - push 0

http://www.wellingtonhelp.org.nz/

- Wellington Rape Crisis

(04) 8018973 http://wellingtonrapecrisis.org.nz/ 


\section{Appendix 4: Focus Group Participant Consent Form}

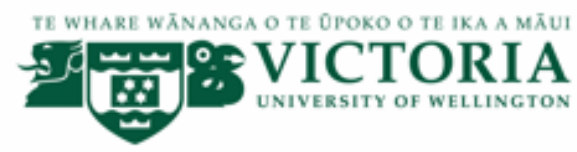

\section{How do gender and sexuality norms influence young people's understandings of relationships?}

\section{CONSENT TO PARTIICIPATE IN FOCUS GROUP}

This consent form will be held for four years.

Researcher: Bonnie-Estelle Trotter-Simons, School of Social \& Cultural Studies, Victoria University of Wellington.

- I have read the Information Sheet and the project has been explained to me. My questions have been answered to my satisfaction. I understand that I can ask further questions at any time.

- I agree to take part in an audio recorded focus group discussion.

- I have read and agreed to the focus group ground rules.

I understand that:

- I may withdraw from this study at any point prior to or during the discussion without giving any reason. I may not withdraw my responses after the discussion has taken place, due to the interactive nature of focus groups.

- The information I have provided will be destroyed four years after the research is finished.

- Any information I provide will be kept confidential to the researcher and the supervisor. I understand that the results will be used for a Masters report and a summary of the results may be used in academic reports and/or presented at conferences.

- I consent to information or opinions which I have given to be used in any reports on this research.

Yes $\square$ No

- I would like to receive a copy of the final report and have added my email Yes $\square$ No address below.

Signature of participant:

Name of participant:

Date:

Contact details: 


\section{Appendix 5: Interview Discussion Schedule}

Interview schedule:

The questions and prompts will be centred around these areas, but the course of discussion may also be dependent on what the interviewee would like to focus on (given that some areas might pertain to their field of work/expertise more than others).

- Gender and sexuality discourses

-Views on whether gender norms have changed over time

-The ways in which understanding gender helps when working with youth

-Views on how young people experience and think about gender, and the ways they talk about it -How gender shapes young people's experiences of school

-Educator's own views on gender, whether these have shifted or changed as a result of their work

-How gender shapes young people's experiences sexuality

- Personal responsibility

-Views on the ways gender impacts on who tends to take more responsibility in a relationship

-Views on school communication with students about sexual responsibility

-Views on how responsibility exists for non-binary and queer young people in their relationships

- Healthy relationships

-Views on how young people navigate their first relationships, and the emotions they tend to talk about experiencing

-Views on the way gender norms consolidate or influence these relationships

-Views on the pressures which young people face when they enter relationships

-Views on the extent of support for queer relationships and how gender norms impact on these relationships 


\section{Appendix 6: Focus Group Discussion Schedule}

Focus Group Discussion Schedule:

Because focus group discussions are less structured than interviews, the discussion topics will form general, open-ended questions, which foster dialogue. The researcher will provide prompts to continue discussion if they are needed.

- Gender and sexuality discourses

-Views and experiences of gender and the way they describe gender norms

-Describing the ways in which gender gets talked about among their peers and their views on this

-Views and experiences about how negative gender norms can be challenged

- Personal responsibility

-Views on personal responsibility in sexual situations and relationships, with regards to what the responsibilities entail and how they are weighted

-Perspectives on sexuality education and how it teaches responsibility

-Discussion on gender in relation to personal responsibility

- Healthy relationships

-Views on the principles they are taught about having healthy relationships

-What a 'healthy relationship' means to them

-Views on the extent of peers' awareness of these values, and what can be done to raise more awareness if needed

-Views on the way gender norms influence or consolidate relationships

-Views on the way the gendered norms they discussed impact on consent and the attitudes

surrounding it 


\section{Appendix 7: Ethics Approval Memorandum}

TE WHARE WRNANCA O TE DPOKO O TE IKA A MTUUI

MEMORANDUM

$0-4-4635480$

Email susan.corbett@vuw.ac.nz

\begin{tabular}{l|l}
\hline TO & Bonnie Trotter-Simons \\
\hline COPY TO & Rhonda Shaw \\
\hline FROM & AProf Susan Corbett, Convener, Human Ethics Committee \\
\hline DATE & 16 May 2017 \\
\hline PAGES & 1 \\
\hline & $\begin{array}{l}\text { Ethics Approval: } 24493 \\
\text { Gender and Sexuality in New Zealand: Implications for Youth } \\
\text { RUBJECT }\end{array}$
\end{tabular}

Thank you for your application for ethical approval, which has now been considered by the Standing Committee of the Human Ethics Committee.

Your application has been approved from the above date and this approval continues until 6 March 2018. If your data collection is not completed by this date you should apply to the Human Ethics Committee for an extension to this approval.

Best wishes with the research.

Kind regards

\section{Susan Corbett}

Convener, Victoria University Human Ethics Committee 